THE HYPOTHETICAL CORE

DISRUPTIVE ACCIDENT

HANFORD ENGINEERING DEVELOPMENT LABORATORY Operated by Westinghouse Hanford Company

A Subsidiary of Westinghouse Electric Corporation
P.O. Box 1970 Richland, WA 99352

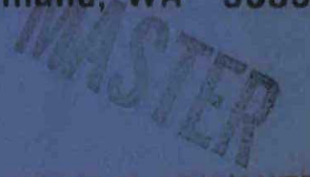

\section{DISTRIBUTION OF THIS DOCUMENT IS UNLIMITED}

Prepared for the U.S. Energy Research and Development

Administration under Contract No. AT(45-1)-2170 


\section{DISCLAIMER}

This report was prepared as an account of work sponsored by an agency of the United States Government. Neither the United States Government nor any agency Thereof, nor any of their employees, makes any warranty, express or implied, or assumes any legal liability or responsibility for the accuracy, completeness, or usefulness of any information, apparatus, product, or process disclosed, or represents that its use would not infringe privately owned rights. Reference herein to any specific commercial product, process, or service by trade name, trademark, manufacturer, or otherwise does not necessarily constitute or imply its endorsement, recommendation, or favoring by the United States Government or any agency thereof. The views and opinions of authors expressed herein do not necessarily state or reflect those of the United States Government or any agency thereof. 


\section{DISCLAIMER}

Portions of this document may be illegible in electronic image products. Images are produced from the best available original document. 


\section{NOTICE}

This report was prepared as an account of work sponsored by the United States Government. Neither the United States nor the U.S. ERDA, nor any of their employees, nor any of their contractors, subcontractors, or their employees, makes any warranty, express or implied, or assumes any legal liability or responsibility for the accuracy, completeness or usefulness of any information, apparatus, product or process disclosed, or represents that its use would not infringe privately owned rights. 
HEDL SA 741 REV

THE HYPOTHETICAL CORE DISRUPTIVE ACCIDENT

D. E. Simpson

Lectures Presented at the Massachusetts Institute of Technology Summer Course

on Fast Reactor Safety

July 23-25, 1975

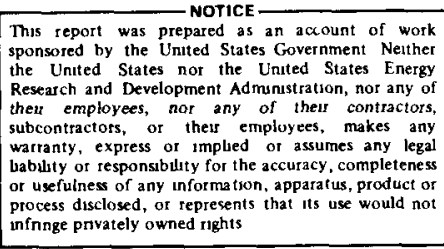

Hanford Engineering Development Laboratory

Operated by the

Westinghouse

Hanford Company 



\section{CONTENTS}

\section{Page}

ILLUSTRATIONS

v

I. INTRODUCTION I-I

A. DESIGN SAFETY PHILOCOPHY I-1

B. DEFENSE-IN-DEPTH I-1

C. HYPOTHETICAL CORE DISRUPTIVE ACCIDENT I-3

D. PERTINENT REACTOR CHARACTERISTICS I-5

II. SCOPE OF THE LECTURE SERIES II- T

III. INITIATING MECHANISIMS AND PROBALILISTIC ANALYSES III-1

IV. REACTOR DYNAMICS IV-1

A. BASIC THEORY IV-1

B. HISTORY AND EVOLUTION IV-7

C. FFTF HCDA STUDIES IV-15

D. CURRENT CONCLUSIONS SUMMARY IV-73

V. MECHANICAL CONSEQUENCES V-1

A. BASIC PHENOMENA V-l

B. HISTORY AND DEVELOPMENT V-3

C. PROCEDURE FOR APPLICATIONS OF HYPOTHETICAL ACCIDENTS TO DESIGN $\quad \mathrm{V}-6$

D. FFTF STANFORD RESEARCH INSTITUTE (SRI) TEST PROGRAM V-10

E. CONCLUSION V-15

VI. POST-ACCIDENT HEAT REMOVAL VI-1

ACKNOWLEDGEMENTS VII-1

REFERENCES VII-2 



\section{ILLUSTRATIONS}

Figure

Page

I-1 Design Safety Approach I-2

I-2 Hypothetical Accident Paradox I-4

I-3 HCDA Study Origin and Objectives I-6

I-4 Comparative Reactor Characteristics Affecting HCDA Evaluations

I-5 Historical Maximum Accident in SAR's I-9

II-1 MIT Lecture Series Outline II-2

III-1 Initiating Mechanisms Investigation III-2

III-2 Techniques for Initiating Mechanisms Investigation III-3

III-3 Accident Source Diagram; Fuel Assembly Inlet Blockage III-5

III-4 Potential HCDA Initiator Classes III-7

III-5 Acceptable Probability of Class 9 Accident III-9

III-6 Initiating Mechanisms Summary III-10

IV-1 Leakage Reactivity Variation IV-2

IV-2 Dynamics Equations IV-3

IV-3 Simple Models for Nuclear Excursions IV-6

$\begin{array}{lll}\text { IV-4 } & \text { Proportionality of Nuclear Excursion Energy to } \\ & \text { Reactivity Addition and Core Size } & \text { IV-8 }\end{array}$

IV-5 Fast Reactor Containment Design IV-9

IV-6 Beth-Tait Accident IV-11

IV-7 Sequence of US Fast Reactor Hypothetical Accident

IV-8 FFTF HCDA Studies IV-16

IV-9 Phase I FFTF HCDA Studies - $1967 \quad$ IV-18

$\begin{array}{ll}\text { IV-10 Effect of Fuel Slumping on Disassembly Ramp Rates } & \text { for Sodium-Out FTR }\end{array}$

IV-11 Various Degrees of Sophistication Used in Formulating
an Equation of State
IV-21

IV-12 Sensitivity of Energy Release to Percent Void in Core IV-23

IV-13 Hypothetical Accident Analysis IV-24

IV-14 Hypothetical Accident Analysis Uncertainties IV-26

IV-15 Experimental Summary for Top HCDA IV-28 


\section{ILLUSTRATIONS (Cont'd)}

Figure

Page

IV-16 Axial Macrostructure Variation in High Power Irradiated Fuel Pin

IV -29

IV-17 Overpower Transient Fuel Failure Models IV-30

IV-18 Sequence of Events During an HCDA Overpower Transient IV-32

IV-19 Experimental Data-Vehicle: Mark-IIA Loop IV-33

IV-20 Major Nonprototypic Aspects of Mark-IIA Loop Results IV-35

IV-21 Fuel Assembly Flow/Temperature Distribution IV-36

IV-22 Melt-III Computational Features IV-38

IV-23 Damage Parameter Prediction IV-41

IV-24 Potential Accident Sequence Paths for the Unprotected Transient Overpower

IV -42

IV-25 Top Input to PAHR Requirements IV -44

IV-26 Conclusions IV-45

IV-27 Experiment Summary for LOF-HCDA IV-47

IV-28 Comprehensive Approach to LOF-HCDA Analysis IV-48

IV-29 Shutdown Protection for Loss of Primary Power IV-49

IV-30 Flow Coastdown Voiding Profile FFTF Equilibrium Core IV-52

IV-31 Typical Flow Regimes for Liquid Metal-Vapor Flows IV-54

IV-32 Liquid Film Flow Illustratim IV-55

IV-33 Illustration of Clad Movement for SAS Analysis of
Test R-5 IV-56

IV-34 Initiatim Phase of FFTF LOF IV -58

IV-35 Latter Stage of Disassembly Expansion IV-60

IV-36 Illustration of Noncoherence Effects and Cladding
Relocation

IV-37 Illustration of Early Fuel Relocation and Dispersal IV-63

IV-38 Molten Fuel Boiling Chracteristics IV-64

IV-39 Fuel Ejection From the Core Region up Into the Liquid
Sodium Pool

$\begin{array}{ll}\text { IV-40 LOF Summary IV-66 } & \text { IV }\end{array}$

IV-41 Model of Post-Irradiation Fuel Expansion and
Interaction with Pool Sodium 


\section{ILLUSTRATIONS (Cont'd)}

Figure

Page

IV-42 PV Relationship for Disassembly Fuel Temperature of $4850^{\circ} \mathrm{K}$

IV -69

IV-43 Comparison of SOCOOL II and Experimental (S-Series)

Efficiencies for Conversion of Nuclear to Mechanical

Work Energy

IV -71

IV-44 Comparison of Spontaneous Nucleation and Sudden

Contact Temperatures

IV -72

IV-45 Evolution of Coupled Neutronics - Hydrodynamics

Models

IV -76

V-1 Reactor Geometry and Mechanics of Potential Damage

$\mathrm{V}-2$

V-2 Localization Factors of Vessels Dilated with Pentolite in Air and Water

V-4

$V-3 \quad$ Typical Functional Criteria

V-7

$V-4 \quad$ REXCO Model of FFTF

V-8

V-5 Force-Time Input Function for Core Support Structure

V-9

V-6 Motion Flexible Head Simulation

$v-11$

V-7 $150 \mathrm{MW}-$ Sec HCDA

$V-12$

$V-8 \quad$ Primary System Components

$V-13$

V-9 150-MW Sec SOCOOL and CM-10-1 PV Change Curves

$V-14$

V-10 1/10 Size Complex Test

V-16

V-11 $1 / 10$ Size Vessel and Support Vessel Connections to Primary Loop

$V-17$

$V-12$ Head Components

$\mathrm{V}-18$

V-13 Prototype Vessel Strains

$V-19$

VI-1 PAHR Provisions in Fast Reactors

VI-2

VI-2 PAHR Provisions in Fast Reactors (Cont'd)

VI -4

VI-3 Leveling Experiments with Bed Initially Peaked in

Center

VI-6

VI-4 Inlet and Outlet Piping-Guard-Reactor Vessel VI-7

VI-5 Core Support Structure

VI-9

VI-6 In-Vessel PAHR Summary VI-11

VI-7 Post-HCDA Event Tree VI-12

VI-8 Postulated Melt-Through Consequences Analysis VI-15

VI-9 Lower Cavity Design Alternatives VI-16

VI-10 Containment Lower Cavity Conclusion VI-19 
HEDL S/A-741 Rev

\title{
THE HYPOTHETICAL CORE DISRUPTIVE ACCIDENT
}

\author{
D. E. Simpson
}

I. Introduction

A. Design Safety Philosophy Nuclear reactors in the United States have achieved an I-1 enviable safety record applying a design approach involving both design for accident prevention and for the mitigation of consequences of accidents should they occur. In the area of accident prevention, the reactors are carefully designed to minimize the potential for serious malfunctions and to incorporate automatic protective features which will terminate the effects of identifiable malfunctions within defined acceptable limits. Through this approach, the potential for a serious accident which might have significant public impact is reduced to a very low level. There are those who believe that this application of the accident prevention approach can in fact reduce the probability of serious accidents to such an acceptably low level that no further protective features need be incorporated. Nevertheless, the approach has been followed to date for nuclear reactors in the United States to provide, in addition to the accident prevention features, consequence-limiting features which would protect the public against the effects of an accident beyond the capacity of the normal process and protective systems. Predominant among such features is the containment vessel for light-water reactors, together with the related engineered safety features such as emergency core cooling, containment cleanup systems, etc.

\section{B. Defense-In-Depth}

This design approach provides the multiple levels of safety which have been called "defense-in-depth." The incorporation of consequence-limiting features in addition to the accident prevention features offers a diversity of public protection not only for identified potential accidents but for unidentified malfunctions or 
FIGURE 1-1

\section{DESIGN SAFETY APPROACH}

- RELIABILITY OF NORMAL OPERATION

- PLANT PROTECTION PROVISIONS

- FiJRTHER MARGIN OF SAFETY - CONTAINMENT SYSTEM 
accidents as well. But in the area of protection for unknown or unidentified events the incorporation of consequence-limiting features presents a paradox. In order to establish an appropriate I-2 design concept and in order to perform analyses to demonstrate the capability of the consequence-limiting feature, it is necessary to have a concept of the nature and severity of the accident of concern. The paradox is that once such an accident is identified, then the design approach is to eliminate the initial cause, or otherwise prevent the accident, rather than rely on limiting its consequences to the public. This produces a situation such that there can be no accident for which the consequence-limiting features would be applied unless:

- engineered systems of the reactor plant, including protective systems, fail to perform; or

- unpredicted phenomena exist which create conditions exceeding the capability of the normal process and protective systems.

This situation leads to characterization of such an event as "hypothetical." Nevertheless, substantial confidence in the extra safety margin provided by consequence-limiting features can be derived through evaluation of the inherent reactor system response to a broad spectrum of initial conditions and potential modes of progression consistent with the physical characteristics of the system.

\section{Hypothetical Core Disruptive Accident}

The term HCDA was coined to represent a class of events which arose in fast reactor safety investigations into the potential consequences of self-limited reactor accidents. The key characteristics in this class of accidents are the assumption of loss of control of the balance between heat generation and heat removal, ineffectiveness of the plant protective systems, and the ultimate termination of the excursion by dispersal of the core material into a non-critical array. 
FIGURE I-2

\title{
HYPOTHETICAL ACCIDENT PARADOX
}

\author{
SAFETY MARGIN EVALUATION GOAL: \\ DEMONSTRATE PUBLIC PROTECTION AGAINST POSSIBLE \\ ACCIDENTS
}

DESIGN SAFETY GOAL:

PREVENT POSSIBLE ACCIDENTS BY ELIMINATING CAUSES OR PROVIDING PROTECTIVE SYSTEMS 
The study of such accidents became a focus of a major part of the fast reactor safety development program. (1) These studies can be described in terms of two alternate objectives. In the first place, the results of a hypothetical accident analysis may be used to establish design characteristics of applicable portions of the reactor plant and in particular the containment system. Thus, the HCDA could become a design basis event ${ }^{(2)}$ for establishing an appropriate containment design concept and for evaluating the safety margins provided by that concept. On the other hand, an event of such a nature as the hypothetical core disruptive accident may be considered so nearly impossible, at least of such a low probability, that it need not be a basis for containment design; that is, it might be a class 9 accident. (2) In either case, conclusions from these studies should affect design choices; and evaluation of the potential consequences of the Class 9 event is a likely requirement associated with environmental impact assessments. For either of these applications, then, investigations can be and are carried out to seek to identify in as realistic a way as possible the potential consequences of plant accidents or malfunctions as limited by the physical characteristics of the reactor plant. More specifically, the studies seek to identify the most likely consequences of hypothetical events and also to assess the range of uncertainty. The scope of these investigations covers all consequences up to attainment of a stable coolable configuration of the heat generating materials.

\section{Pertinent Reactor Characteristics}

Two basic differences between the light-water reactor and I-4 the fast breeder reactor are particularly pertinent to consideration of the most severe potential or hypothetical accident. In the light-water reactor the core is arranged in what is nearly the most reactive possible core geometrical array. Thus, changes in the core constituents or geometry are likely to result in a loss of reactivity, not in an addition of reactivity. The fast breeder reactor, on the other hand, is not arranged in a most reactive core configuration. In the absence of a moderator, the most reactive array 
FIGURE 1-3

HCDA STUDY ORIGIN AND OBJECTIVES

- INVESTIGATION OF INHERENT CHARACTERISTICS AND SELF-LIMITED ACCIDENT RESPONSES

- BASIS FOR CONTAINMENT DESIGN OR CLASS 9EVALUATIONS

- REALISTIC BEHAVIOR AND CONSEQUENCES ANALYSIS

- ASSESSMENT OF UNCERTAINTIES 
FIGURE I-4

\section{COMPARATIVE REACTOR CHARACTERISTICS AFFECTING HCDA EVALUATIONS}

\begin{tabular}{|c|c|c|}
\hline CHARACTERISTICS & LWR & LMFBR \\
\hline CORE ASSEMBLY & $\begin{array}{l}\text { OPTIMAL REACTIVITY } \\
\text { GEOMETRY (FIM RATIO) }\end{array}$ & DISTRIBUTED, NOT MOST REACTIVE \\
\hline STORED ENERGY IN COOLANT & HIGH; PRESSURIZED SYSTEM & NONE; SUBCOOLED AT l atm \\
\hline CHEMICAL ENERGY POTENTIAL & NONE AT NORMAL TEMPERATURES & HIGH; SODIUM-AIR/WATER \\
\hline \multicolumn{3}{|l|}{ RADIOLOGICAL INVENTORIES } \\
\hline - FISSION PRODUCTS (KR, I) & EQUIVALENT & EQUIVALENT \\
\hline - PLUTONIUM & LOW & $\mathrm{HIGH}$ \\
\hline \multicolumn{3}{|l|}{ NUCLEAR } \\
\hline$\bullet \beta$ & 0.007 & $0.00 B$ \\
\hline$\bullet \lambda$ & $2-6 \times 10^{-5} \mathrm{sec}$ & $6 \times 10^{-7} \mathrm{sec}$ \\
\hline
\end{tabular}


would be the maximum density of fuel material. The necessity for heat removal results in an array in which the fuel material is diluted and coolant as well as structural materials are incorporated within the core. Thus, at least theoretically, changes in core constituents and/or geometry could potentially result in large reactivity additions. On the other hand, there is a large cuantity of energy stored in the pressurized coolant of both boiling and pressurized water reactors -- also conventional fossil-fueled steam power piants, but there is little or no stored energy in the fast reactor coolant, whether it be gas or liquid metal. For the LMFBR, this characteristic means that a break in the primary coolant boundary does not result in either a loss of cooling to the reactor core nor a "blowdown" of coolant fluid and energy. The sodium coolant of liquid metal fast breeder reactors does have the characteristics of being chemically reactive, and large quantities of energy could be released by the chemical reaction of the coolant, and this is an important consideration in the design of sodium reactor structures, and steam generators.

The fast reactor also has a shorter neutron lifetime $(\lambda)$ and generally a lower delayed neutron fraction $(\beta)$ (because of the use of $\mathrm{Pu}$ fuel). These have some effect on the kinetics of reactor excursion, but they are not major factors in assessing excursion potential. The radioactivity inventories of fast and thermal reactors are not greatly different. There has been much discussion of the Pu hazard associated with fast reactors. This has been in my opinion misrepresented, but the important difference, to the extent there is one, is in the potential for pu dispersal and release rather than in the inventory.

VG Considering the characteristics of the light-water reactor, I-5 it is not unreasonable that containment design bases have been established which provide for containing the release of the stored energy from the coolant and subsequent containment of radioactivity from the reactor core. The detailed engineering requirements hinge upon the rate at which this energy release might occur as well as 
FIGURE I-5

HISTORICAL MAXIMUM ACCIDENT IN SAR'S

LWR: DOLBLE-ENDED PIPE BREAK LOCA

LMFBR: HYPOTHETICAL CORE DISRUPTIVE ACCIDENT

("BETHE-TAIT" ACCIDENT) 
upon secondary effects which might affect either the amount of energy released to the containment or the chemical or radioactive products which could affect the ability of the containment to remain effective through the necessary long period of time. The event which has been chosen as a Design Basis Accident ${ }^{*}$ is a doubleended break of the largest primary coolant pipe, which results in the release of the stored energy at the maximum rate possible, short of a major rupture of the reactor vessel itself. This latter event has been judged to be of sufficiently low probability that, al though it might be evaluated as a Class 9 event, it need not be considered a design basis event.

Now, the corresponding accident for the fast breeder reactor might also be considered the double-ended pipe break for the largest primary coolant pipe. In this connection, it's proper to note that several factors exist which tend to make a large pipe break even less likely in an LMFBR than an LWR; e.g:

- LMFBR stresses are largely secondary; i.e., thermal and bending. There is little stress due to internal fluid pressure.

- There is little stored energy, either in the fluid or in the elastic deformation of the pipe, which could act to sustain rapid propagation of a crack.

In any case, if a pipe break of significant size should occur, the result would be a release of sodium (or gas) coolant. The release of energy would be generally neither large nor rapid. The effect of a pipe break on core cooling and fuel integrity would be a consequence of the coolant flow transient. However, in addition to the question of pipe break, or other sodium spills for the LMFBR, the fast breeder reactor's potential for reactivity addition upon

\footnotetext{
* The containment system is conservatively designed to sustain the effects of the Design Basis Accident (DBA) and prevent the release of amounts of radioactivity in excess of guidelines of 10 CFR 100.
} 
rearrangement of the core has led to consideration of potential nuclear excursion accidents in evaluation of the over-all safety of fast reactors.

This possibility was first documented by Bethe and Tait in 1956 in a document entitled "An Estimate of the Order of Magnitude of the Explosion when the Core of a Fast Reactor Collapses. "(4) This study made no attempt to assess the possibilities for collapse of a fast recictor core, or the probability of such an event, but rather looked into the consequences should such an event occur and be terminated by the natural response of the system. This was the original "Bethe-Tait" accident and the forerunner to extensive studies of hypothetical core disruptive accidents which are the subject of discussions in this series of lectures. In some of these discussions we will be talking about the investigation of nuclear excursion accidents and the resulting release of substantial quantities of energy. It should be emphasized that, unlike the case of the conventional steam boiler and the light-water reactor in which the energy released is the stored energy which is already present, in the fast reactor HCDA the energy release is not previously stored energy but must be generated in the nuclear excursion accident if it is, in fact, to exist at all. 


\section{Scope of the Lecture Series}

I have been asked to give a series of three lectures on the

II-1 hypothetical core disruptive accident and subsequent postaccident heat removal. In addition to the foregoing introductory remarks I plan to break the series down into four sub-topics. First, I want to introduce concepts of initiating mechanisms to identify some potential accident causes and accident progression mechanisms which have been and are considered in the evaluation of hypothetical core disruptive accidents. I will also mention studies of the probability of a hypothetical core disruptive accident and some views as to what might be an acceptable value of the low probability.

The second area of discussion will be the core disruptive accident analysis itself. I shall review some of the pertinent history and evolution of hypothetical core disruptive accident studies, including the types of studies which have been carried out; the key changes in analytical methods and the experimental or theoretical data on which these codes and analytical methods are now based; finally concluding with review of the current status and what I think may be the outlook for the continuation of these studies in the fairly near future.

The third phase of the discussion will deal with the mechanical effects of a core disruptive accident occurring in a liquid metal cooled fast reactor, leading into the fourth phase which is discussion of the postaccident heat removal. I will discuss the condition in which the reactor and the heat transport system may be left following an HCDA, the characteristics of the damaged core, and the capability of the system to remove the decay heat on a long-term basis. Note that the lecture series does not include another major area of consideration in these safety studies, which is the analysis of the radiological consequences of an HCDA. 
FIGURE II-1

\title{
MIT LECTURE SERIES OUTLINE
}

\author{
INTRODUCTION \\ FOUR SUB-TOPICS -- LMFBR FOCUS \\ 1. INITIATING MECHANISMS/PROBABILITIES ANALYSES \\ 2. CORE DISRUPTIVE ACCIDENT ANALYSES \\ 3. MECHANICAL EFFECTS OF DISRUPTIVE ACCIDENTS \\ 4. POST-ACCIDENT HEAT REMOVAL
}


III. Initiating Mechanisms and Probabilistic Analyses

First of al1, what do we mean by an initiating mechanism? We are talking about some system fault, malfunction, ma'operation, or error which might conceivably progress to the point of initiating

VG a serious accident, even an energetic nuclear excursion. Why do we III-1 study initiating mechanisms? For three reasons. First, we want to identify if there exist any design characteristics such that the failure of a component or a system in any realistic potential way might, in fact, progress to that sort of event. Should we find such a situation we would, of course, revise the design to eliminate it. This leads to the second objective; that is to demonstrate that there are no realistic means for initiating a hypothetical core disruptive accident or, stated another way, to demonstrate the capability of the designed operational and protective features. And third, should any doubt remain or should it be necessary to investigate even further into the question of how an accident might progress or what might be the most severe accident consistent with the physical characteristics of the system, the initiating mechanism study provides a way to establish some reasonable, physicaliy consistent, initial conditions for subsequent accident analysis. Our ultimate objective is to assure that every possible initiating mechanism is accommodated by design protective measures which are consistent with an acceptable level of risk.

VG The use of fault trees is a useful technique for conducting III-2 initiating mechanisms studies. The fault tree provides a systematic method for searching for potential accident initiating circumstances or combinations of circumstances as well as for identifying inhibiting conditions characteristic of the piant design. The fault tree is also amenable to quantitative and probabilistic analysis and through such an approach one can, given adequate input data, make quantitative calculations of the very low probability of severe accidents of this type. Fault tree methodology can be supplemented by failure modes and effects analysis. In this technique, all plant components and systems are assessed to determine what modes 
FIGURE III-1

\section{INITIATING MECHANISMS INVESTIGATION}

1. DESIGN ASSURANCE - IDENTIFICATION OF POTENTIALLY SERIOUS FAULTS

2. DESIGN ASSURANCE - PREVENTION OF SEVERE ACCIDENTS

3. BASES FOR PHYSICALLY CONSISTENT ACCIDENT ANALYSIS AND SAFETY ASSES SMENT 


\section{TECHNIQUES FOR INITIATING MECHANISMS INVESTIGATION}

1. FAULT TREES

- LOGICAL

- PROBABILITIES

2. FMEA

- COMPREHENSIVE

3. SAFETY ASSURANCE DIAGRAMS

- EVENT PROGRESSION AND LINES OF DEFENSE

- PHENOMENOLOGICAL BRANCH-POINTS 
of failure are possible and what initial consequences of such failure would result. The failure mode and effects analysis, by originating in the actual details of the plant design, is a useful technique for providing maximum assurance that all sources of potential malfunctions and faults would be exposed in the evaluation.

VG The third technique has more recently been developed, known III-3 as the technique of safety assurance diagrams. (5) The safety assurance diagram is a systematic fault progression network which, in addition to identifying conceivable or possible lines of progression beyond an initial postulated fault condition, also identifies the lines of defense; that is, the design features or expected behavior characteristics which would prevent the progression along a given, generally unfavorable, line. This technique is useful for assessing multiple levels of protection which could be counted on to prevent reaching some specified level of accident severity. The technique, in addition, is useful for identifying the possibility of accident progression along one or more phenomenological lines. That is, it is quite possible, even likely, that if one postulates the continued progression of an accident, one comes to branch points where the direction of progression is uncertain or unknown. The safety assurance diagram provides a systematic way of laying out these alternate progression paths, and an evaluation of these paths is useful in identifying the need for specific experimental data or analytical evidence to determine which path is, in fact, consistent with the nature of the system and of the applicable processes.

What are the general conclusions that can be reached through evaluation of initiating mechanisms? First, because of the design approach, analysis will show that any event which can be reasonably postulated would proceed, with a high probability, to a stable final condition without progressing into the range of core disruption. However, on the side of extremely low probability, three classes of events are conceivable. First, an event which 


\section{FIGURE III-3}

\section{ACCIDENT SOURCE DIAGRAM; FUEL ASSEMBLY INLET BLOCKAGE}
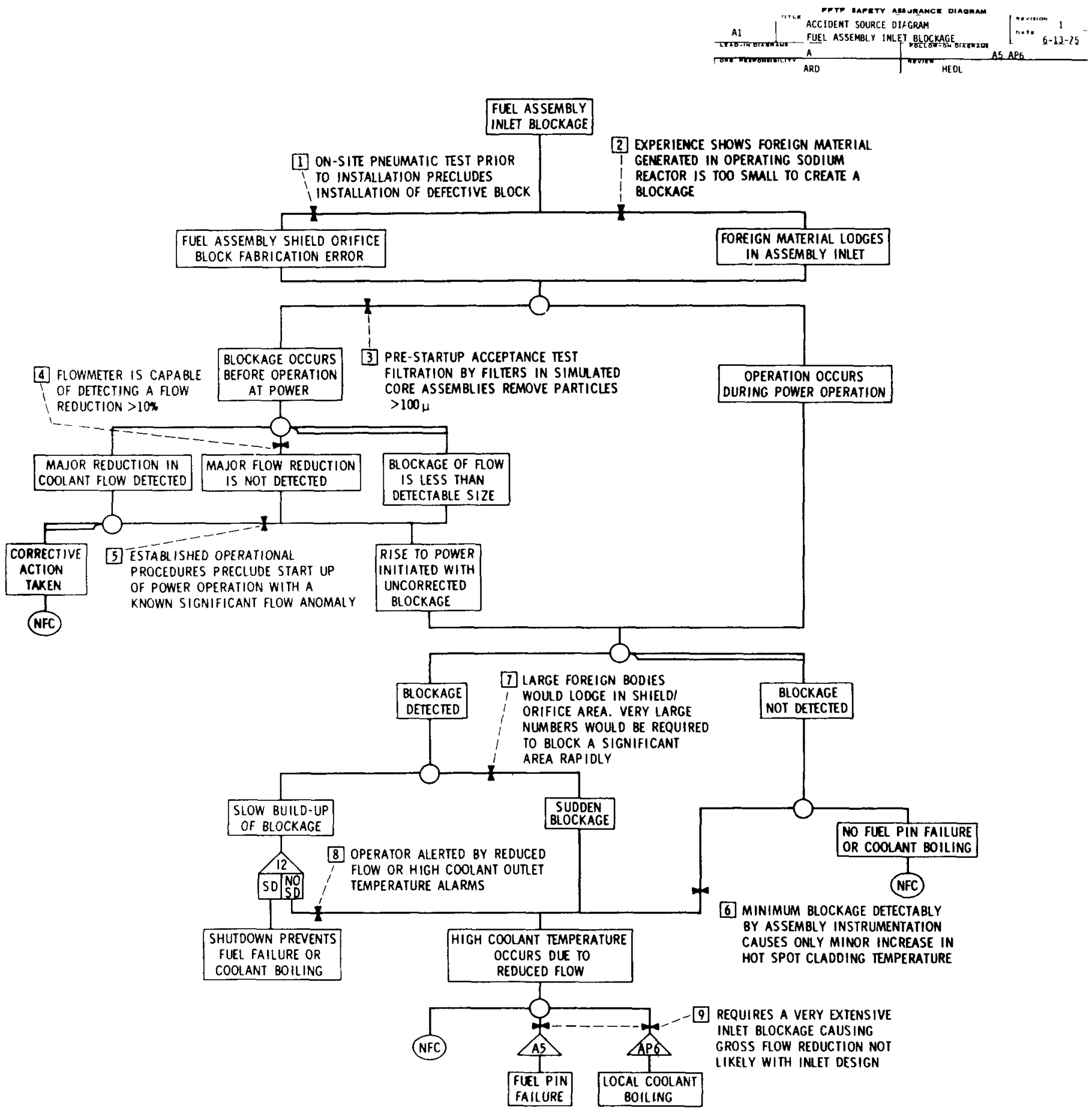
VG might exceed the capability of the Plant Protective System; second, III-4 an event which might progress rapidly beyond the PPS capability; and third, an event which the Plant Protective System is capable of terminating safely, but coupled with a postulated failure of the Plant Protective System.

It is possible to design so that there is a very, very low chance of an event of such severity that it will exceed the capability of a plant protective system. An LWR example of such an event is the disruption of a pressure vessel. Fast reactor events which have been considered include reactor vessel or core support structure ruptures, or passage of a large coherent gas bubble through the positive void reactivity portion of the core, or expulsion of a control rod. It would seem, on a qualitative basis, at least, that such events should be of a remote probability similar to that for LWR's.

There is also no more than a remote chance of an event occurring which would progress undetected and unchecked until it reached a point at which it exceeded the capability of the Plant Protective System. The propagation of individual fuel element failure is the classic concern in this regard and all evidence is that little propagation of failures is likely and it is even less likely that progression would be both large and rapid. $(6,7,8)$

The only other way for an HCDA to be initiated would be by failure of the PPS some time when called on to protect against some fault. The probability of plant protective system failure is certainly very low, al though it has not been established on a quantitative basis for LMFBR's. Many people believe that the probability of complete PPS failure is sufficiently low as to be considered negligible. It has become the common practice to incorporate redundant reactor shutdown systems in fast reactors. In the FFTF the systems are mechanically similar although electrically diverse. In the CRBR diverse mechanical shutdown systems are also incorporated. It is not yet clear but it may well be that the design of plant protective systems will come to be looked upon 
FIGURE III-4

\section{POTENTIAL HCDA INITIATOR CLASSES}

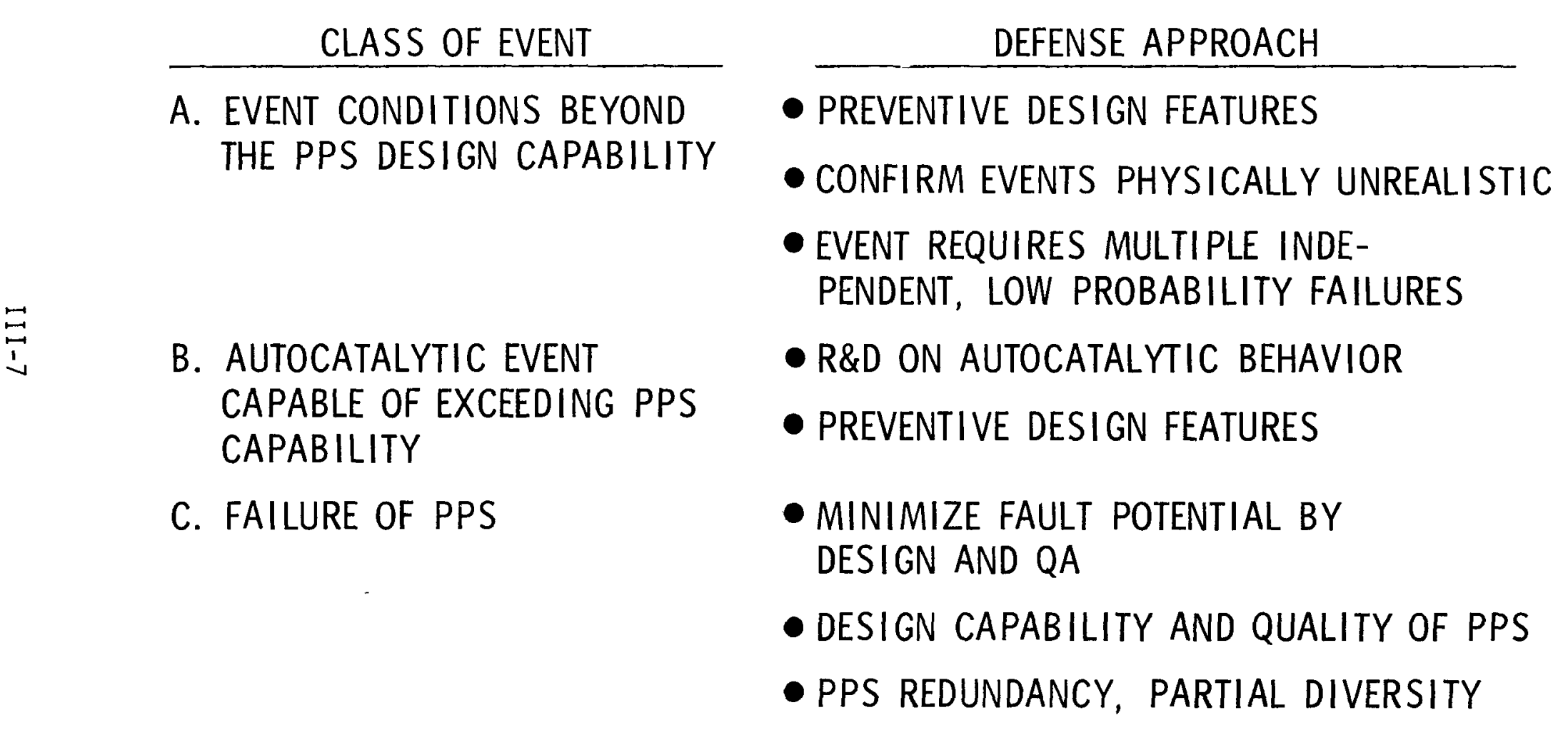

HEDL 7407-66.6 
with sufficient confidence that in fact one need not provide, as a design basis for containment systems, the ability to contain an VG event in which the plant protective system fails to work. Such an III-5 approach would be consistent with the water reactor approach as embodied in the Anticipated Transients Without Scram report. ${ }^{(9)}$ That report in effect established a requirement for future LWR's to incorporate redundant reactor shutdown systems which incorporate diversity of circuitry and logic but which do not necessarily incorporate diversity of mechanical shutdown devices. It was concluded that this approach should reduce the probability of an anticipated transient without scram to a value of less than $10^{-6}$ per reactor year. ${ }^{(9)}$ This was concluded to be an acceptably low probability. The ACRS has recently concluded that the probability of gross LWR pressure vessel rupture is less than $10^{-6}$ per reactor year. (3) This appears to be the acceptable probability of a Class 9 accident.

Now, if one has demonstrated or concluded that the VG probability of an initiating mechanism which could lead to a III-6 hypothetical core disruptive accident is negligibly sma11, then one need not design consequence-limiting safety features on the basis of such an event. On the other hand, if the probability is not sufficiently small, or not demonstrably so, it may be necessary to provide such consequence-limiting features. In any case, it may be necessary or appropriate to investigate the consequences of such an accident progression as a Class 9 accident. What, then, would be the most reasonable initial conditions to identify for such an accident analysis? If there were events which might exceed the PPS capability or might progress to the point of exceeding the PPS capability, these could result in reactivity addition at a rate sufficiently rapid that a nuclear excursion would result before the plant protective system could respond. All such events should be amenable to prevention by design, to an adequate degree of assurance. 
FIGURE III-5

ACCEPTABLE PROBABILITY OF CLASS 9 ACCIDENT

$$
\text { (REACTOR YEAR) }^{-1}
$$

- REG (NRC) ATWS REPORT

$$
\text { (WASH-1270) }
$$$$
<10^{-6}
$$

- ACRS LWR PRESSURE VESSEL

REPORT (WASH-1285)

$$
<10^{-6}
$$


FIGURE III.6

\section{INITIATING MECHANISMS SUMMARY}

NO REALISTIC INITIATION OF HCDA

STUDIES CARRIED OUT OF PROTECTIVE MARGINS FOR UNEXPECTED AND UNFORESEEN EVENTS

MECHANISTIC ACCIDENT CLASSES STUDIED

1. LOSS-OF-FLOW (WITHOUT SCRAM)

2. TRANSIENT OVERPOWER (WITHOUT SCRAM) 
For the other class of events, in which the plant pritective system is postulated to fail, the types of plant malfuncticins or faults which can be identified as events of a realistic potential for occurrence, can be grouped into two classes. These are malfunctions which result in inadequate flow of coolant to the reactor, on the one hand, or an increase in power level beyond the cooling capability of the existing flow conditions, on the other hand; that is, loss of flow without scram or transient overpower without scram. These events themselves could lead to disruption of the core geometry, but would not result in a prompt nuclear excursion. The focus of hypothetical accident progression analysis has been on the consideration of feedback mechanisms and phenomena that might be autocatalytic or at least would govern the progression of the accident. The progression of the loss of flow accident wi thout scram and the transient overpower accident without scram have been the major elements of the AEC/ERDA's hypothetical core disruptive accident analys is programs in recent years.

Until recently most of the emphasis was on the characteristics and consequences of prompt nuclear excursion events. More recently, greater emphas is has been placed on phenomenology which might terminate postulated accidents without the possibility of a nuclear excursion. 


\section{Reactor Dynamics}
A. Basic Theory

VG Remember

IV-1

$$
k=\frac{k_{\infty}}{1+B^{2} M^{2}}
$$

$B^{2} M^{2}$ represents the leakage probability.

If you change the geometry of the reactor, and don't change the constituents, the principal change in multiplication occurs because of leakage changes -

So -

$$
\Delta k \approx-\Delta\left(B^{2} M^{2}\right)
$$

Although the buckling, $B^{2}$, gets smaller if the core expands, $M^{2}$ gets larger at a more rapid rate. In fact, $M^{2}$ varies roughly as the volume-squared, ${ }^{*}$ whereas $B^{2}$ varies inversely roughly as volume to the $2 / 3$ power (radius squared).

Thus, increasing volume (and reducing density) causes loss of reactivity, and the reverse.

Since a fast reactor core doesn't depend on the coolant for reactivity, one can imagine a nuclear excursion due to the volume reduction which might occur if a core melted down. Similarly, the dispersal of the core would cause a large loss of reactivity. This was the set of circumstances envisaged by Bethe and Tait in their 1956 study.

VG

In the Bethe-Tait study, the reactor kinetics equation was IV-2 simplified to include prompt neutrons only, and no source.

$$
\frac{d^{2} Q}{d t^{2}}=\frac{\rho-\beta}{\ell} \frac{d Q}{d t} \quad\left[\text { or, } \frac{d p}{d t}=\frac{\rho-\beta}{\ell} \cdot p\right]
$$

\footnotetext{
* Two macroscopic cross-sections (product) in the denominator.
} 
FIGURE IV-1

LEAKAGE REACTIVITY VARIATION

$$
\begin{aligned}
& K \approx \frac{K \infty}{1+B^{2} M^{2}}, \therefore \Delta K \approx-\Delta\left(B^{2} M^{2}\right) \\
& B^{2} \alpha \frac{1}{R^{2}} \alpha \frac{1}{V^{2 / 3}} \\
& M^{2} \alpha V^{2}
\end{aligned}
$$

$\therefore B^{2} M^{2} a v^{4 / 3}$

$$
\frac{\Delta\left(B^{2} M^{2}\right)}{\Delta V} a V^{1 / 3}>0
$$

$\frac{\Delta K}{\Delta V}<0$ 
FIGURE IV-2

\section{DYNAMICS EQUATIONS}

$$
\begin{aligned}
& \frac{d^{2} Q}{d t^{2}}=\frac{k-1-\beta}{l} \frac{d Q}{d t} \\
& k(t)=k_{0}+k_{P}(t)+K_{D}(t) \\
& K_{D}(t)=\int_{V} U(r, t) \times \nabla D(r) d V \\
& \frac{d^{2} U(r, t)}{u^{\prime} t^{2}}=-\frac{1}{P} \nabla P(r, t) \\
& P(r, t)=F \quad[E(r, t)]
\end{aligned}
$$


where

$$
Q(t)=\int_{0}^{t} p(t) d t,
$$

i.e. energy $=$ integral of power.

The reactivity was the sum of input plus disassembly,

$$
k(t)=k_{0}+k_{p}(t)+k_{D}(t),
$$

i.e. $\quad$ net $=$ initial + programmed + disassembly feedback and the disassembly feedback was calculated from perturbation weighting of material displacement.

$$
\begin{aligned}
k_{D}(t) & =\int_{V} \underline{U}(\underline{r}, t) \cdot D(r) d V \\
\underline{U}(\underline{r}, t) & =\text { material displacement } \\
\nabla D(\underline{r}) & =\text { gradient of the worth distribution }
\end{aligned}
$$

Material displacement resulted from acceleration down the pressure gradient

$$
\frac{d^{2} \underline{u}(\underline{r}, t)}{d t^{2}}=-\frac{1}{\rho} \nabla P(\underline{r}, t) .
$$

Pressure was calculated according to the material equation of state

$$
P(\underline{r}, t)=f(E[\underline{r}, t])
$$

where here the pressure buildup was assumed to be proportional only to the energy deposition. The functional form used by Bethe and Tait was to assume zero pressure prior to the point where fue 1 expanded sufficiently to fill the space vacated by sodium. This point was defined as $Q^{\star}$. Upon differentiating Equation (4) twice, substitution of Equation (5) results in

$$
\ddot{k}_{D}(t)=\frac{1}{\rho}\{(\nabla P[\underline{r}, t]) \cdot(\nabla D[\underline{r}]) d V
$$


or, for spherical geometry,

$$
\ddot{k}_{D}(t)=-\frac{f(Q[t])}{\rho} \int r^{2} \frac{d N(r)}{d r} \frac{d D(r)}{d r} d r
$$

where $N(r)$ is the radial power distribution.

In order to solve the coupled set of equations, Bethe and Tait divided the problem into two phases -- Phase I characterized the first time interval in which the reactivity insertion was emphasized (a molten core collapsing only under gravity was the assumed insertion mechanism). Phase II dealt only with core disassembly and the associated negative reactivity feedback.

Although the method as developed was perhaps adequate for a first cut, several rather serious approximations were made to render the problem tractable for a hand solution. Among the approximations were the neglect of the effect of fuel vapor pressure as a disassembly force, neglect of delayed neutrons, and the neglect of a density dependence in the equation of state.

A comprehensive description of the theory of excursion accidents is given by Okrent and McCarthy in Chapter 10 of the Technology of Nuclear Reactor Safety. (10) In Chapter 7 of the same book, Nyer (11) gives some interesting simple models which can be used to illustrate the reactivity feedback effects.

In the vu-graph:

$\alpha_{0}=$ inverse period corresponding to an initial prompt reactivity step $=\frac{\rho_{0}-\beta}{\ell}$

$B$ and $A$ are constants defining the feedback as an appropriate function of energy

$E$ is energy; $E_{t h}$ is a threshold for disassembly feedback For a ramp reactivity insertion, Nyer says

$$
\alpha_{0}(\text { eff }) \approx\left(\frac{30 \dot{\$}}{\ell / B}\right)^{1 / 2}
$$


FIGURE IV-3

\section{SIMPLE MODELS FOR NUCLEAR EXCURSIONS}

A. LINEAR ENERGY MODEL

$$
\begin{aligned}
& \frac{\stackrel{\circ}{\Phi}}{\Phi} a_{0}-B E \\
& E_{f} \approx \frac{2 \alpha_{0}}{B}
\end{aligned}
$$

B. LOG ENERGY MODEL

$$
\begin{aligned}
& \frac{\stackrel{\Phi}{\Phi}=a_{0}-B l n(1+A E)}{E_{(\operatorname{Tmax})}} \approx \frac{1}{A}\left[\exp \left(\frac{a_{0}}{B}\right)-1\right]
\end{aligned}
$$

C. THRESHOLD DISASSEMBLY MODEL

$$
\begin{aligned}
& \frac{\stackrel{\circ}{\Phi}}{\Phi}=a_{0}-B \iint\left(E-E_{t h}\right) d t \cdot d t \\
& E_{f} \approx \frac{a_{0}^{3}}{B}+E_{t h}
\end{aligned}
$$


VG The vu-graph compares several measures of the excursion energy in IV-4 terms of their variation with core size and input reactivity.

Note that the disassembly feedback model is very sensitive to both input reactivity and core size, while the continuous feedback models are much less sensitive to core size. This illustrates one important aspect of the Doppler coefficient or a prompt thermal expansion feedback.

Also note that the disassembly feedback model necessarily requires generation of vapor and the imposition of kinetic energy to the core. The other models do not, and if thermal feedbacks are important, the core may disassemble relatively non-energetically at a power limited by the thermal feedback rather than free to increase until stopped by disassembly.

B. History and Evolution

$V G$

A summary comparison of containment designs for U.S. and

IV-5 Western European fast reactors is given in this vu-graph.

The earliest fast reactors were Clementine, at LASL, and EBR-I, at Idaho Falls. These were small, experimental reactors, built without special containment features at remote experimental sites.

Later reactors incorporated containment systems capable of withstanding large sodium fires and/or energetic nuclear excursions; margins for the magnitude of both, relative to reactor size, have come down since the first generation of contained FBR's.

In 1954, the EBR-I experienced a core meltdown in the course of experiments to evaluate a positive power coefficient of reactivity, due to thermal-induced fuel pin bowing. The accident sequence and the subsequent investigation have been described in the Titerature. $(12,13)$ The final condition of the core was that the fuel had melted from the center and moved both upward and downward, and the molten fuel had subsequently frozen, leaving a 


\section{FIGURE IV-4}

PROPORTIONALITY OF NUCLEAR EXCURSION ENERGY TO REACTIVITY ADDITION AND CORE SIZE

\begin{tabular}{|c|c|c|c|}
\hline FEEDBAC & $\begin{array}{r}\text { DISASSEMBLY } \\
b \iint\left\langle E-E_{t h}\right) d t \cdot d t\end{array}$ & $\begin{array}{l}\text { LINEAR ENERGY } \\
\left(\frac{\mathrm{dl}}{\mathrm{dT}}=\text { CONSTANT }\right) \\
\mathrm{bE}\end{array}$ & $\begin{array}{c}\text { LOG ENERGY } \\
\left(T \frac{d h}{d T}=\text { CONSTANT } K_{0}\right. \\
b \cdot \ln (1+A E)\end{array}$ \\
\hline TOTAL HEAT & $\begin{array}{r}a_{0}^{3} v^{7 / 3} \\
\left.+\quad v T_{\text {th }}-T_{0}\right) \\
\end{array}$ & $a_{0} V$ & $\begin{array}{l}V T_{0}\left[\operatorname{exf}\left(\frac{a_{0}}{K_{D}}\right)-1\right] \\
\left.L E=E\left(T_{\text {max }}\right)^{\prime}\right]\end{array}$ \\
\hline $\begin{array}{l}\text { HEAT ABOVE } \\
\mathrm{UO}_{2} T_{\text {melt }}\end{array}$ & $\begin{aligned} & a_{0}^{3} v^{7 / 3} \\
&+\left.c v T_{m}-T_{0}\right) \\
&\end{aligned}$ & $\begin{aligned} & a_{0} V \\
&-c \vee\left(T_{m}-T_{0}\right) \\
&\end{aligned}$ & $\begin{array}{l}\vee T_{0}\left[\exp \left(\frac{\alpha_{0}}{k_{D}}\right)-1\right] \\
-c \vee\left(T_{m}-T_{0}\right)\end{array}$ \\
\hline $\begin{array}{l}\text { HEAT ABOVE } \\
\mathrm{UO}_{2} \mathrm{~T}_{\text {th }}\end{array}$ & $a_{0}^{3} v^{7 / 3}$ & $\begin{array}{c}a_{0} V \\
-c V\left(T_{\text {sat }}-T_{0}\right)\end{array}$ & $\begin{array}{l}\vee T_{0}\left[\exp \left(\frac{a_{0}}{K_{D}}\right)-1\right] \\
-c \vee\left(T_{\text {sat }}-T_{0}\right)\end{array}$ \\
\hline $\mathrm{UO}_{2} \int \mathrm{PdV}$ & $a_{0}^{3} v^{7 / 3}$ & -- & -- \\
\hline $\begin{array}{l}\text { KINETIC ENERGY } \\
\text { AT DISASSEMBLY }\end{array}$ & $a_{0}^{4} v^{3}$ & $\cdots$ & -- \\
\hline
\end{tabular}

NOTE: EXPRESSIONS GIVEN ARE PROPORTIONAL TO APPROXIMATE ENERGY, NOT EQUAL. PROPORTIONALITY CONSTANTS ARE OMITTED, AND DIFFER FOR DIFFERENT CASES. 
FIGURE IV-5

FAST REACTOR CONTAINMENT DESIGN

\begin{tabular}{|c|c|c|c|}
\hline REACTOR & $\begin{array}{c}\text { CONTAINMENT } \\
\text { BUILDING }\end{array}$ & $\begin{array}{l}\text { INNER } \\
\text { BARRIER }\end{array}$ & ENERGY (MW-SEC) \\
\hline EBR-I & --- & --- & --- \\
\hline EBR-11 & $\begin{array}{c}\text { STEEL SHELL } \\
24 \mathrm{psi}\end{array}$ & REACTOR CAVITY & 600 \\
\hline FERMI & $\begin{array}{c}\text { STEEL SHELL } \\
32 \mathrm{psi}\end{array}$ & $\begin{array}{l}\text { CAV/CELLS/MACH. } \\
\text { DOME }\end{array}$ & 2000 \\
\hline DFR & $\begin{array}{c}\text { STEEL SHELL } \\
18 \mathrm{psi}\end{array}$ & -- & \\
\hline RAPSODIE & $\begin{array}{c}\text { STEEL SHELL } \\
34 \mathrm{psi}\end{array}$ & $\because$ & \\
\hline SEFOR & $\begin{array}{c}\text { STEEL SHELL } \\
34 \mathrm{psi}\end{array}$ & CAV/CELLS/HOT CELL & 400 \\
\hline PFR & FILTER BLDG & REACTOR CAVITY & $600-1000$ \\
\hline PHENIX & FILTER BLDG & REACTOR CAVITY & $300-1000$ \\
\hline FFTF & $\begin{array}{c}\text { STEEL SHELL } \\
10 \mathrm{psi}\end{array}$ & CAV/CELLS & $150-350$ \\
\hline SNR-300 & RE-VENTED BLDG & $\begin{array}{l}\text { CAV/CELLS/HEAD } \\
\text { COMPT }\end{array}$ & $150-370$ \\
\hline SUPER-PHENIX & CONCRETE BLDG & SAFETY VESSEL/DOME & --- \\
\hline CRBRP & $\begin{array}{c}\text { STEEL SHELL } \\
10 \mathrm{psi}\end{array}$ & CAVICELLS & --- \\
\hline
\end{tabular}


low density, porous region in the middle of the core. This geometry is less reactive than the initial core geometry. If, however, the molten fuel had all moved downward so that it had formed a higher density array toward the center or the lower half of the reactor, then the reactivity could have increased; and under such conditions, the excursion in which the melting took place could have been autocatalytic. Or if the upper portion of the core, after production of the central void, had collapsed toward the lower part, a secondary excursion could have been initiated.

VG I'm not sure what impact the EBR-I accident had upon initiation IV-6 of the Bethe-Tait analysis, but in any event, in 1956 the BetheTait report ${ }^{(4)}$ appeared. For their analys is Bethe and Tait assumed as initial conditions that the core was completely molten in its original geometrical size, that the core was totally void of sodium, and that at time zero it began to collapse coherently upori itself with an acceleration of gravity; that is, that the lower plane remained fixed and the upper plane collapsed with an acceleration of $1 \mathrm{~g}$. The resulting increase in density would cause an increase in reactivity and once the array became prompt critical power would go up rapidly. This excursion would only be terminated by the dispersal of the core material due to the fuel pressure exerted once it had reached a sufficiently high temperature. Upon termination of the excursion by dispersal of the core, Bethe and Tait considered the damaging potential of the event to be the equivalent of a TNT explosion in which an amount of heat energy liberated would be equal to the excursion energy above the disassembly threshold. That is, approximately $2 \mathrm{MW}-\mathrm{sec}$ of nuclear excursion energy was taken to be the equivalent of one pound of TNT.

VG In the late 1950's and extending into the early 1960's the IV-7 EBR-II and the FERMI reactors were built in the United States and the Dounreay fast reactor in the United Kingdom. The Bethe-Tait accident analysis was applied in the safety evaluation of EBR-II (14) and FERMI, (15) with an accident energy in the range of 5-10 MW-sec or more per reactor megawatt (or 5-10 full power seconds). During 
FIGURE IV-6

\section{BETHE-TAIT ACCIDENT}

REFERENCE: BETHE AND TAIT, UKAEA-RHM (56)/113 (1956)

ASSUMPTIONS

$\begin{array}{ll}\text { CORE CONDITIONS: } & \text { MOLTEN CORE } \\ & \text { GRAVITY COLLAPSE } \\ \text { NUCLEAR ANALYSIS: } & \text { HOMOGENEOUS SPHERE } \\ & \text { PERTURBATION THEORY } \\ \text { END CONDITIONS: } & \text { HYDRODYNAMIC DISASSEMBLY } \\ & \text { ENERGYITNT EQUIVALENT }\end{array}$




\section{FIGURE IV-7}

SEQUENCE OF US FAST REACTOR HYPOTHETICAL ACCIOENT STUDIES

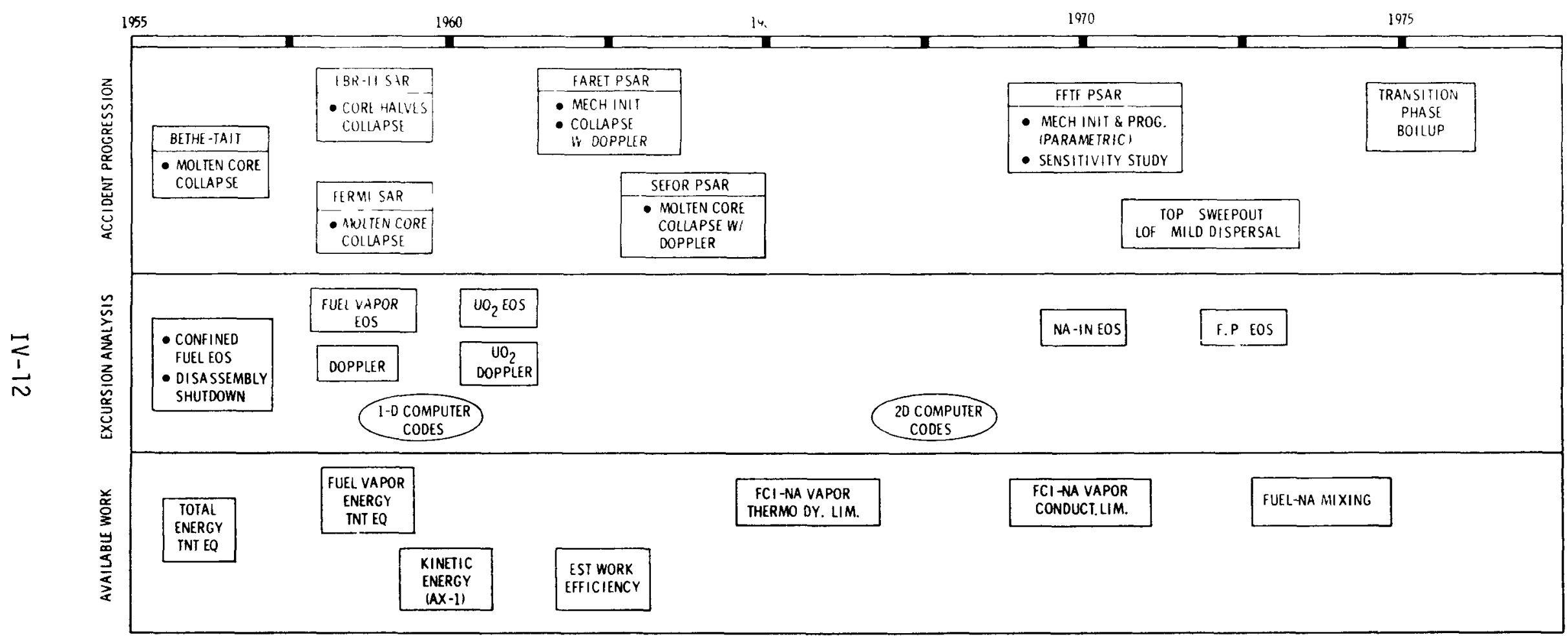


this time period analytical methods for application in these projects were developed which were improvements over the original Bethe-Tait mode].

- Nicholson $(16,17,18)$ modified the Bethe-Tait method and programmed the problem for digital computer solution (Weak Explosion Program - WEL,K or WEP). He also incorporated fuel vapor pressure forces (in addition to confined liquid or supercritical fluid pressures) and the Doppler coefficient of reactivity.

- Stratton (19) developed a computer code for excursion analysis representing the core as a series of concentric shells. Subsequently, Okrent, et al., at ANL and LASL, collaborated on the AX-1 program ${ }^{(20)}$ which treated the core as a series of shells and which employed transport theory neutronics and explicit hydrodynamics.

- Jankus $(21,22)$ developed an improved basis for assigning a TNT explosion equivalence. This equivalence was taken not on the basis of that amount of TNT which would liberate an equal amount of thermal energy, but rather on the basis of the quantity of TNT which would, for an ideal isentropic expansion of the explosion gases, produce an amount of energy equal to that which would be liberated by the isentropic expansion of the fuel vapor produced in the nuclear excursion.

- In studies of oxide fueled fast reactors the Doppler coefficient contribution to excursion energetics was evaluated extensively for oxide reactors, and several favorable effects of the Doppler contribution were illuminated. $(23,24,25)$ The Doppler coefficient reduces the energy produced in the excursion and also reduces the sensitivity of the energy to core size, which is a favorable result when one looks ahead toward larger fast reactors in the future. The Doppler coefficient also reduces the sensitivity of accident energy to the reactivity insertion ramp rate. 
In the early 1960's two smaller and more specifically developmental fast reactor projects in the United States followed the EBR-II and FERMI. One of the projects was ANL's FARET, which was to be a 50 megawatt fast test reactor. The other project was SEFOR; a 20 megawatt oxide fueled fast reactor designed and built for the specific purpose of demonstrating the Doppler coefficient in an oxide fuel fast reactor.

The SEFOR was very conservatively designed, with a capability for sustaining a reactor accident with energy of $400 \mathrm{MW}-\mathrm{sec} .{ }^{(26)}$ This quantity of energy was not tied to specific mechanistic accident conditions, al though a number of analyses were carried out using modified Bethe-Tait methods and considering fuel vapor expansion for work energy evaluations.

FARET was never built, but the reactor was designed fairly completely and the preliminary safety analysis report was completed ${ }^{(27)}$ and reviewed by ACRS. A major contribution to slbsequent fast reactor analyses was made by Persiani of ANL in the FARET safety analyses; ${ }^{(28)}$ this was the first reactor project to apply a mechanistic approach to the analysis of the initial conditions in hypothetical core disruptive accidents. Persiani analyzed, for example, a reactor meltdown accident in which he considered the rate at which molten fuel might slump under physically realistic axial power and temperature conditions, and the resulting reactivity insertion rate. He initiated efforts to include the additional effects of incoherence in melting and resultant slumping. All of this was directed toward a more realistic assessment of the reactivity addition rates which might occur under a core rearrangement, rather than the arbitrary initial conditions of Bethe-Tait analysis. Persiani also applied a lower estimate of energy yield based partly on calculated kinetic energy of the core at disassembly, as computed by $A X-1$.

Also, in the middle 1960's Hicks and Menzies ${ }^{(29)}$ of the United Kingdom identified a potential for increased damaging energy as the result of heat transfer between molten reactor fuel and 1 iquid 
sodium in the reactor. They showed that under theoretical thermodynamic conditions, transfer of heat from fuel to sodium and the isentropic expansion of the sodium vapor could increase the damaging work potential substantially above the work potential of the fuel vapor itself. This development had a major impact on subsequent reactor accident analyses and the related experimental and theoretical development programs.

Later in the 1960's emphasis shifted to the FFTF. Also, a number of studies were done in connection with the relicensing of the FERMI reactor following the fuel assembly meltdown which occurred in 0ctober 1966. The FERMI relicensing studies made use of a new computer code for fast reactor analys is known as the MARS code. (30) MARS was a two-dimensional version of the previous Nicholson Weak Explosion Program.

C. FFTF HCDA Studies

In 1967, FFTF accident analys is studies intended to be used as the basis for the Regulatory Review were initiated. Following the lead established by Persiani in his FARET studies, mechanistic reviews of potential initiating events were carried out to identify appropriate initial conditions or initial assumptions for the severe accident analyses. Accident progression analyses were carried out mechanistically on as realistic a basis as possible within existing understanding of what the accident progression phenomenology would be.

VG For clarity, I've divided the FFTF studies into a number of IV-8 phases. The initial phase took place during initial scoping calculations and addressed for the first time the potential impact of the Hicks-Menzies analysis on work potential. This phase also developed the first sodium-in calculations leading to early disassembly. The next phase developed the PSAR analyses and included analytical rate-limiting effects on FCI's. The next phase initiated the more detailed mechanistic approach currently being used, based on results of experimental and theoretical programs 
FIGURE IV.8

FFTF HCDA STUDIES

PHASE 1: NA-IN, 2D DISASSEMBLY

(MELT-I, MAX)

PHASE 2: MECHANISTIC PROGRESSION, LIMITED FCI

(MELT-II, VENUS, SOCOOL-II)

PHASE 3: R \& D-BASED MECHANISTIC STUDIES

TOP: MELT-IIA \& III (HEDL)

LOF: SAS-2 \& 3 (ANL)

PHASE 4: TRANSITION TO STABLE GEOMETRY 
carried out to provide data for improved mechanistic analyses. The last phase is the area of primary current interest.

- Phase 1: The first phase of these studies investigated events which might be postulated to induce reactivity insertion ramp rates in the neighborhood of $50-100 \$ / \mathrm{sec}$. Subsequent design studies and design choices indicate the potential for such events to be essentially vanishingly small. Also investigated were somewhat more realistic events such as reactivity insertion rates which might range up to a few dollars/second, and loss of flow conditions characteristic of pump coastdown and of large pipe breaks.

The whole core accident analysis code, MELT-I, (31) was developed at HEDL for analysis of hypothetical accidents prior to the onset of "hydrodynamic disassembly;" that is, core disassembly as the result of fuel vapor pressure acting to disperse the core. The disassembly analysis was performed with the code, MAX, (32) which performed a modified Bethe-Tait analysis in spherical geometry, with the capability of handling multiple core regions and sodium-in calculations. The major phenomena investigated in order to assess accident progression characteristics which might be significant with respect to reactivity feedback characteristics were sodium voiding and fuel motion. In the overpower (reactivity IV-9 addition) transient analysis, sodium voiding received the greatest emphasis because of the positive sodium void coefficient for the central region of the reactor core.

Three potentially important sodium voiding mechanisms were considered. At that time there was little understanding of sodium superheat and the possibility of large amounts of superheat followed by massive sodium flashing was considered. The second potentially rapid voiding mechanism was the release of fission gas from within the fuel pins following failure of fuel pin cladding. The third voiding mechanism was production of sodium vapor by molten fuel-coolant interaction. It was shown that these mechanisms, if it were assumed that sodium voiding initiated from the axial center of the core, could be capable of changing the 
FIGURE IV-9

PHASE 1 FFTF HCDA STUDIES - 1967

\author{
KEY PHENOMENA \\ - SODIUM VOIDING \\ SUPERHEAT \\ FISSION GAS \\ $\mathrm{FCl}$
}

- FUEL MOTION 
characteristics of an initially slow reactivity insertion or loss of flow into a rapid reactivity insertion of the order of perhaps $100 \$ / \mathrm{sec}$ due to rapid voiding from the center and the corresponding rapid positive reactivity feedback.

It was considered more probable that sodium voiding would begin near the core outlet wi thout a positive effect, but the studies pointed up the need for understanding fuel failure locations and sodium voiding mechanisms.

$V G \quad$ Analyses assuming fuel slumping indicated that the reactivity IV-10 insertion rates probably would not exceed approximately $20-30 \$ / \mathrm{sec}$, dependent upon slumping coherency and forces acting on the molten fuel.

A significant factor noted in these early studies was that events which could cause a very large reactivity insertion, in the neighborhood of $100 \$ / \mathrm{sec}$, unless they were associated with some arbitrarily postulated circumstance beyond the capability of the plant protective systems, were only produced by voiding in the center of the core. In any such case, most of the core volume would still contain its original sodium inventory. If large portions of the core were already voided, the major reactivity feedback mechanism would be fuel motion, and the maximum potential reactivity insertion rates would be reduced. The importance of this observation is in the effectiveness of central core region pressures in causing outward fuel motion and corresponding negative reactivity feedbacks in the early part of the core disassembly phase.

$V G \quad$ In the classical Bethe-Tait analysis, sodium was assumed to

IV -11 be out of the reactor and the fuel then was assumed to have an initial reduced density as if it occupied the entire core volume. Under these conditions the only dispersing force acting would be the fuel vapor pressure up until the time that the fuel temperatures reached such a high level that the liquid (or supercritical) fuel would fill all the available volume. Beyond that point the core would have the characteristics of a confined liquid (or supercritical fluid) and small increases in temperature would result in 
FIGURE IV-10

EFFECT OF FUEL SLUMPING ON DISASSEMBLY RAMP RATES FOR SODIUM-OUT FTR

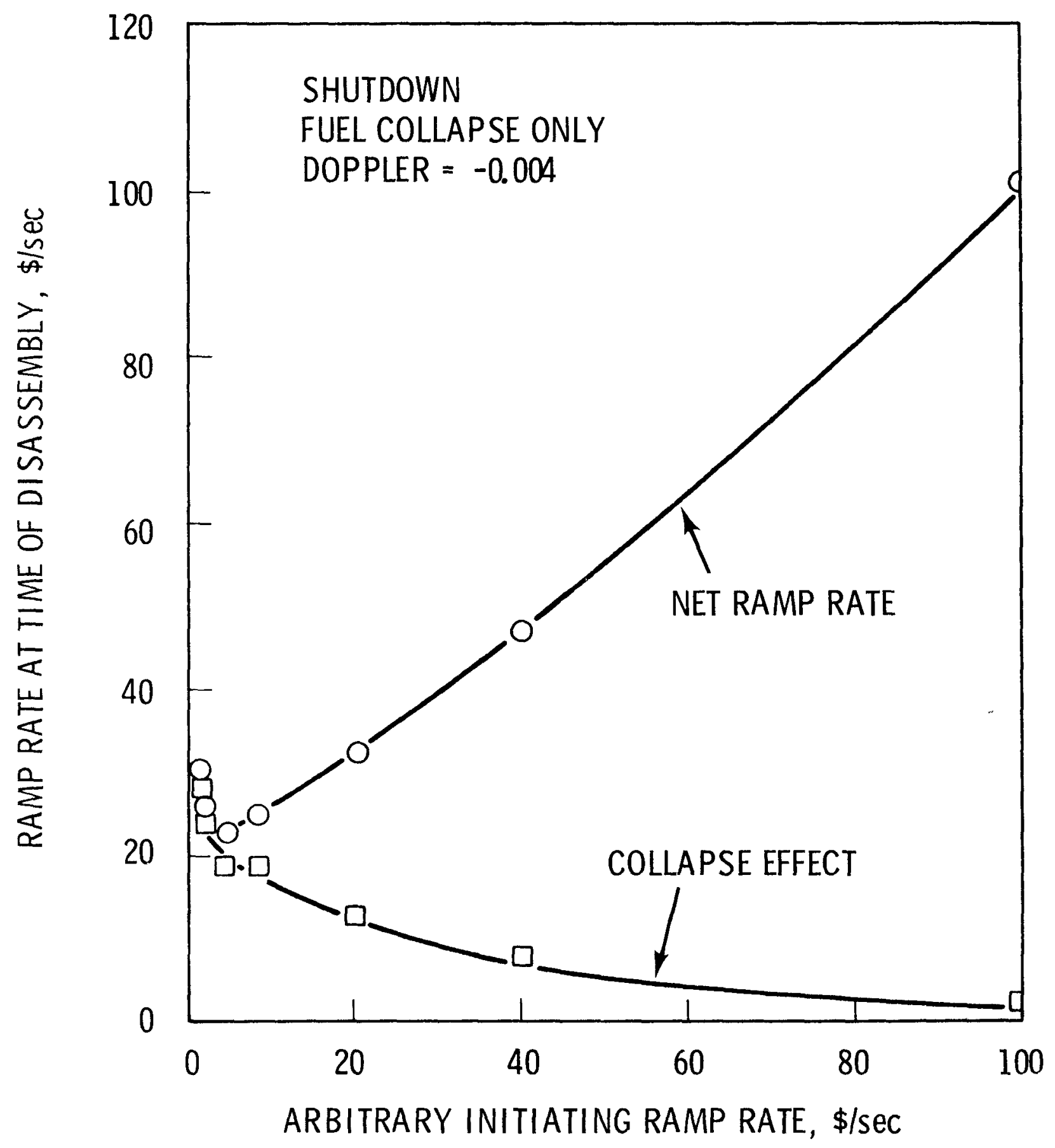


FIGURE IV-11

VARIOUS DEGREES OF SOPHISTICATION USED IN FORMULATING AN EQUATION OF STATE

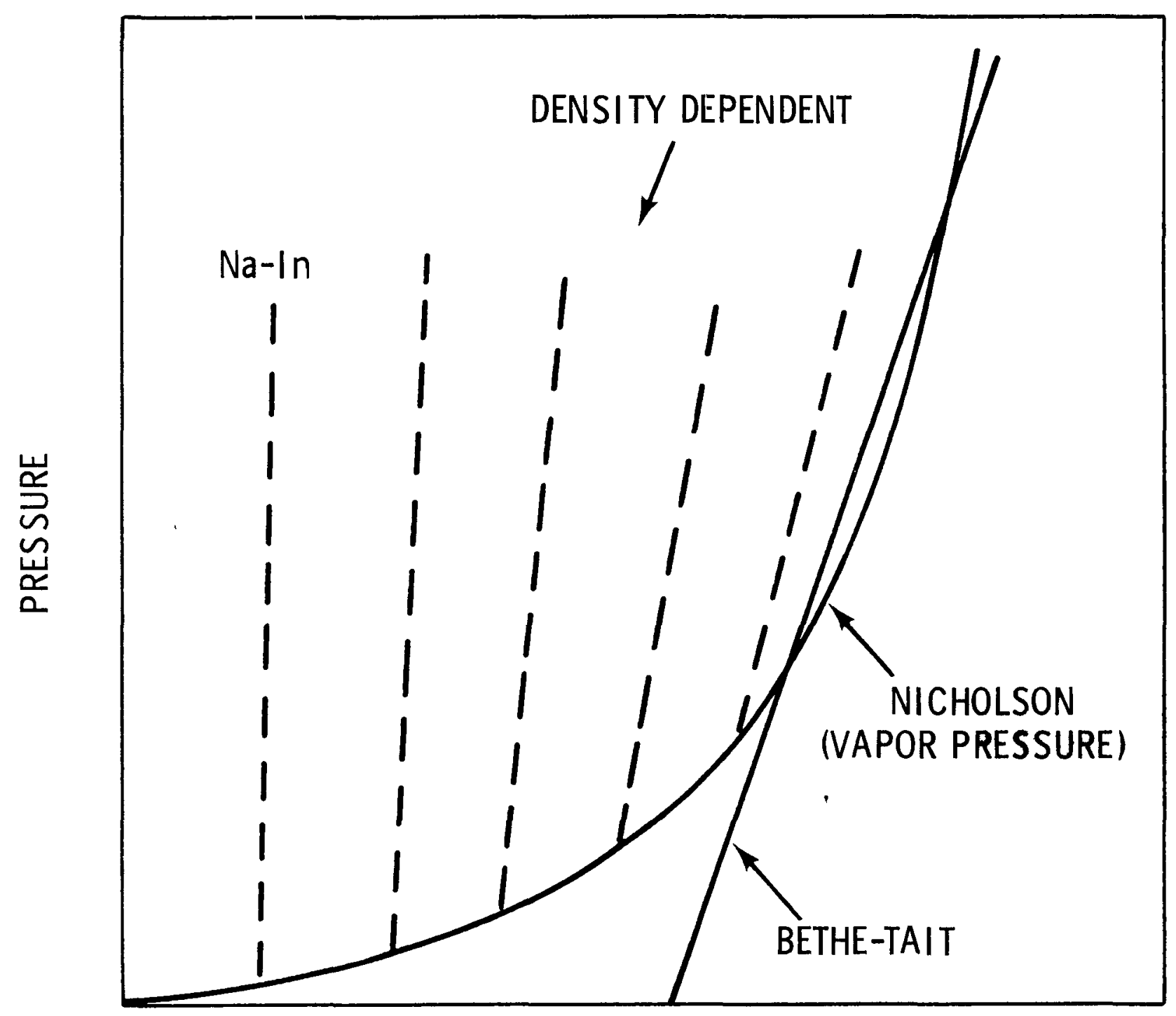

ENERGY · 
very large increases in pressure and correspondingly rapid acceleration of fuel material away from the high-pressure region. In the cases in which sodium was still occupying its original positions in the core, the available initial void volume would be relatively small and a much smaller increase in fuel temperature and correspondingly much smaller fuel energy density would be required in order to lead to conditions of an effectively confined liquid and large core material accelerations down the pressure gradient. (33)

Since the effective sodium-in equation of state significantly reduced calculated energy levels from those using a voided core VG EOS, later studies investigated the effects of small quantities of IV-12 voids in the system. For uniformiy distributed voids (at the onset of disassembly) there is a significant energy reduction only when the void fraction is less than about $4 \%$. For void distributions more typical of core temperature distributions when disassembly from core is first generated, the void fraction could be as high as about $15-20 \%$. The possible adverse effect of implosion into a "lumped" void at the core center was also investigated and it was found to have but small effect. $(34,35)$

VG - Phase 2: The second phase of parametric investigations was IV-13 undertaken in order to reach a more realistic estimate of characteristics and energy, together with a reasonable assessment of the range of uncertainty in such an estimate. ${ }^{(34)}$ The accident progression analysis is outlined in the vu-graph. Transient behavior of the integral reactor core in response to the condition of either reactivity increase or coolant-flow decay was calculated by a coupled analysis of neutronics and thermalhydraulics. The progression of events was analyzed with the MELT-II ${ }^{(36)}$ computer code until conditions reached a point at which the core became subcritical without hydrodynamic disassembly or until conditions were such that hydrodynamic pressures would begin to become significant. In the latter case the core parameters at that point were used to establish input conditions for the VENUS 
FIGURE IV-12

SENSITIVITY OF ENERGY RELEASE TO PERCENT VOID IN CORE

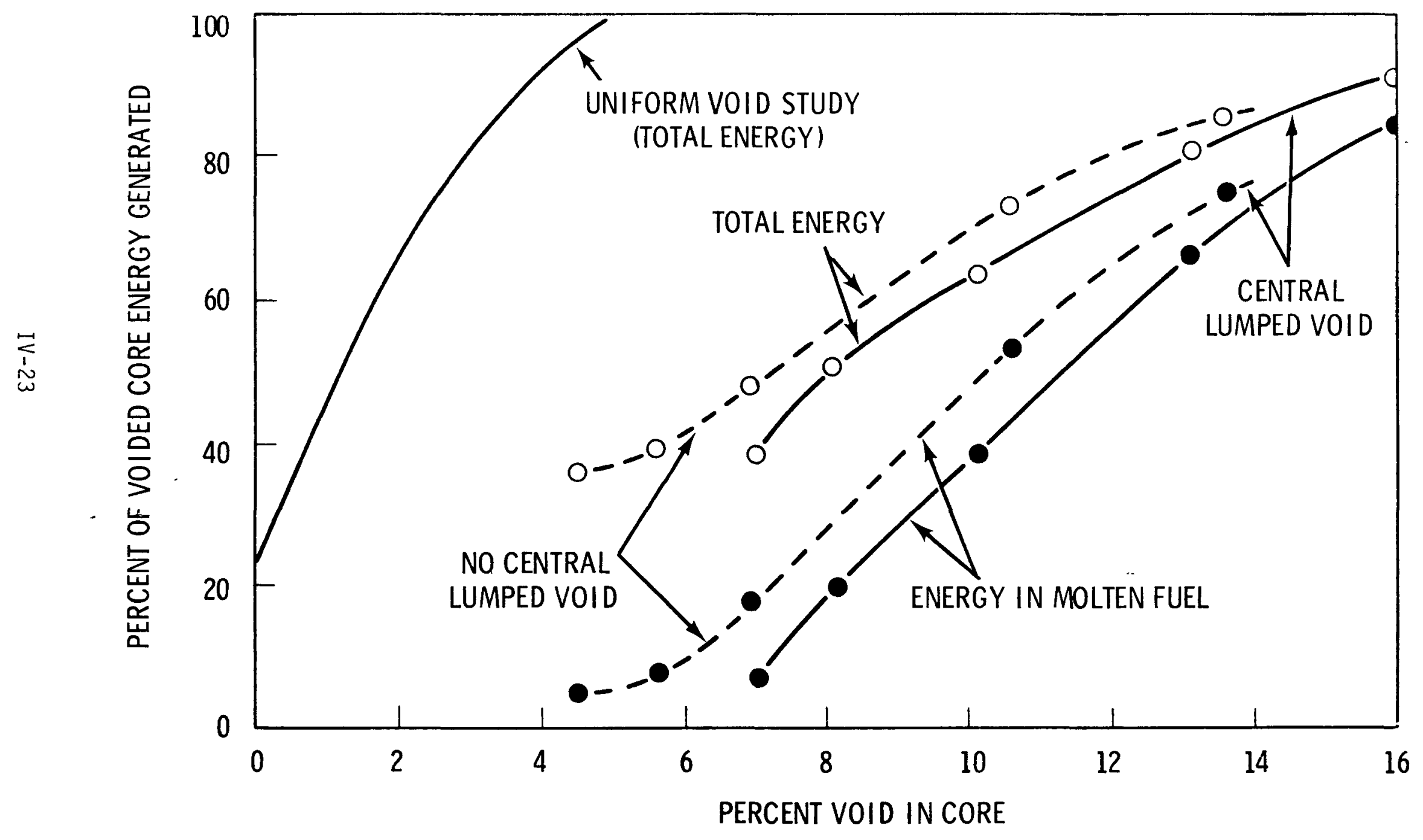


FIGURE IV-13

HYPOTHETICAL ACCIDENT ANALYSIS

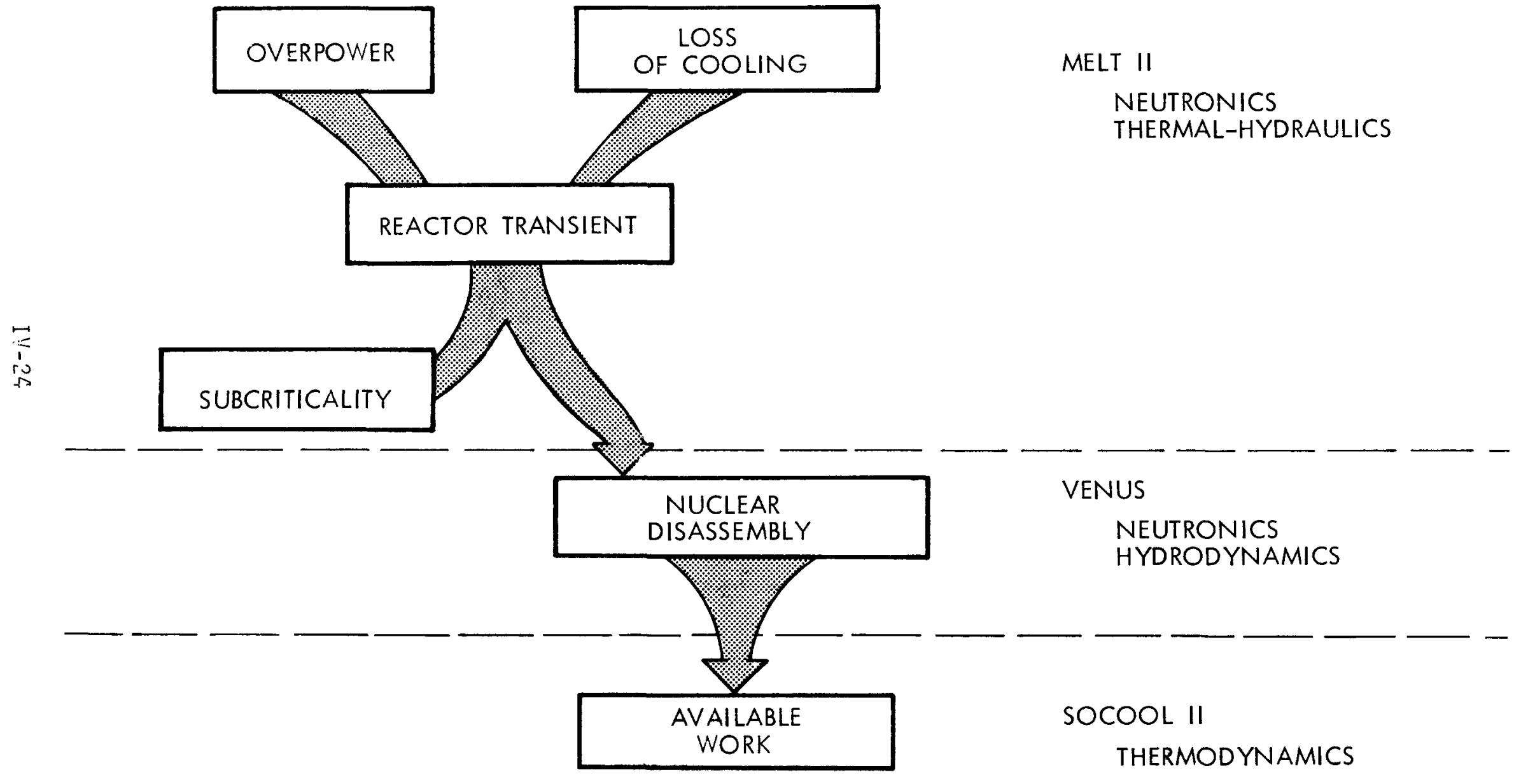


code, (37) which performs a coupled, two-dimensional neutronicshydrodynamics analysis until the nuclear excursion is terminated.

If nuclear disassembly should occur, the energy which might become available to do destructive work on the reactor vessel and other structures was calculated with the SOCOOL-II code, (38) which performs a transient thermodynamic calculation of heat transfer from molten fuel to sodium, assuming the fuel to be instantly fragmented and uniformly dispersed into its associated sodium volume in the core.

VG Using this system of codes, parametric studies were carried IV-14 out to determine the importance of variations in phenomenology and in analytical parameter values. Analytical parameters varied over ranges of interest included Doppler coefficient, sodium void coefficient, fuel heat capacity, and characteristic parameters of the cort equation of state. Initial assumptions were also varied. In the case of overpower transient conditions, a range of reactivity insertion rates up to $5 \$ / \mathrm{sec}$ was investigated. For flow coastdown corditions, a range of rates of flow reduction was investigated. In the area of accident progression phenomenology, alternate characteristics were investigated for sodium voiding and for fuel motion, and the sensitivity to the time and condition of fuel at failure was studied.

It was concluded that the most important areas of uncertainty, that is, the areas in which the accident characteristics were most sensitive and in which the potential for very great conservatism in conventional assumptions was high, lay in the areas of the accident progression phenomenology, specifically, sodium voiding characteristics and fuel motion characteristics, and also in the area of the fuel coolant interaction with the resultant energy generation. These conclusions provided significant impetus to experimental and analytical development programs (primarily at Argonne National Laboratory) to investigate sodium void phenomenology, fuel motion phenomenology and fuel coolant interactions. This phase of FFTF calculations was concluded in 1970 and was used as the basis for 
FIGURE IV-14

HYPOTHETICAL ACCIDENT ANALYSIS UNCERTAINTIES

PARAMETER

INITIATING PHASE

INITIATING RAMP RATE

FLOW DECAY RATE

ACCIDENT PROGRESSION PHASE

DOPPLER COEFFICIENT

FUEL HEAT CAPACITY

EQUATION OF STATE

PIN FAILURE

SODIUM VOID WORTH

SODIUM EXPULSION

MOLTEN FUEL MOVEMENT

WORK F.NERGY

ENERGY EXCHANGE
RANGE OF UNCERTAINTY

IN PARAMETER

\section{EFFECT \\ ON ENERGY \\ RELEASE}

NOT CONTROLLING

SMALL

SMALL

VERY LARGE

LARGE

LARGE

LARGE

LARGE

VERY LARGE
SMALL

CONSERVATISM

CURRENTLY

EMPLOYED

$\begin{array}{ll}\text { SMALL } & \text { NOMINAL } \\ \text { SMALL } & \text { NOMINAL } \\ \text { SMALL } & \text { NOMINAL } \\ \text { SMALL } & \text { SMALL } \\ \text { LARGE } & \text { MEDIUM } \\ \text { LARGE } & \text { LARGE } \\ \text { LARGE } & \text { LARGE }\end{array}$

VERY LARGE

VERY LARGE 
the FFTF safety evaluation reported in the Preliminary Safety Analysis Report. (39)

Immediately following the preparation of the PSAR the next round of calculations was initiated to attempt to represent the key feedback phenomena more accurately and also to carry the analyses through to the existence of a stable, coolable core configuration. HEDL concentrated on the analys is of the transient overpower without scram hypothetical accident, and Argonne National Laboratory undertook analysis of the loss of flow without scram.

- Phase 3: In support of these analytical efforts, a substantial body of experimental data has been developed on sodium and fuel behavior under applicable transient conditions, and many of the experimental results are documented. $(40,41,42,43)$

Transient Overpower (TOP) HCDA

VG

The experimental data base applicable to the TOP HCDA analys is IV-15 is summarized on the vu-graph.

VG Under transient overpower conditions, experimental data

IV-16 indicated that fuel failure characteristics would differ depending on the fuel pin microstructure and the quantity of trapped fission gas; ${ }^{(44)}$ these in turn are related to the temperature and specific power in the fuel pin during its operation prior to the accident. Relatively high power fuel would be extensively restructured with little fission gas retained within the restructured region, whereas low power fuel would be less restructured and would contain substantially more fission gas within the fuel matrix. Upon the onset of melting, considerable melting of the restructured fuel with very little fission gas can be accommodated without causing fuel failure, whereas the melting of relatively small quantities of less fully restructured fuel with a high fission gas content seems

VG capable of causing a fuel pin failure. Since all fuel pins have a

IV-17 low power region at the upper and lower ends, this behavior indicated that fuel failure away from the center at either the upper or lower end was a more probable failure mode than failure at 


\section{EXPERIMENTAL SUMMARY FOR TOP HCDA}

TEST DESCRIPTION

IN-REACTOR TESTS IN TREAT

LOOP TESTS - H3, H4, H5, E6, E7, E\&, (I) *

STATIC CAPSULES - HOP 3-3C, HUT 5-3A

$$
5-5 A, 5-1 A, 3-3 A, 3-5 A
$$

$\underset{\substack{\dot{j} \\ \tilde{\omega}}}{\overrightarrow{2}}$

$$
5-5 B(1)^{*}
$$

FCI CAPSULES - S11, S12 (F) **

EX-REACTOR PHENOMENOLOGICAL TESTS

ENERGY DISSIPATION TESTS 1,2

FUEL SWEEPOUT (IN PLANNING)

* (I) PRE-IRRAdIATEd FUel

**(F) FRESH FUEL
PRIMARY AREAS OF INVESTIGATION

FAILURE CRITERIA, FUEL EXPULSION, FCI

FAILURE CRITERIA

FUEL-COOLANT INTERACTION ON EXPULSION

FUEL-COOLANT INTERACTION

FUEL INTERACTION, SWEEPOUT/PLATEOUT 
AXIAL MACROSTRUCTURE VARIATION IN HIGH POWER IRRADIATED FUEL PIN

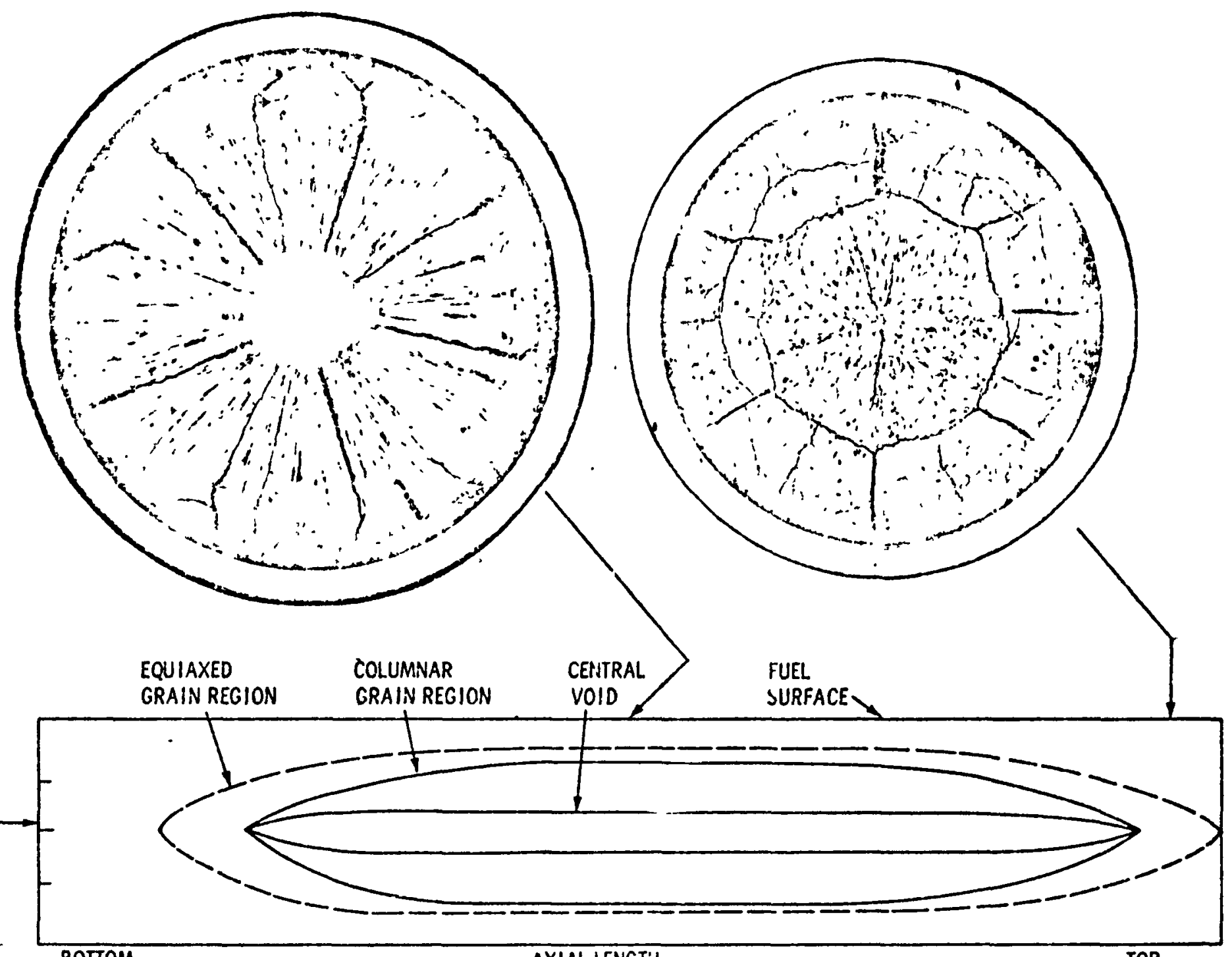




\section{FIGURE IV-17}

\section{OVERPOWER TRANSIENT FUEL FAILURE MODELS}

\begin{tabular}{|c|c|c|}
\hline FUEL TYPE & FAILURE CONDITIONS & $\begin{array}{c}\text { PIN AXIAL } \\
\text { POSITION OF FAILURE }\end{array}$ \\
\hline FRESH & $\begin{array}{l}\text { EVENTUAL MELT THROUGH } \\
\text { (SUBSTANTIAL MELTING REQUIRED) }\end{array}$ & TOP \\
\hline $\begin{array}{l}\text { LOW POWER } \\
\text { (IRRADIATED) }\end{array}$ & $\begin{array}{l}\text { INCIPIENT MELTING IN } \\
\text { AS FABRICATED MICROSTRUCTURE }\end{array}$ & CENTER $\longrightarrow$ TOP \\
\hline $\begin{array}{l}\text { HIGH POWER } \\
\text { (IRRADIATED) }\end{array}$ & $\begin{array}{l}\text { INCIPIENT MELTING IN } \\
\text { AS FABRICATED MICROSTRUCTURE }\end{array}$ & TOP OF CENTRAL VOID \\
\hline
\end{tabular}


the center, with failure preferentially expected toward the upper end because of higher temperature cladding in that region. Tests also showed that the fission gas in the fuel pin plenum under overpower conditions could not readily reach the break in the active fuel region but would be effectively sealed within the plenum. VG Therefore, rather than massive fission gas escape when fuel pin IV-18 failure occurred, the observed behavior was the ejection of molten fuel from the central region of the pin into the coolant channel. observations also indicated that when this molten fuel contacted sodium in the channel, it would break up into fragments with the potential of being dispersed hydraulically out of the core region with a corresponding negative reactivity feedback.

VG The following vu-graph summarizes the experimental data base IV-19 which we now have in hand from the tests most relevant to the TOP accident sequence. The $\mathrm{H}$-series tests were conducted to simulate a 50 $\$ / \mathrm{sec}$ ramp insertion and the E-series tests were driven harder to simulate a $3 \$ / \mathrm{sec}$ ramp insertion. $\mathrm{H} 2$ and $E 4$ were fresh pins whereas the remaining tests all contained at least one irradiated pin. $\mathrm{H} 5, \mathrm{H} 4$, and $\mathrm{E} 6$ had a central irradiated pin surrounded by six peripheral fresh pins, whereas E7 and E8 had a full complement of seven irradiated pins.

Although it is difficult in some of these tests to designate the precise axial failure location, in all cases, failure occurred well above the axial midplane.

The experimental evidence for hydraulic fuel sweepout is not entirely positive nor conclusive. All of the E-series tests for which we have data (namely E4, E6, and E7) resulted in coolant channel plugging. Considerable flow could be reestablished in all of the lower ramp H-series tests -- a trend which is reasonable since more time is available for dispersing the fuel in the lower ramp rate cases. Even for these $50 \$ / \mathrm{sec}$ simulations, significant plugging did take place.

In assessing these data, it should be recognized that the MARK IIA test loop was designed primarily for obtaining fuel 
FIGURE IV-18

SEQUENCE OF EVENTS DURING AN HCDA OVERPOWER TRANSIENT

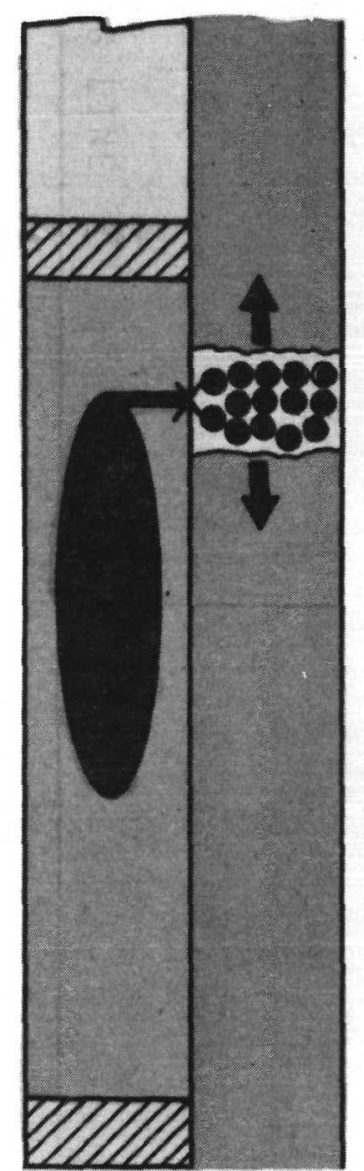

EXPULSION OF MOLTEN FUEL/GAS MIXTURE

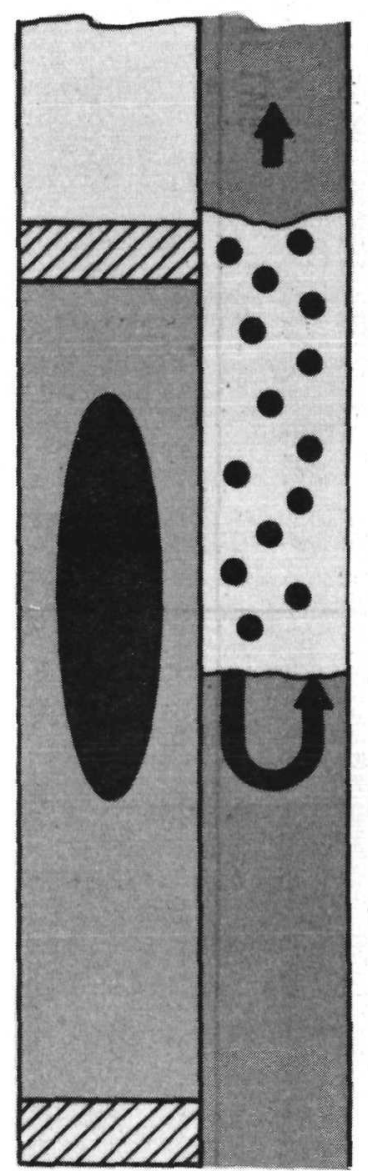

EXPANSION OF SODIUM VAPOR GENERATED BY $\mathrm{FCl}$

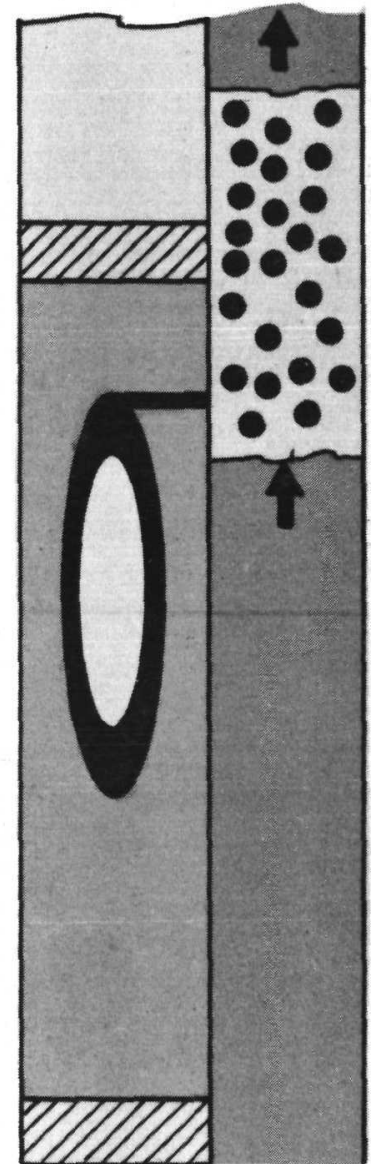

SWEEP OUT OF SOLIDIFIED FUEUGAS/SODIUM VAPOR

No. $7210-78.1$ 
FIGURE IV-19

EXPERIMENTAL DATA

VEHICLE: MARK-IIA LOOP

\begin{tabular}{|c|c|c|c|c|c|c|c|}
\hline TEST & RAMP & FUEL TYPE & $\begin{array}{l}\text { FRESH/ } \\
\text { IRRAD } \\
\end{array}$ & PINS & $\begin{array}{l}\text { AXIAL } \\
\text { FAILURE } \\
\text { LOCATION }\end{array}$ & $\begin{array}{c}\% \text { FLOW } \\
\text { AFTER TEST } \\
\end{array}$ & $\begin{array}{l}\text { COOLANT } \\
\text { EJECTION } \\
\text { MECHANISM } \\
\end{array}$ \\
\hline $\mathrm{H} 2$ & 50d/SEC* & UNRES. & $\mathbf{F}$ & 1 & TOP & $>0$ & BOILING \\
\hline H5 & 50ф/SEC & EQUIAXED & 1 & $1+6$ & $3 / 4$ UP & 45 & MILD FCI \\
\hline H4 & 50 $\phi /$ SEC & COLUMNAR & 1 & $1+6$ & $2 / 3$ UP & 10 & F.G. RELEASE \\
\hline E4 & $3 \$ /$ SEC $^{*}$ & UNRES. & $\mathbf{F}$ & 1 & TOP & $\mathbf{0}$ & BOILING \\
\hline E8 & $3 \$ /$ SEC & EQUIAXED & I & 7 & $\cdots$ & -.-.- & $\cdots$ \\
\hline E6 & $3 \$ /$ SEC & COLUMNAR & 1 & $1+6$ & $3 / 4$ UP & $\mathbf{0}$ & F.G. RELEASE \\
\hline E7 & $3 \$ /$ SEC & COLUMNAR & 1 & 7 & $>3 / 4$ UP & 0 & F.G. RELEASE \\
\hline
\end{tabular}

* NO PRE-HEAT 
failure data in a flowing system and not specifically to investigate post-failure fuel motion. There are at least two aspects of

$V G$ the tests which reduce the applicability of the data to the question IV-20 of sweepout, as shown in the next vu-graph.

First, the system hydraulics of the MARK-IIA loop are significantly different from that of the real reactor. The coolant velocity is only about half that of full flow FFTF conditions and the system pressure and inertial parameters are such that a given pin failure would allow a much greater perturbation to coolant flow conditions in the test vehicle than under actual reactor accident conditions.

Secondly, any fuel movement which occurred in the tests had essentially no reactivity influence on the TREAT reactor; i.e., on the power burst, whereas such motion is the controlling factor on terminating the power burst in an actual reactor. Hence, in many of the test cases, considerable overdriving took place; i.e., a large amount of molten fuel was generated after pin failure.

Despite the fact that a considerable amount of plugging did occur in several of the tests, in all cases the fuel was configured in a less reactive arrangement after the tests than existed prior to failure.

VG To consider further the question of possible channel plugging, IV-21 preliminary analyses have been done taking into account the coolant temperature distribution across a typical subassembly in FFTF. As shown on the figure there is a sizeable temperature drop near the outer 2 or 3 rows of pins. This difference between the coolant temperature of the inner 50 to 70 percent of the pins and the outer rows is of the order of $100^{\circ} \mathrm{F}$ at steady state and could rise to around $300^{\circ} \mathrm{F}$ at the inception of boiling. Hence, since cladding properties are important to failure for both fresh and irradiated pins, the central cluster of pins would be expected to fail well before the outer rows. This, of course, means less reactivity feedback due to fuel motion -- since fewer pins are initially involved -- but it also means a clear coolant flow path even if 


\section{FIGURE IV-20}

MAJOR NONPROTOTYPIC ASPECTS OF

MARK-IIA LOOP RESULTS

1. SYSTEM HYDRAULICS

- COOLANT VElocity $=1 / 2$ THAT OF FFTF

- PRESSURE AND INERTIAL PARAMETERS ALLOW MUCH GREATER FLOW PERTURBATION THAN IN FFTF

2. TEST OVERDRIVING

- NO REACTIVITY INFLUENCE ON TREAT

- LARge amount of molten fuel generated after PIN FAILURE 


\section{FUEL ASSEMBLY FLOW/TEMPERATURE DISTRIBUTION}

$\stackrel{\longmapsto}{\leftarrow}$
$\omega$
$\sigma$
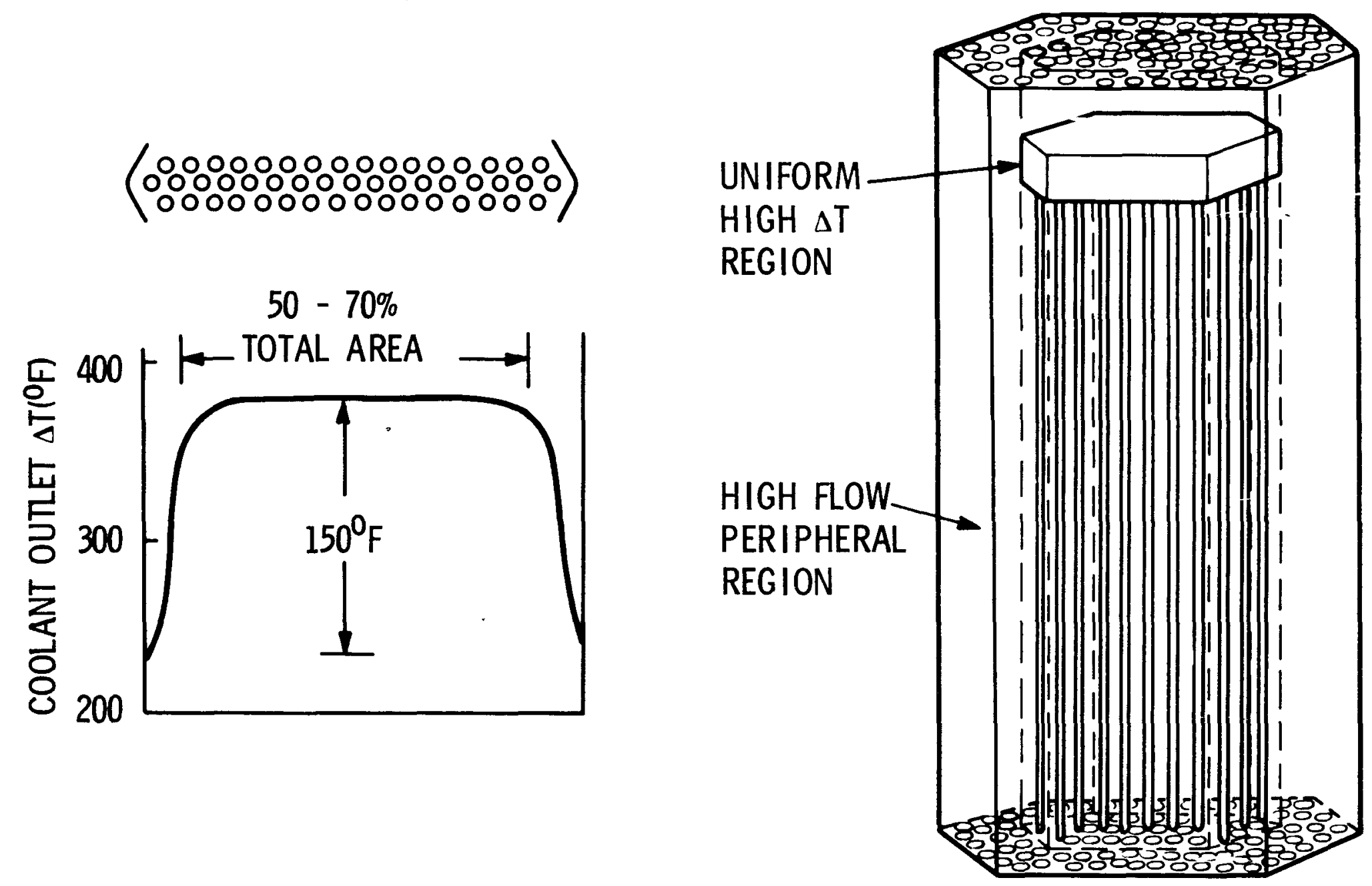

HEDL 7502-28.7 
fuel leaving the failed inner pins should form a blockage at the rupture point.

A preliminary set of calculations has been performed assuming no hydraulic fuel sweepout at all; i.e., the fuel freezes in the channel at the axial position of cladding rupture. These calculations show that there can be sufficient reactivity loss due to fuel re-location from high worth regions of the core inside the fuel pin to a low worth rupture location -- even without moving once it moves into the coolant channel -- to provide sufficient reactivity shutdown to arrest the power burst and prevent failure in the outer row of pins.

Current TOP HCDA analyses at HEDL are being performed with the MELT-III computer code. The following vu-graph identifies the

IV-22 computational features that have been included in this code system. As indicated on the left, the primary focus has been on the dynamic activity inside the reactor vessel. A primary loop has been modeled because it is important to know something about the pump characteristics and to account for inertial terms in the primary loop should flow reversal occur inside the core region. Also, as indicated, there is a capability of modeling three independent hydraulic loops.

If one views the top of the core, as indicated by the sketch on top, for the FFTF, ninety-one subassemblies are contained in two driver zones -- an inner and outer zone. This includes not only driver fuel but control rods, closed loops, and open loops for testing fuel. The approach that is used is to single nut a few fuel pins which are descriptive of the overall core response. In particular, as indicated by number 1 , a pin representative of all pins in that subassembly is neutronically and thermal hydraulically modeled and likewise a pin from another channel is picked out and modeled in the same manner. In addition to normally assuming that all pins within a subassembly behave identically, since it is not possible in any reasonable running time to model all 91 subassemblies individually, it is common practice to pick out those 


\section{MELT-III COMPUTATIONAL FEATURES}

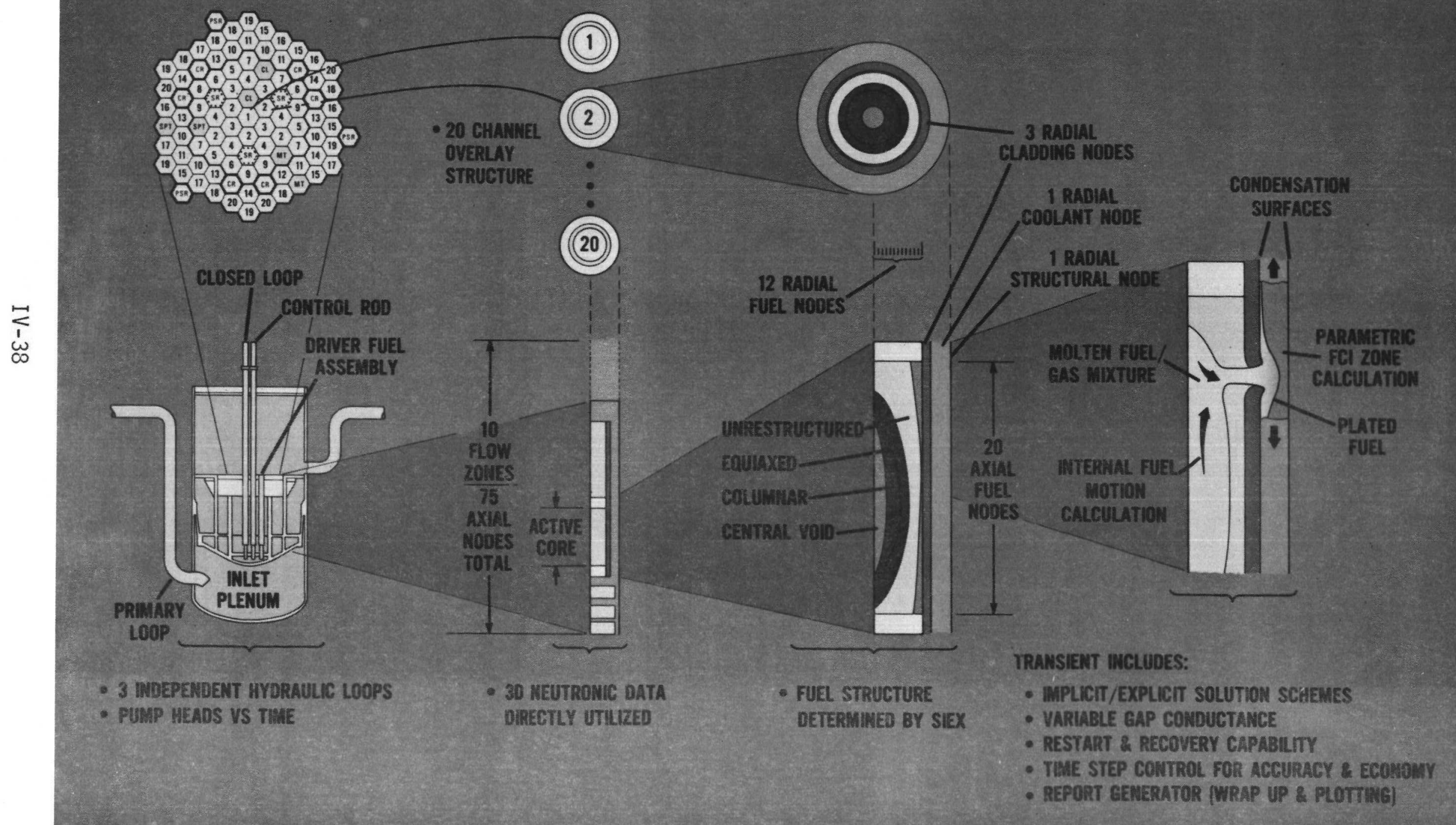


subassemblies which have similar burnup and power patterns and lump them together. So, as indicated in this picture, channel 2 consists of about 5 subassemblies. At the present time, MELT-III can model up to 20 channels in this manner.

The next region indicates a side view of the pin. The coolant enters the subassembly through a flow orificing region and then passes up through the fuel pin region on its way to the pool and on around the primary 10op. MELT-III currently models about ten flow zones, which denote area changes as the coolant makes its way up through the subassembly; up to 75 axial nodes can be employed to allow this detail.

If we then move to the right and focus more on just the active core region itself, there is even more detail. For mixed oxide fuel pins, as the fuel temperatures increase there is a density change in the fuel; long lenticular grains form, and this is called a columnar region. What physically happens is that gas migrates from this region to the center of the core producing a central void (actually it is filled with fission gas, which is assumed to be in equilibrium with the plenum, which is immediately above the top reflector in the case of FFTF). Then outside that radial fuel region is an equiaxed grain growth region where there is a relatively much smaller density change. Some of the original fission gas that is generated during steady state is retained in that microstructure but the unrestructured region contains essentially all the fission gases generated during steady state irradiation.

The right-most figure illustrates the calculation of what happens during the molten fuel phase, where molten fuel moves inside the fuel pin out into the coolant channel and ultimately either freezes or is swept out. The code incorporates a mechanistic internal fuel motion calculation (HOTPIM). (45) Once the fuel reaches the coolant channel, however, it is treated parametrically at the present time; some of it can be plated out and some nf it can be mixed with sodium, become fragmented, and moved out of the core. 
Because of the importance of the axial failure location, a considerable amount of effort has been expended to determine where fuel pins of different microstructure and irradiation history would fail under unprotected TOP conditions. An empirical Damage Parameter correlation has been developed for prediction of fuel failure time and location. (L.6)

VG The vu-graph illustrates the "Damage Parameter" prediction for IV-23 a moderately high power pin $(\approx 10 \mathrm{~kW} / \mathrm{ft}$ peak power) in which the central restructuring region comprises about the middle half of the pin. Failure is predicted to occur near the top of the central void region, with a shaded error band extending approximately \pm 6 inches from that point. For a high power $(12.5 \mathrm{~kW} / \mathrm{ft}$ peak power) pin in which the central void region extends nearly the full length of the pin, the failure is predicted to occur at the top of the pin -- again with an error band of approximately 6 inches.

VG The vu-graph presents a general accident path tree from which IV-24 we can hopefully view the overall situation from a good perspective.

Both analytical and experimental evidence strongly support the position that we do not expect central axial failure locations. Hence, we would expect an accident path down the left side of this vu-graph. It might be helpful to point out, however, that even if one did hypothesize massive failures near the midplane, the reactivity insertion due to fue 1 rapidiy moving toward the core centerline would be limited to the neighborhood of a hundred dollars/sec. Such conditions, although arising from a different mechanism, were considered in the FFTF PSAR and the eventual energy yield was fairly modest because a sodium-in equation of state is controlling for such situations.

Turning to the left side of the vu-graph, there exists a very strong probability for early termination of unprotected TOP accident by reactivity loss due to fuel motion from high worth to low worth regions -- even if hydraulic sweepout does not occur. 


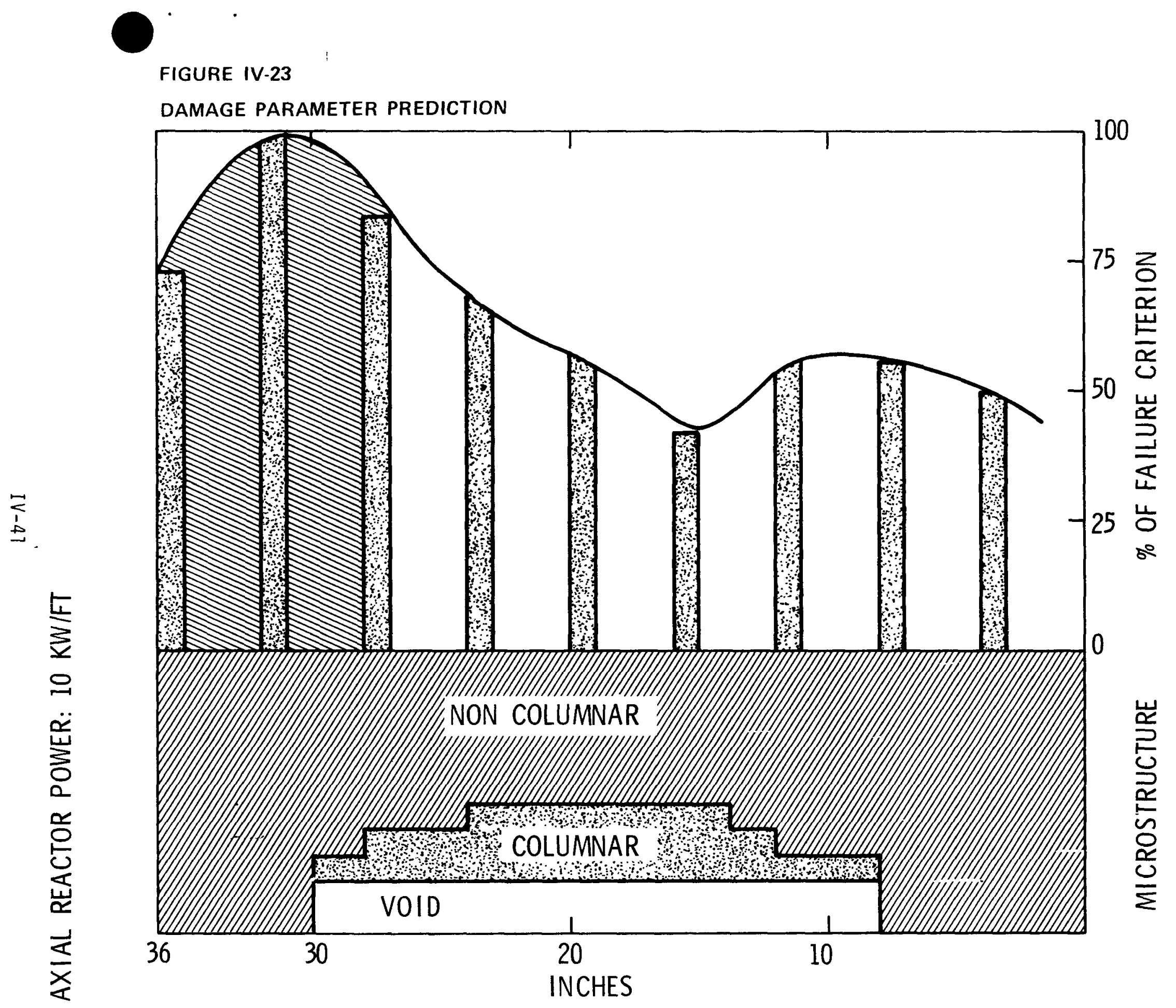

HEDL 7411-96.4 
FIGURE IV-24

POTENTIAL ACCIDENT SEQUENCE PATHS FOR THE UNPROTECTED TRANSIENT OVERPOWER

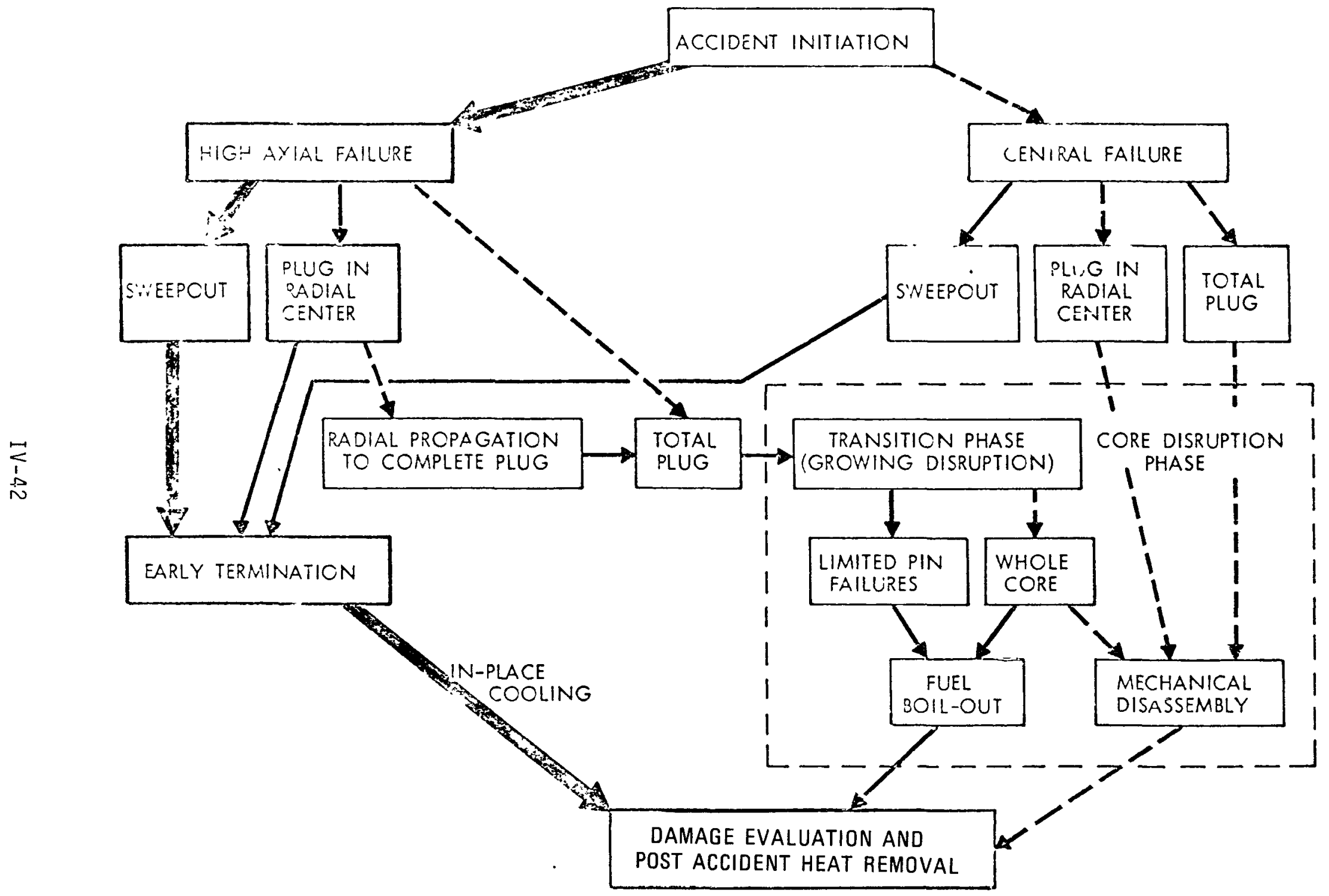


While the evidence is considered strong for fuel failure locations near the top of the pins and for hydraulic sweepout of fuel with limited, if any plugging, this evidence has not been accepted as conclusive in the NRC regulatory review process. Further experimental and analytical work will be carried out to establish more definitive information.

In the meantime, consideration has been given to the possible effects of complete plugging of flow channels. Under such a hypothesis, the rate at which a plugged TOP configuration would enter a Transition Phase would probably not be dissimilar to that of the LOF case -- despite the time scales involved in getting up to the first failure. (A "Transition Phase" implies the development of a largely molten core, and will be discussed more fully as part of the review of the LOF HCDA analyses status.)

VG Finally, it is worth noting, as shown in the vu-graph, that IV-25 very little fuel is expected to be removed from the core, under TOP conditions, to burden postaccident heat removal requirements outside the core. For base case calculations, in which substantial hydraulic fuel sweepout is expected, only about $1 \%$ of the original fuel inventory is computed to leave the active core prior to permanent neutronic shutdown. If we postulate the type of plugging discussed above; i.e., solid plugging at the rupture location for the hot central pins within the failed subassemblies, the total fuel reaching the coolant channel may be as high as $10 \%$. However, since it has been postulated to plug, very little of this would eventually be carried throughout the vessel. In the extreme case of solid plugging throughout the subassemblies, a transition phase similar to the LOF would be entered and the demand upon the PAHR system would be comparable to that case.

VG The final TOP vu-graph summarizes current conclusions an the IV-26 TOP accident sequence for FFTF.

First, early termination appears to be by far the most likely sequence. Substantial shutdown is expected from fuel sweepout -- 
FIGURE IV-25

TOP INPUT TO PAHR REQUIREMENTS

EXPECTED CASE: SUBSTANTIAL HYDRAULIC SWEEPOUT

$\approx 1 \%$ OF FUEL REMOVED FROM CORE

PLUGGED CASE: CENTRAL SUBCHANNELS SOLIDLY PLUGGED AND NO HYDRAULIC SWEEPOUT

$\approx 10 \%$ OF FUEL IN COOLANT CHANNEL (SMALL $\%$ OF THIS EVENTUALLY REMOVEDI 
FIGURE IV-26

CONCLUSIONS

A. EARLY TERMINATION

- SHUTDOWN REACTIVITY FROM FUEL MOTION

- hydRaulic SWEEPOUt NOT ESSENTIAL

B. IN-PLACE COOLING

- FAILURE INCOHERENCY WITHIN SUBASSEMBLIES

- SUBSTANTIALLY LARGER BLOCKAgE ALLOWABLE THAN UNDER LOF CONDITIONS

C. REACTIVITY INSERTION BOUND

- STRONG ARgUMENTS to PREVENT RECRITICALITY CONCERNS

- EVEN UNDER EXTREME CONDITIONS, NO INSERTION MECHANISM IDENTIFIED WHICH EXCEEDS RATE CONSIDERED IN

I. PSAR

II. CURRENT LOF ANALYSIS 
especially for irradiated cores -- but such sweepout is not entirely essential to the conclusions.

Second, failure incoherency within the subassemblies combined with early shutdown indicate in-place cooling. It should be noted that a substantially larger blockage is allowable with the pumps on than is the case for LOF conditions.

Finally, the above conclusions indicate little likelihood for core recompaction leading to a potential recriticality. Even under such a hypothesis, however, the only mechanistic path envisioned for such an event is via a massive plugging process which would lead to a transition phase in a manner not dissimilar to the conditions considered within the context of the LOF accident sequence, which will be discussed next.

It should be remembered that large reactivity insertion rates were considered in the calculations which led to the $150 \mathrm{MW}-\mathrm{sec}$ design evaluation work energy level, and any mechanistic path envisioned would not lead to ramp rates larger than those considered then.

\section{LosS-Of-FIOW HCDA}

Beginning in the 1970-1972 period, extensive efforts to improve the understanding of LOF HCDA conditions were made by ANL, using the SAS series codes. $(47,48,49,50)$ The major objectives of model development were to evaluate the long-term core behavior; to apply improved modeling of sodium-void dynamics and fuel relocation; to evaluate more realisticaliy the dynamics of fuelcoolant interaction behavior as it would apply to such an accident if a hydrodynamic disassembly were to occur; and, overall to assess

VG the expected and conservative bounds to a final, stable configura-

IV-27 tion of the core. The current experimental data base supporting the LOF HCDA analysis is summarized on the vu-graph.

VG The vu-graph gives a comprehensive accident analysis path IV-28 structure and indicates the most probable accident sequence for this accident in the FFTF. The sequence of events is that of a 
FIGURE IV-27

EXPERIMENT SUMMARY FOR LOF.HCDA

\section{TEST DESCRIPTION}

IN-REACTOR RESTS IN TREAT

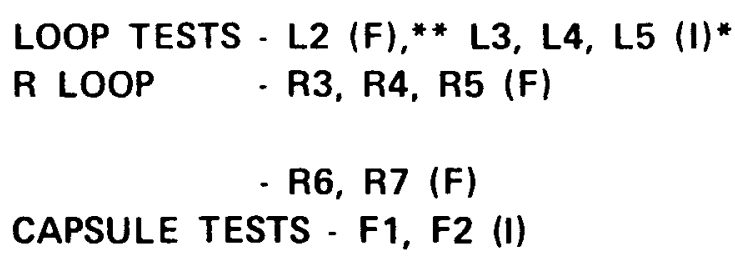

EX-REACTOR PHENOMENOLOGICAL TESTS

OPERA 1, 2

CLADDING MOTION TESTS FISSION GAS RELEASE TESTS

FUEL PENETRATION TESTS

* (I) PRE-IRRADIATED FUEL

** (F) FRESH FUEL
PRIMARY AREAS OF INVESTIGATICIN

CLADDING AND FUEL DYNAMICS COOLANT DYNAMICS, CLADDING MOTION (R4)

CLADDING AND FUEL DYNAMICS FG \& FUEL VAPOR EFFECTS ON FUEL MOTION

COOLANT BOILING AND VOID DYNAMICS CLADDING FLOODING FG RELEASE (FUEL MOTION) FUEL PENETRATION \& FCI IN PLENUM REGION 
COMPREHENSIVE APPROACH TO LOF HCDA ANALYSIS

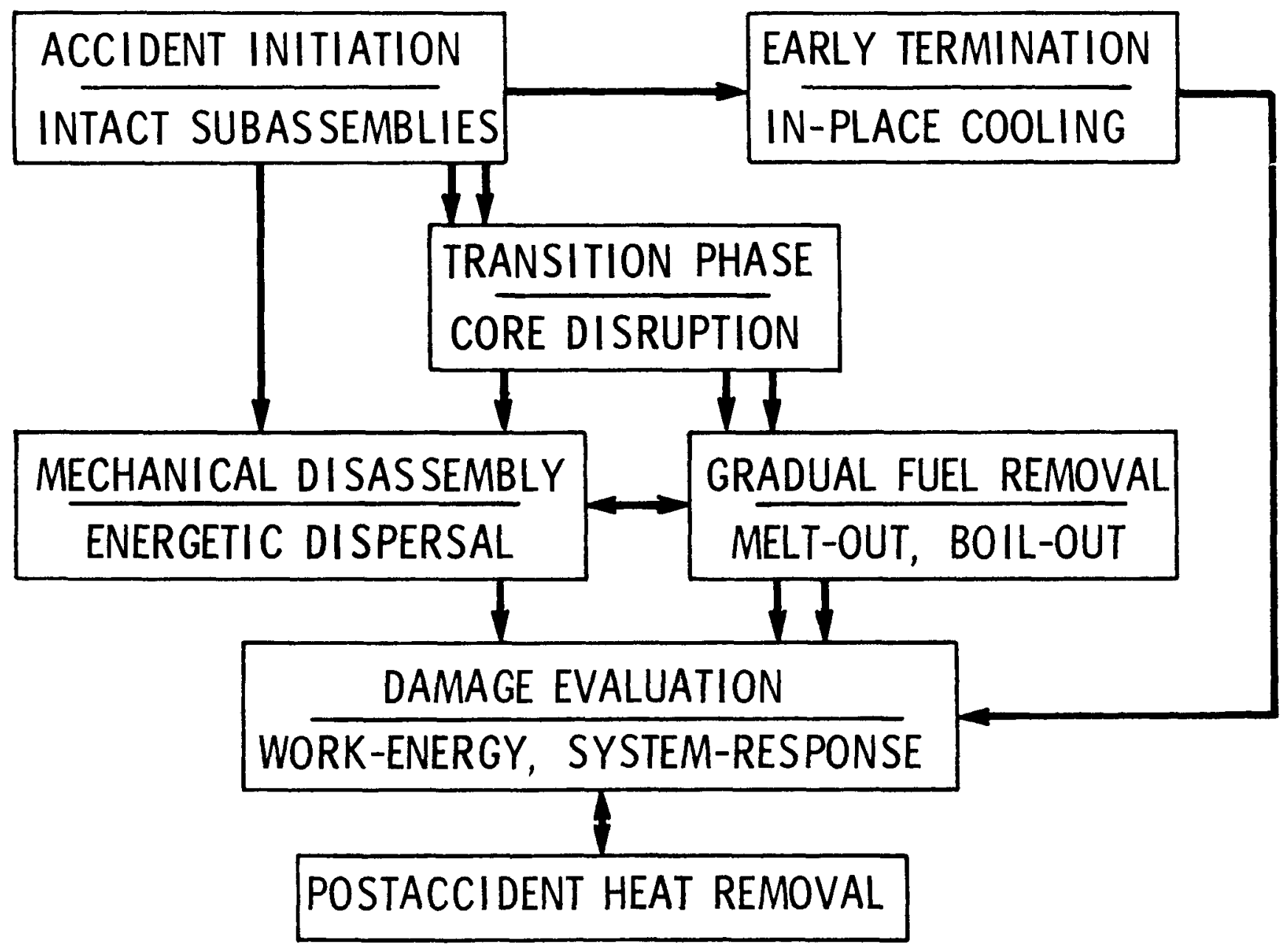


SHUT-DOWN PROTECTION FOR LOSS OF PRIMARY POWER

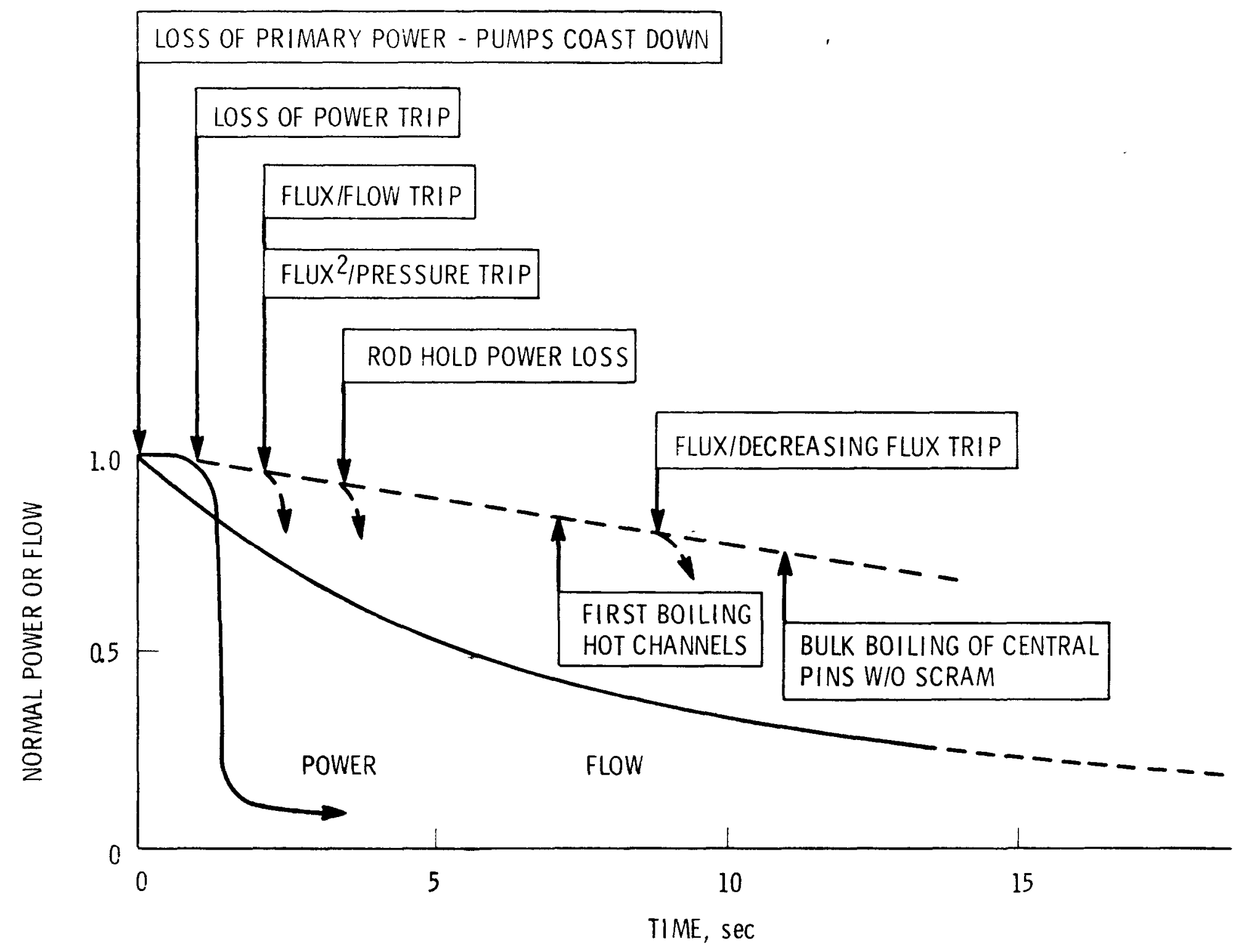


somewhat slow but progressive melting of the core. The specific scenario for FFTF is as follows: The flow coasts down until boiling is reached. In the absence of scram, the power remains near full power. Sodium boils, cladding melts, and fuel begins to melt. As the subassemblies successiveiy progress through the stage of coclant voiding and melting, the pressures generated are too low to cause a massive dispersal of molten fuel from the core region. The subassembly duct walls are quickly melted and growing regions of molten fuel and steel begin to form in the hottest portions of the core. By this stage enough local axial fuel dispersal has taken place to bring the reactor subcritical, but extended fuel dispersal may be inhibited by blockages that form because molten core materials refreeze in the colder regions near the axial ends of the core. Continued decay heating causes further core melting and previously melted core materials to boil up and fill the available volume. If paths are available through the upper structure, material will immediately begin to be ejected into the upper sodium pool. If the passages are blocked, rapid melting attack on the upper structures will occur, allowing ejection of molten core materials into the above-core sodium. This upward fuel removal is predicted to occur on a short time scale compared to the time required to melt down through the lower subassembly structure. This ejection would be expected to have little or no damage potential and the materials would mix with the above-core sodium pool and come to rest upon the upper thermal baffle where they can be cooled. The remaining core materials would eventually come to rest on the core support structure where they can be cooled.

VG A typical analys is of the LOF HCDA initiating phase is IV-29 summarized as follows: Because of the relatively long flowcoastdown time due to the FFTF pump design, no bulk boiling or fuel failures are predicted to occur for some 10-15 sec into an unterminated transient following an assumed loss of power to the pumps. This may be noted as a long available time period for protective action to terminate the event, as illustrated on the vu-graph. 
VG The next vu-graph illustrates behavior within a subassembly IV-30 after fuel failure occurs. $(51,52)$ Fission-gas release from the fission gas-plenum into the coolant channel can cause substantial voiding if this release precedes boiling, but reentry of sodium from the bottom of the core would maintain cooling until boiling. Incoherent voiding due to gas release and boiling is calculated to occur for several seconds over a major portion of the core. The analytical models indicate that voiding could be sustained for sufficiently long periods of time for cladding dry-out and melting to occur, followed by clad motion. Analys is of fuel-temperature patterns indicates that sufficient fuel melting to permit fuel relocation might occur about 7-8 seconds after the initial voiding. If gravity slumping is assumed, the reactivity insertion rate is calculated to be in the range of 10 to 16 dollars/sec. This positive reactivity insertion leads to calculated core-disassembly conditions in which the power reaches a factor of about 20 times normal power. The initial neutronics burst would be terminated within a few hundred milliseconds by a combination of several negative reactivity effects including Doppler and axial expansion feedback. Other strong effects are due to fuel dispersal and a Targe negative voiding reactivity from the outer rings. At the termination of this initial burst $\sim 20$ subassemblies would have melted and have been driven from the center of the core axially outward. Cladding blockages may have formed above and below these assemblies. Subassembly walls would have begun melting in the hottest subassembly. This latter condition is used to define the end of the initiating accident phase, since the channel-separated SAS models are not valid beyond this point.

It is worth noting at this point that there is no experimental evidence that irradiated fuel slumps, but these studies did not confirm a dispersal of the fuel, without slumping. Experimental data, in fact, indicate that fission gas may cause initial dispersal of irradiated fuel but is not likely to sustain this dispersal and prevent subsequent slumping. Evidence from in-pile 


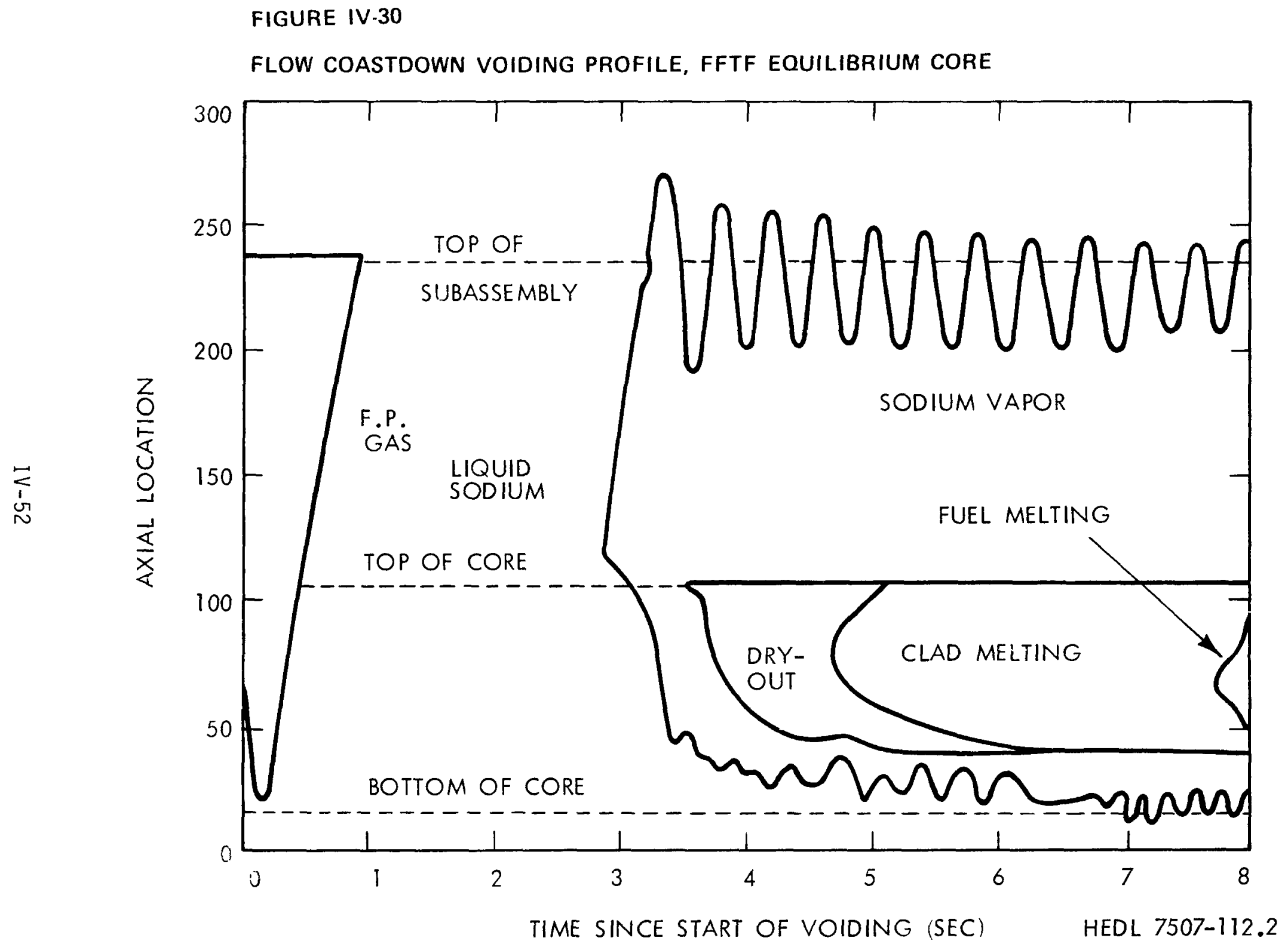


tests is that slumping, when it occurs, is less rapid than a $1 \mathrm{~g}$ acceleration. (41) In this analysis, the dynamics of sodium voiding and, very inportantly, that of clad motion are crucial to the sequence of events.

VG

Sodium boiling is calculated in the SAS-3A code $(49,53)$ by a IV-3l multiple-bubble slug-boiling model, using low superheat. This model correlates well to the slug-annular regimes observed in 7-pin voiding tests after initial flow reversal. Low superheats are expected, because theoretical analysis of sodium boiling experiments has shown that large superheat requires very clean, gas-free surfaces and would not occur under reactor conditions.

VG In sodium boiling, a liquid film is left on surfaces within the IV-32 voided region. This film is depleted by mechanical stripping due to sodium vapor flow over the surface, as well as by vaporization. When the clad dryout occurs it is followed quickly by clad melting.

VG The behavior of molten cladding has been found to be of prime IV-33 importance in assessing accident progression. Molten clad can move either up or down, with initial upward motion likely because of the drag exerted by the rapidly flowing vapor in the coolant channel. Experimental evidence is not entirely conclusive, but there is evidence that molten clad moved into the outlet region of the subassembly would freeze there, blocking or partially blocking the coolant channel. If blockage is sufficient to reduce the sodium vapor flow rate significantly, then gravity forces would dominate and the cladding would tend to relocate downward and the development of a steel plug at the inlet region of the active core could occur. Experimentally, relocated cladding material has been found in both the upper and lower ends of test fuel sections.

As I will discuss shortly, the current view is that cladding plugging may not occur, but that cladding will mix with molten fuel and thus assure a core boilup and dispersal without fuel slumping.

However, if the clad behaves so as to plug the coolant channels, then slumping of molten fuel shortly after clad relocation would be anticipated. Fission gas escape and generated fuel vapor 
TYPICAL FLOW REGIMES FOR LIQUID METAL-VAPOR FLOWS

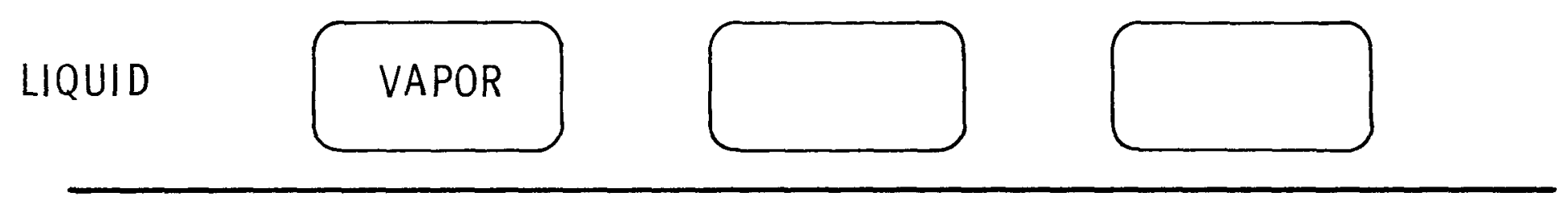

A. SLUG FLOW BOILING INLET FLOW RATE CONSTANT

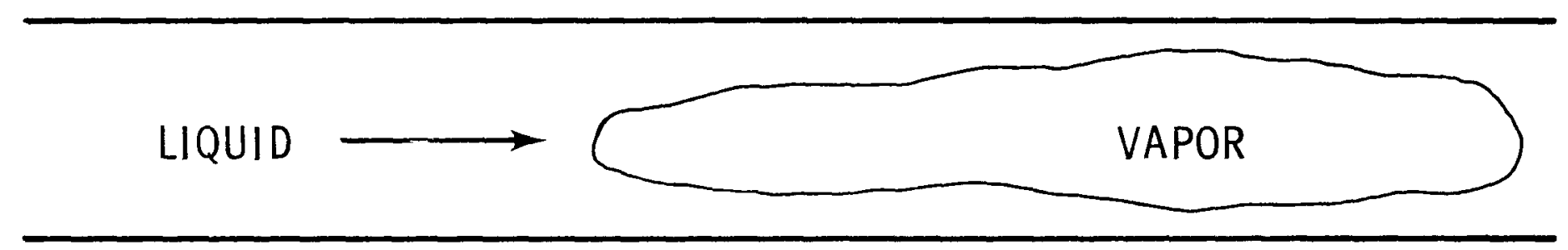

B. ANNULAR FLOW

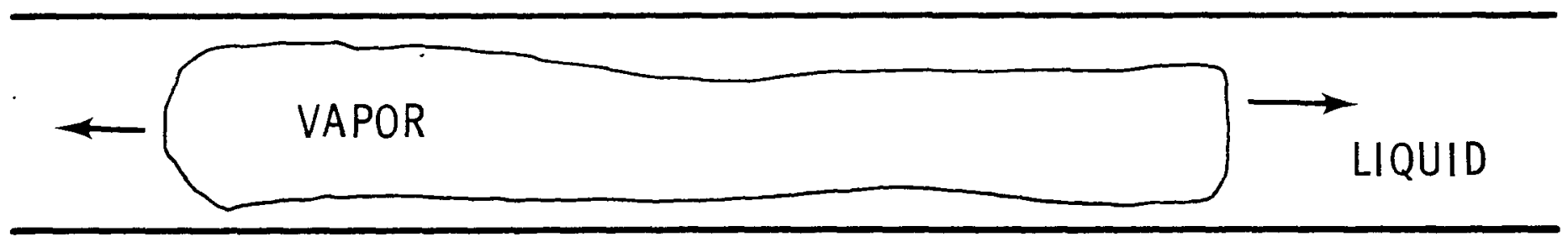

C. SLUG-ANNULAR FLOW, 
LIQUID FILM FLOW ILLUSTRATION

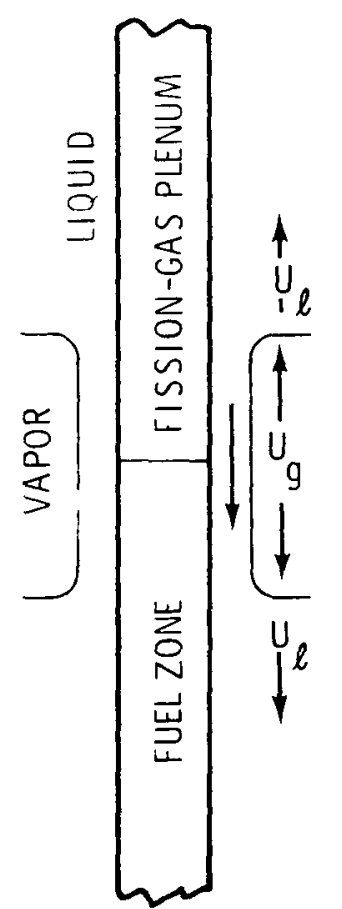

(a)

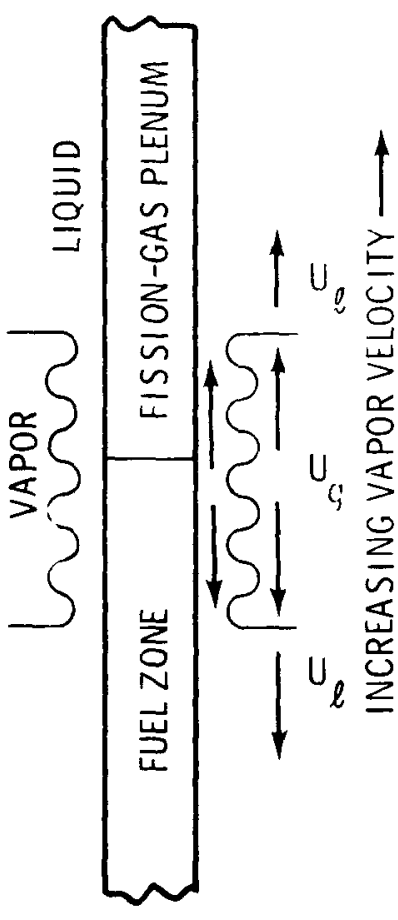

(b)

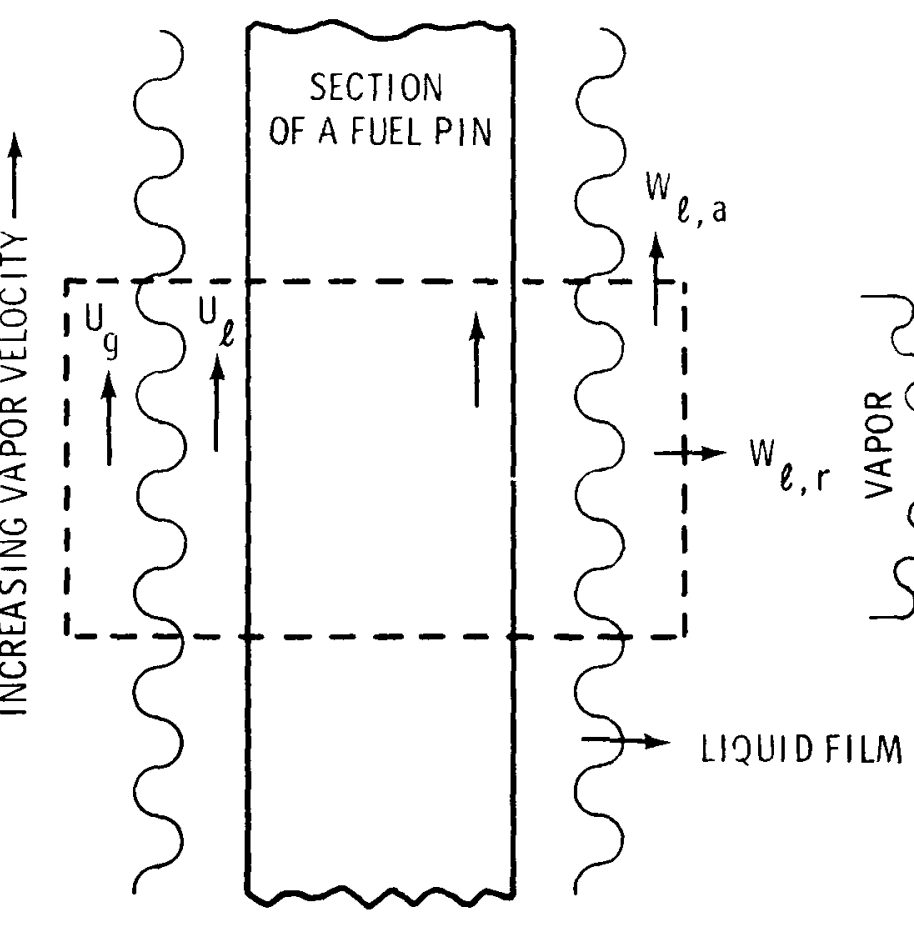

(c)

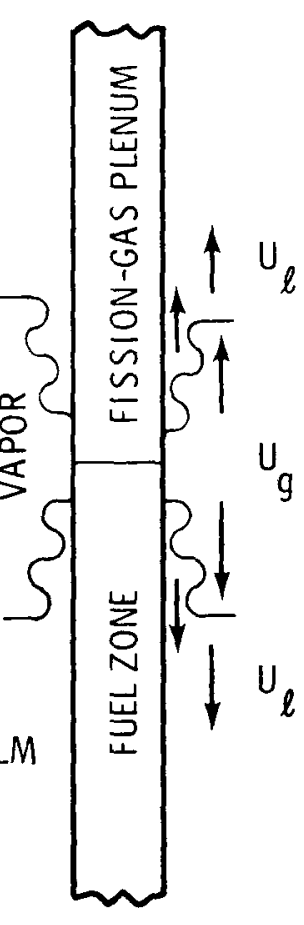

(d)

BEFORE AND AFTER ONSET OF FLOODING - DRYOUT:
(a) LIQUID FILM DRAINING ON FUEL PIN AT INSTANT OF VOID GROWTH
(b) ONSET OF FLOODING AND FLOW REVERSAL -- TYPICALLY AFTER 2 TO 3 IN. AXIAL VOID GROWTH
(c) THINNING OF LIQUID FILM
(d) DRYOUT 
FIGURE IV-33

ILLUSTRATION OF CLAD MOVEMENT FOR SAS ANALYSIS OF TEST R-5

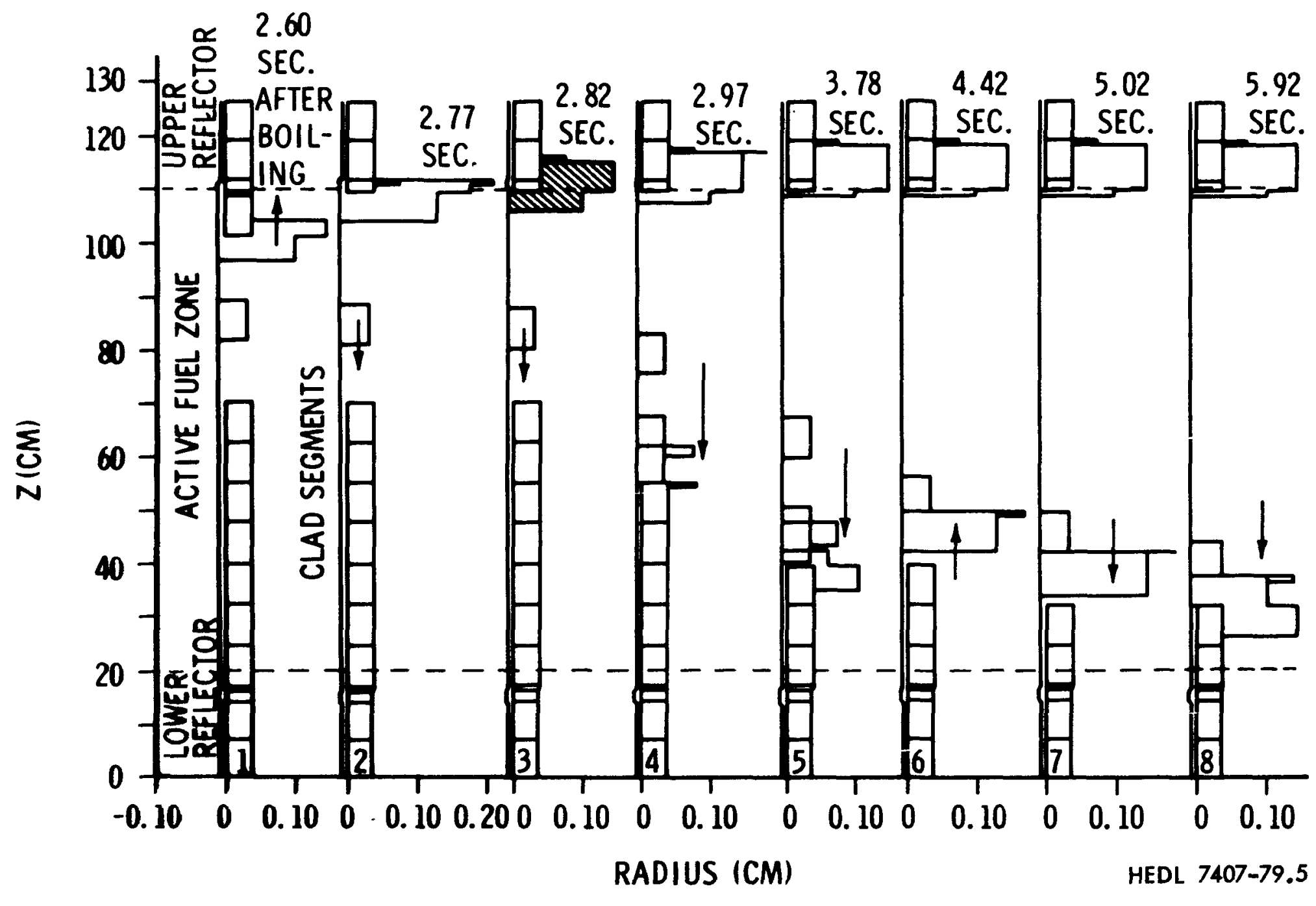


pressure have been shown to disperse some quantity of fuel but this would be short lived, unless ultimately coolable in its relocated position.

VG In addition to the case discussed above, the two other routes IV-34 to permanent shutdown were investigated; i.e., would the accident terminate early or could the initiating accident lead to early energetic disassembly.

A number of analyses were run to study early termination possibilities. Various postulated optimistic phenomena such as incoherent voiding across the subassembly, early fuel removal, etc., were run. All the results were negative; i.e., it was concluded that the entire core would most likely become involved and melt.

Another possible accident sequence is where the initiating phase of the accident leads to early disassembly. The SAS cases run for FFTF do not lead to this result. The negative reactivity effects from sodium voiding, the limited degree to which fuel can compact under gravity in the presence of the available gas and vapor dispersal pressures, and the strong negative Doppler and fuel axial expansion feedbacks tend to predestine mild initiating accident events.

However, at various times in the past, postulated accident scenarios have been suggested where initiating accident phenomena lead directly to mechanical disassembly type conditions. Representative compaction mechanisms such as sodium reentry, plenum fission-gas compaction, fission gas from fuel, outer core implosion and levitation from lower core regions were examined and it was concluded that reasonable arguments exist to exclude previously postulated compaction mechanisms from causing a drastic change in the accident scenarios. Also, available experiments that have simulated the accident sequence have not resulted in any pessimistic fuel compaction. The conclusion of the initiating phase accident studies is that no energetic excursions will occur. The whole core will become involved, is not in a coolable configuration, and the analysis of the accident must be continued. 
FIGURE IV-34

INITIATION PHASE OF FFTF LOF

1. SUCCESSIVE SUBASSEMBLIES EXPERIENCE FOLLOWING SEQUENCE:

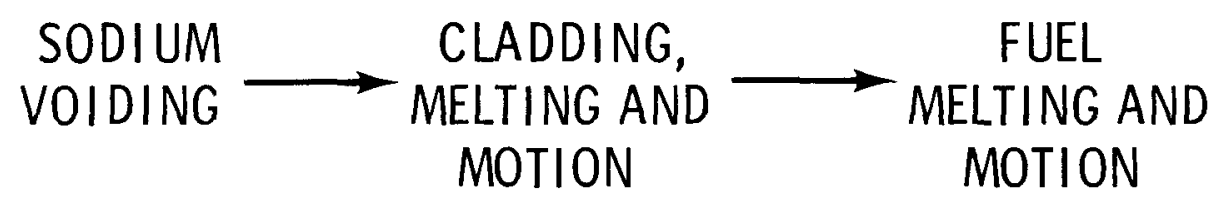

2. INITIAL PRESSURES MILD ( 10 ATM)

3. FUEL DISPERSAL INHIBITED BY PLUGGING

4. TENDS TOWARD WHOLE-CORE INVOLVEMENT WITH MILD EXCURSIONS

5. SUBASSEMBLY DUCTS BEGIN TO MELT

6. ENTERS TRANSITION PHASE 
- Phase 4: Transition Phase Analysis. The analysis of the initiating phase of the accident concluded that a gradual melting of the core would occur. The purpose of the analysis of the transition phase was to continue the analysis to the point where a permanently subcritical and coolable geometry is attained.

A preliminary assessment of the overall accident sequence was summarized as follows. $(54,55)$ successive groups of subassemblies undergo a sequence that involves coolant boiling and voiding, followed by melting of the cladding and fuel. The early stages of core disruption were assumed to be accompanied by a series of mild neutronics excursions induced by incoherent fuel slumping, and terminated by the local axial dispersal of the molten fuel.

VG

Extended fuel dispersal was assumed to be inhibited by blockages that form because molten core materials refreeze in the colder regions near the axial ends of the core. The initial dispersive pressures would be too low to force the core materials beyond the blockages or to push the above-core structure out of the way. Thus, the molten materials would be temporarily trapped in the core. Entrained steel would boil causing the fuel-steel mixture to boil-up. Continued slumping of previously undisrupted fuel might induce mild power excursions. This would lead to a rapid melting of the duct structure and the growth of boiling regions which would eventualiy encompass almost the entire core. The above-core blockages and gas plenum pin structure would be rapidly melted away, allowing a boil-out of molten core materials into the above-core sodium.

More recent work by Fauske has emphasized the role of flooding and fluidization on this phase of the accident and concluded that a high density flow regime consisting of continuous vapor and liquid fuel droplets would be formed very quickly. Because of early dispersal of fuel, initial fuel slumping of disrupted fuel may be largely prevented. 
FIGURE IV'-35

LATTE R STAGE OF DISASSEMBLY EXPANSION

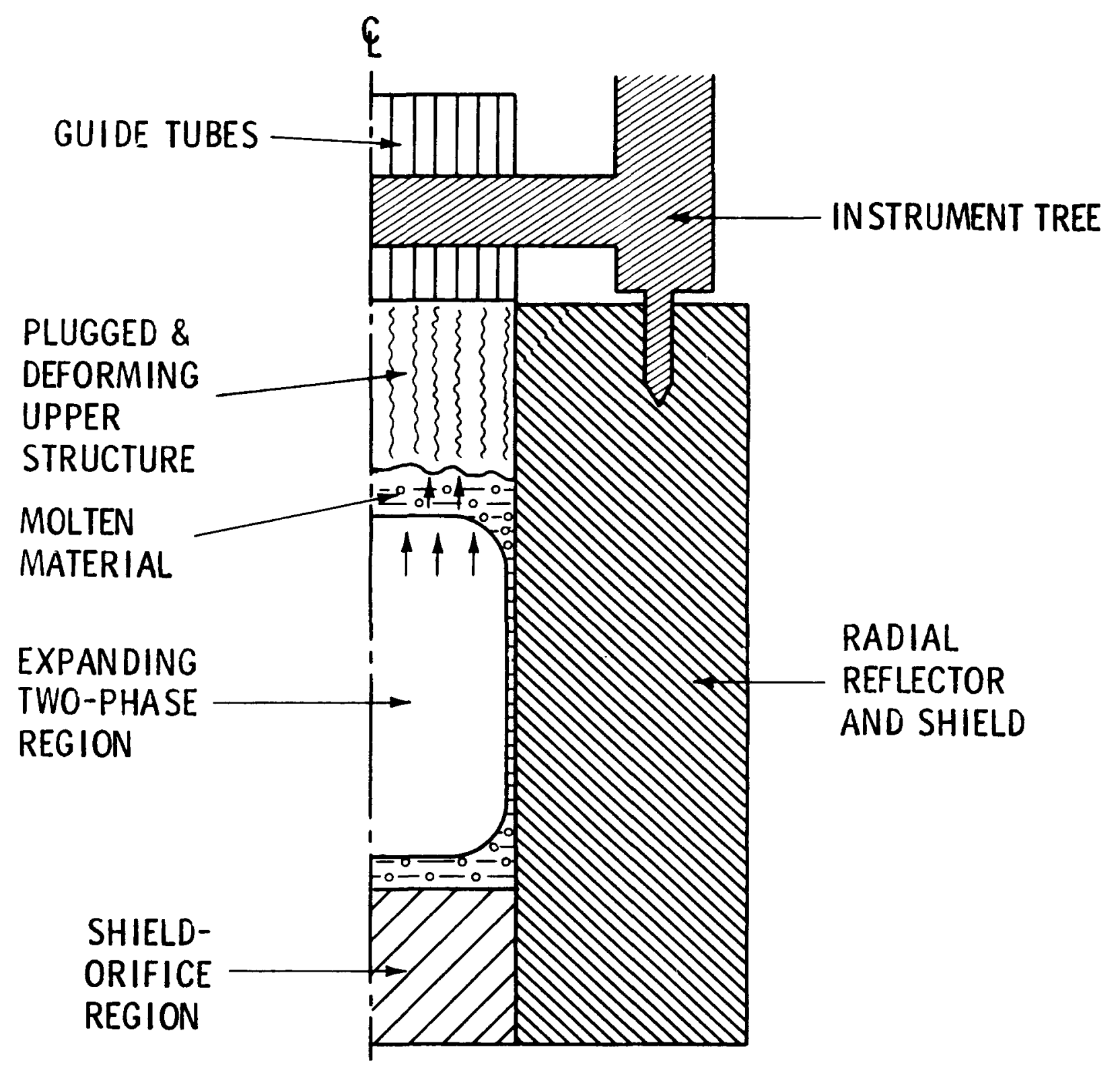

HEDL 7407-79.4 
IV-36 regime. First, the film-flow behavior of molten clad in a flowing stream of sodium vapor is illustrated. Phenomenologically, molten cladding is likely to remain largely in the core region because the effect of clad "flooding", which promotes upward motion also tends to impecle sodium vapor flow which in turn tends to permit clad drainage.

VG Upon fuel melting, molten clad would tend to become entrained IV-37 in molten fuel, or vice versa. Since the fuel melting point is near the boiling point of stainless steel, rapid vapor formation would occur, which would produce a dispersed regime of liquid droplets entrained in a continuous vapor phase.

VG Fluidization of the core by this mechanism can occur even at IV-38 decay heat levels, as indicated on the vu-graph.

VG The dispersed regime would cause rapid expulsion of the core IV-39 into the upper sodium plenum. If blockage of the outlet channels had occurred, melting through the upper blockage would be expected in a few full power seconds, followed by upward expulsion.

VG

Even though the nominal path is expected to be a gradual meltIV-40 out and ejection of core materials to the above-core sodium plenum, more energetic accident terminations were also considered. Cases were investigated in which secondary criticalities occurred which might lead to sufficient fuel vapor pressure ta energetically and permanently disassemble the core.

The possibility of pressure driven recompaction due to fuelcoolant interactions was also considered. If the material were to be driven back into the core with significant overpressures, the situation, at least from parametric considerations, could result in high ramp rates. To address this question a series of experiments were initiated. In summary, the test results, which closely simulate the reactor materials and geometries in question demonstrate a benign interaction between the molten fuel and the sodium coolant and no measurable pressures to provide pressure driven fue 1 recompaction. 
FIGURE IV-36

ILLUSTRATION OF NONCOHERENCE EFFECTS AND CLADDING RELOCATION

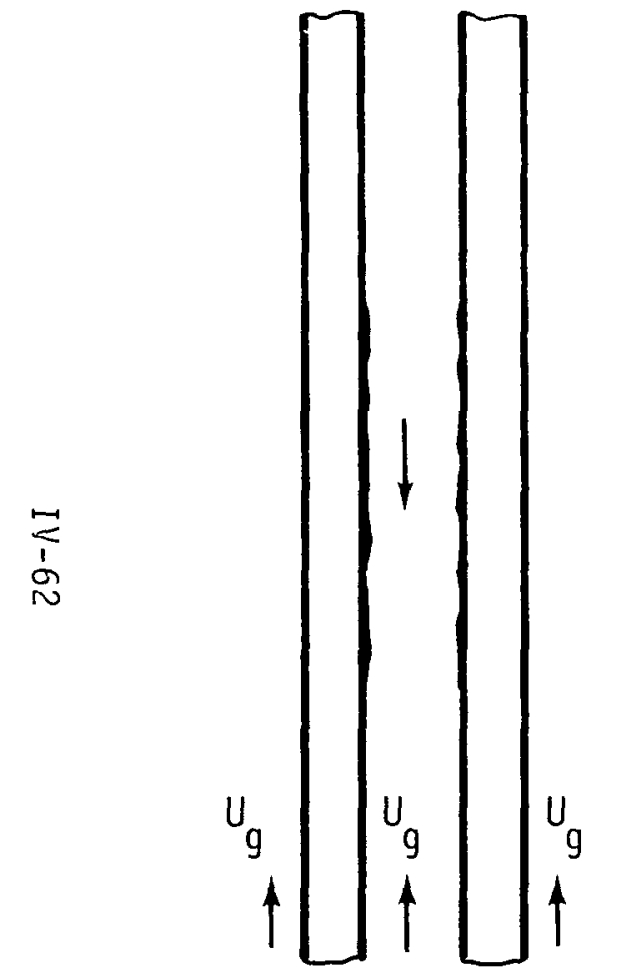

(a) INCIPIENT CLAD MELTING

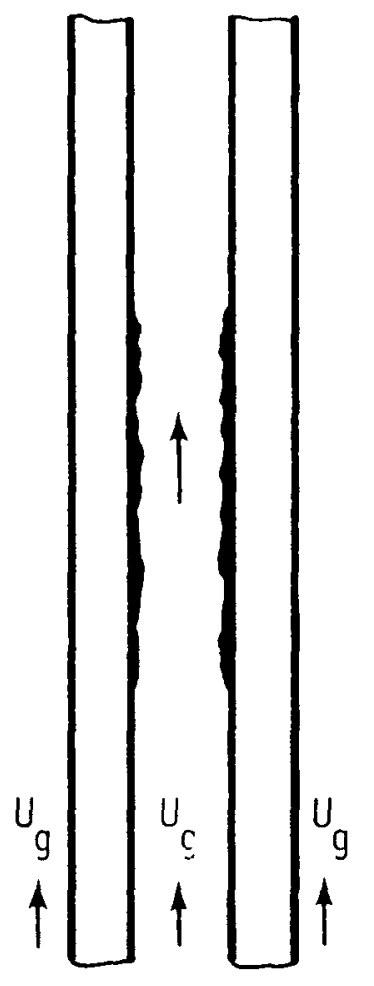

(b) INCIPIENT FLOODING

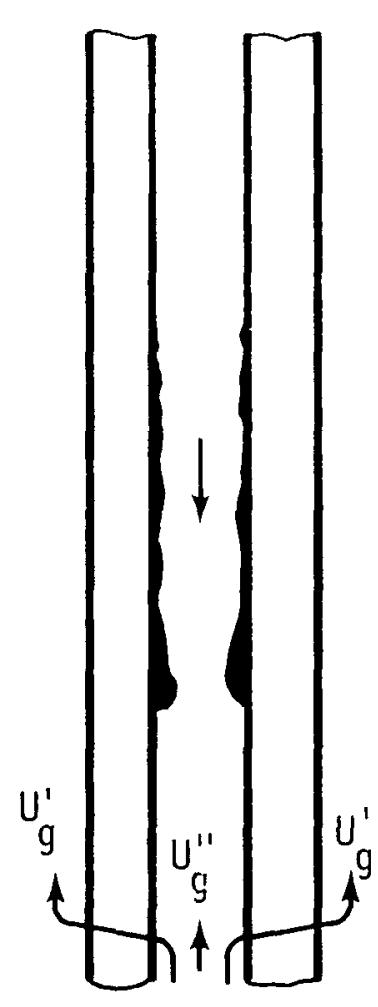

(c) FLOW BYPASS AND DRAINING

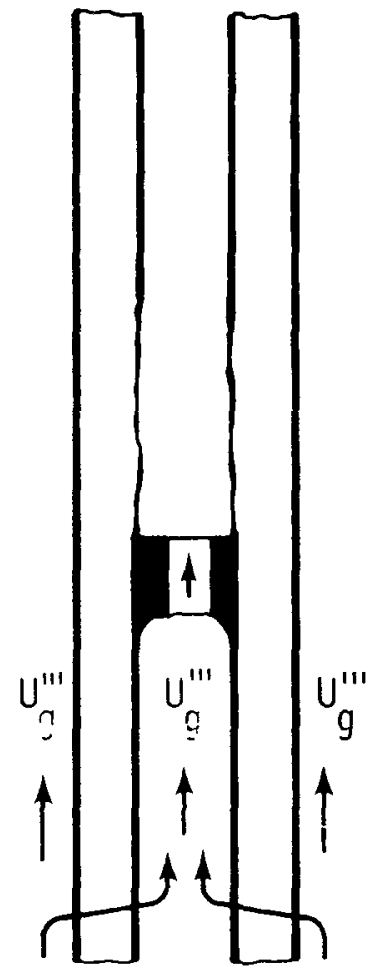

(d) S!UG FLOW AND FLOW RECOVERY

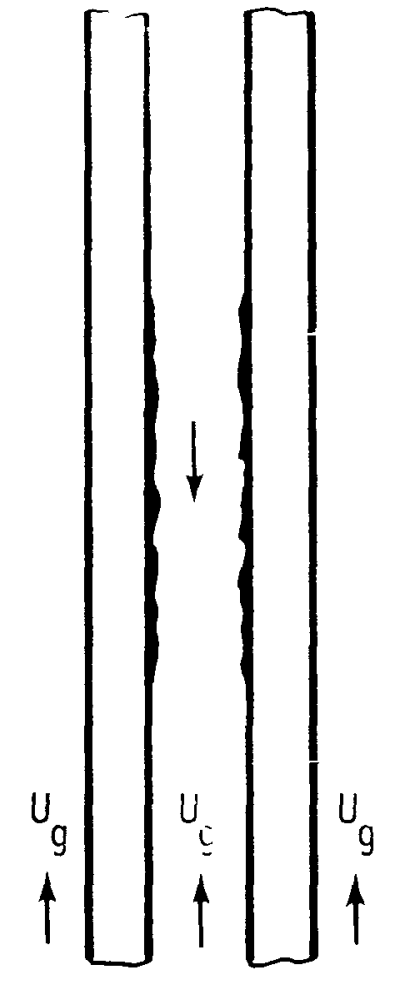

(e) CLAD RENEWAL; SAME AS (a), ETC. 
FIGURE IV-37

ILLUSTRATION OF EARLY FUEL RELOCATION AND DISPERSAL

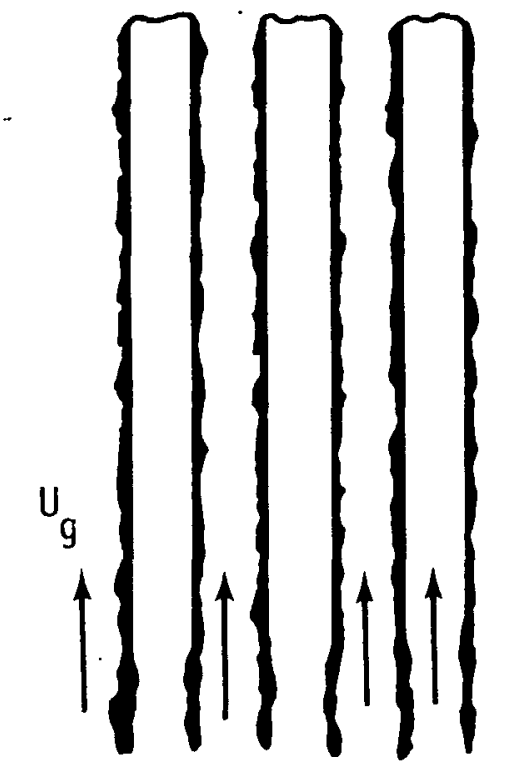

(a) CLAD SLOSHING AND FUEL PIN EDGE MELTING

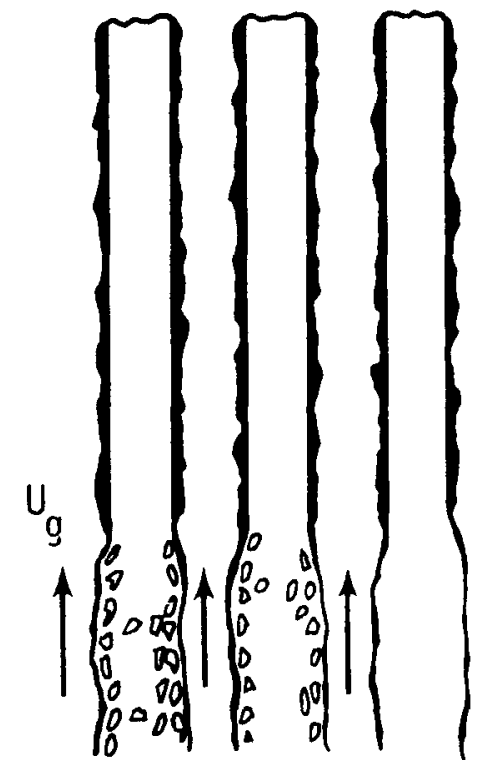

(b) INCIPIENT CLAD ENTRAINMENT AND MIXING WITH FUEL

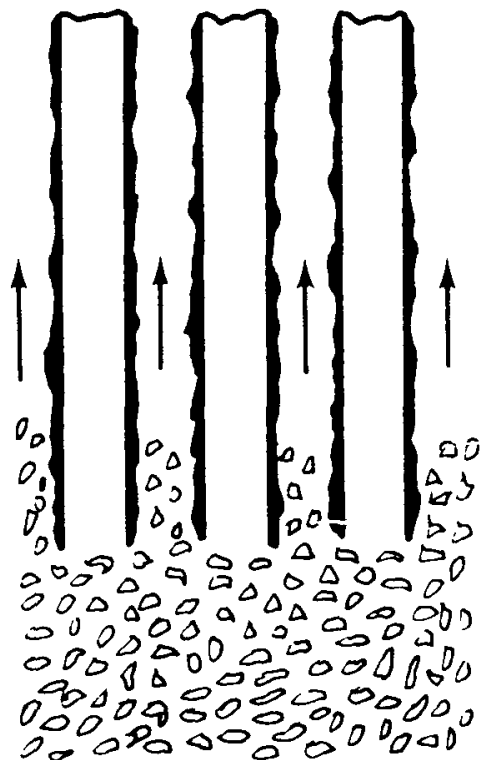

(c) CLAD VAPORIZATION, FUEL DISPERSAL AND FLUIDIZATION 
TIME AFTER SHUTDOWN (DECAY HEAT), SEC

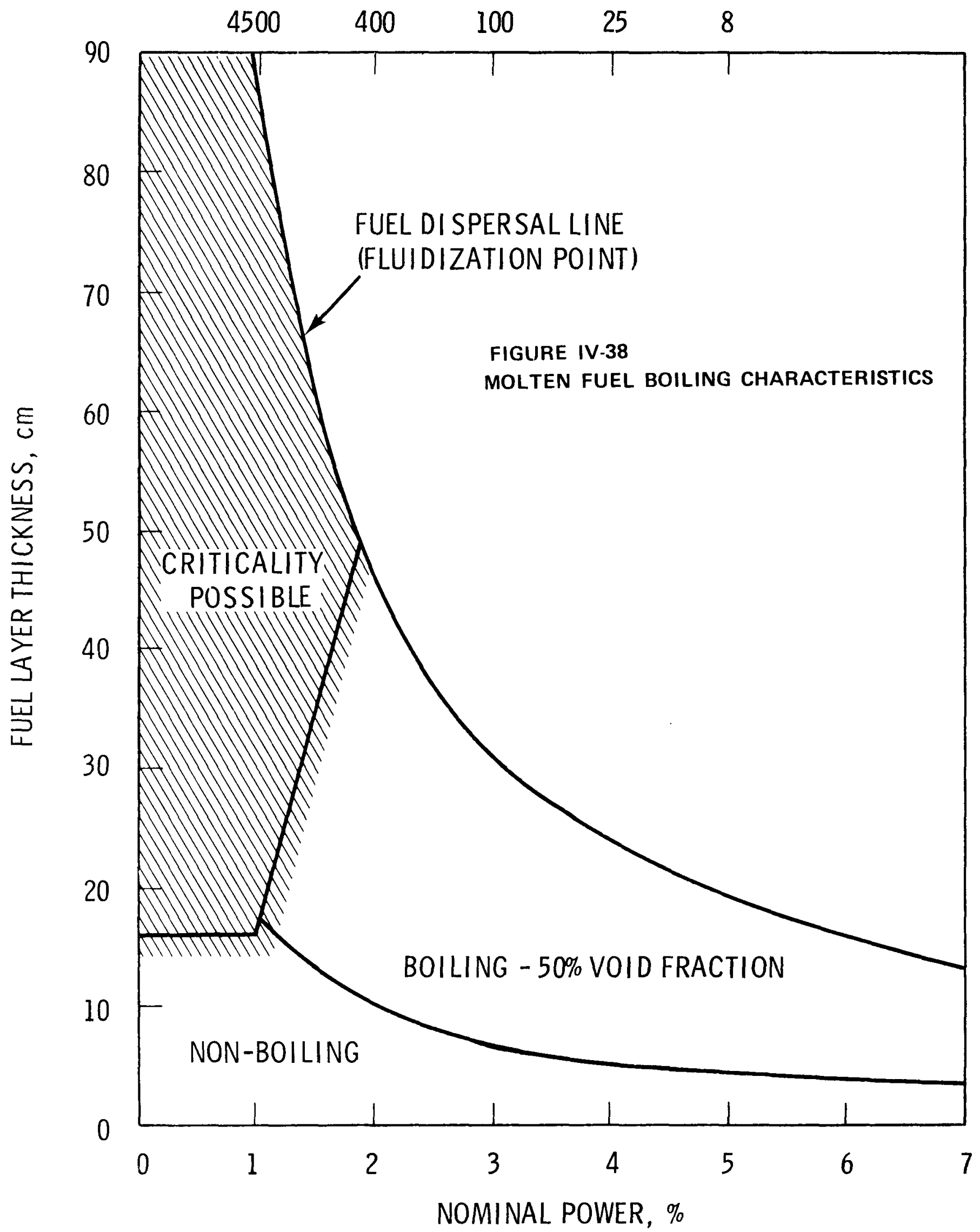


GRADUAL BOILING (NOMINAL CASE)

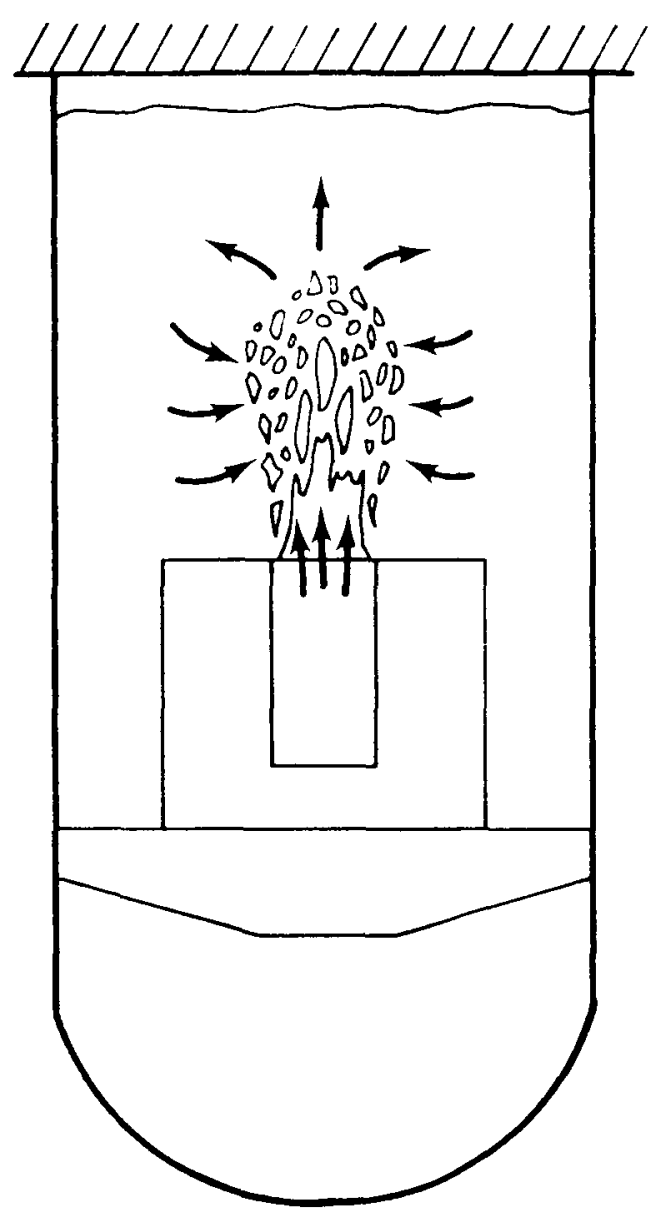

FUEL EJECTION AND PENETRATION (NO SIGNIFICANT WORK DONE)

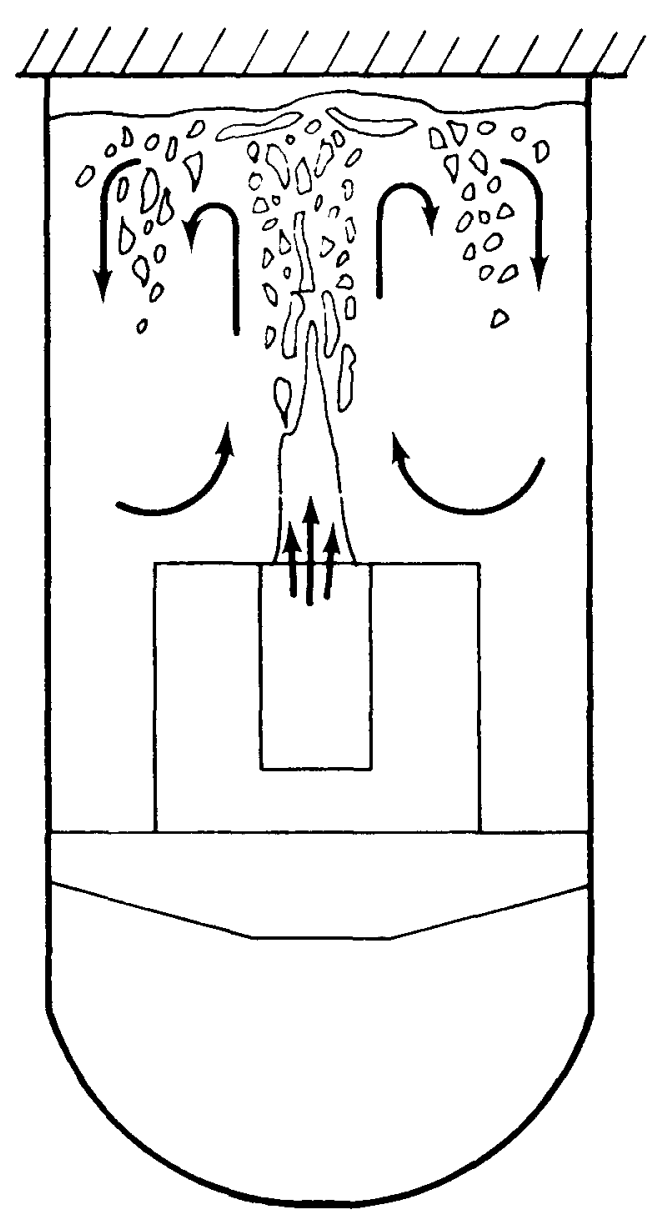

FUEL IS BEING DISPERSED 
FIGURE IV-40

\section{LOF - SUMMARY}

- CORE MELTDOWN RESULTS IN LITTLE OR NO WORK POTENTIAL - MARGIN OF SAFETY CAN BE ASSESSED BASED UPON FUEL VAPOR EXPANSION.

- PERFERRED DIRECTION OF FUEL EJECTION IS UPWARD LEAVING BEHIND A RELATIVELY SMALL AMOUNT OF FUEL IN THE CORE REGION AND BELOW.

- FUEL EJECTION VELOCITIES ARE SUFFICIENTLY HIGH TO RESULT IN A RELATIVELY UNIFORM DISTRIBUTION OF FUEL DEBRIS ABOVE THE CORE REGION ON THE THERMAL BAFFLES. 
On the basis of these studies, judgement was reached that it is very unlikely that ramp rates as high as $100 \$ / \mathrm{sec}$ could be induced in FFTF as a result of the unprotected loss-of-flow accident. Accident Energetics

As previously noted, the most likely accident termination is a two-phase blowdown of the core material through the tops of the subassemblies. Although the ejection rates may be quite rapid (say half the core in about $1 \mathrm{sec}$ ) they are slow compared to an explosive mechanical disassembly. The material would enter the above-core sodium largely in the form of a two-phase jet containing dispersed fuel and with a temperature near the steel boiling point ( $3200^{\circ} \mathrm{K}$ ). Material ejected in this mode would not be expected to interact energetically with the sodium and the resulting work-energy would be low.

Although the mild blowdown of fuel material is the expected path, to investigate the damage potential of secondary excursions, a series of secondary excursions were calculated using VENUS-II.

$V G \quad T 0$ assess work potential the following model was used. A

IV-4I mixture of fuel vapor and liquid is ejected from the core region and expands into the sodium pool, forming a single bubble. Some of the surrounding liquid sodium may be entrained in the form of droplets in the expanding fuel bubble. The bubble expands against the inertia of the pool sodium until the sodium slug impacts the reactor vessel head. Note that this model considers work energy effects due to both fuel expansion and potential vaporization of sodium mixed with the ejected fuel. Best judgement would be that essentially no sodium entrainment would occur.

The results of these calculations have been used to examine the damage to the FFTF reactor. A P-V curve resulting from such $V G$ an analysis is shown on the vu-graph, together with the original IV-42 $150 \mathrm{MW}$-sec PSAR P-V curve. 
FIGURE IV-41

MODEL OF POSTDISASSEMBLY FUEL EXPANSION AND INTERACTION WITH POOL SODIUM

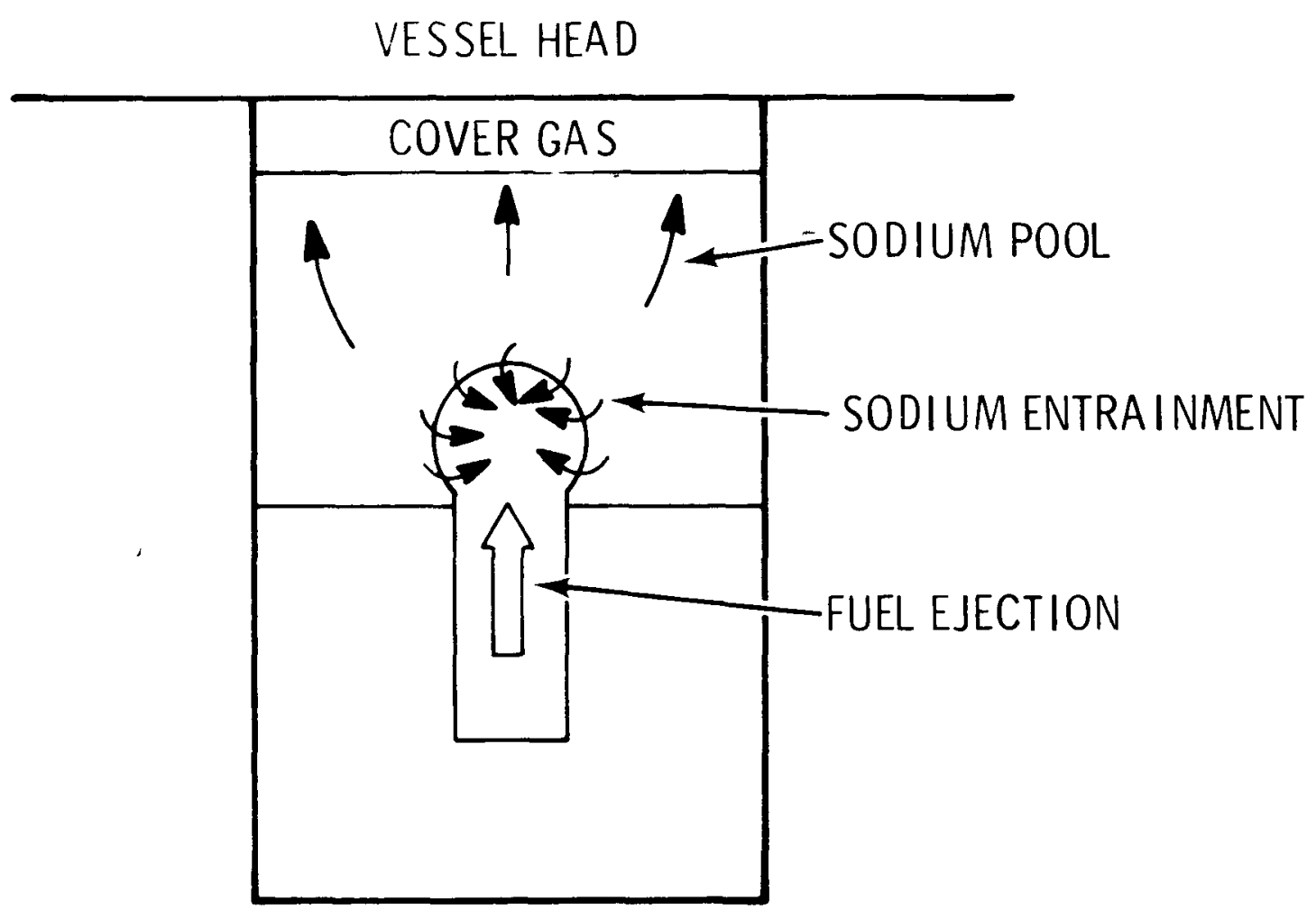


FIGURE IV-42

PRESSURE VOLUME RELATIONSHIP FOR DISASSEMBLY FUEL TEMPERATURE OF $4850^{\circ} \mathrm{K}$ CASE OF OPTIMUM SODIUM ENTRAINMENT

(FUEL EJECTION AREA $=11,700 \mathrm{~cm}^{2}$ )

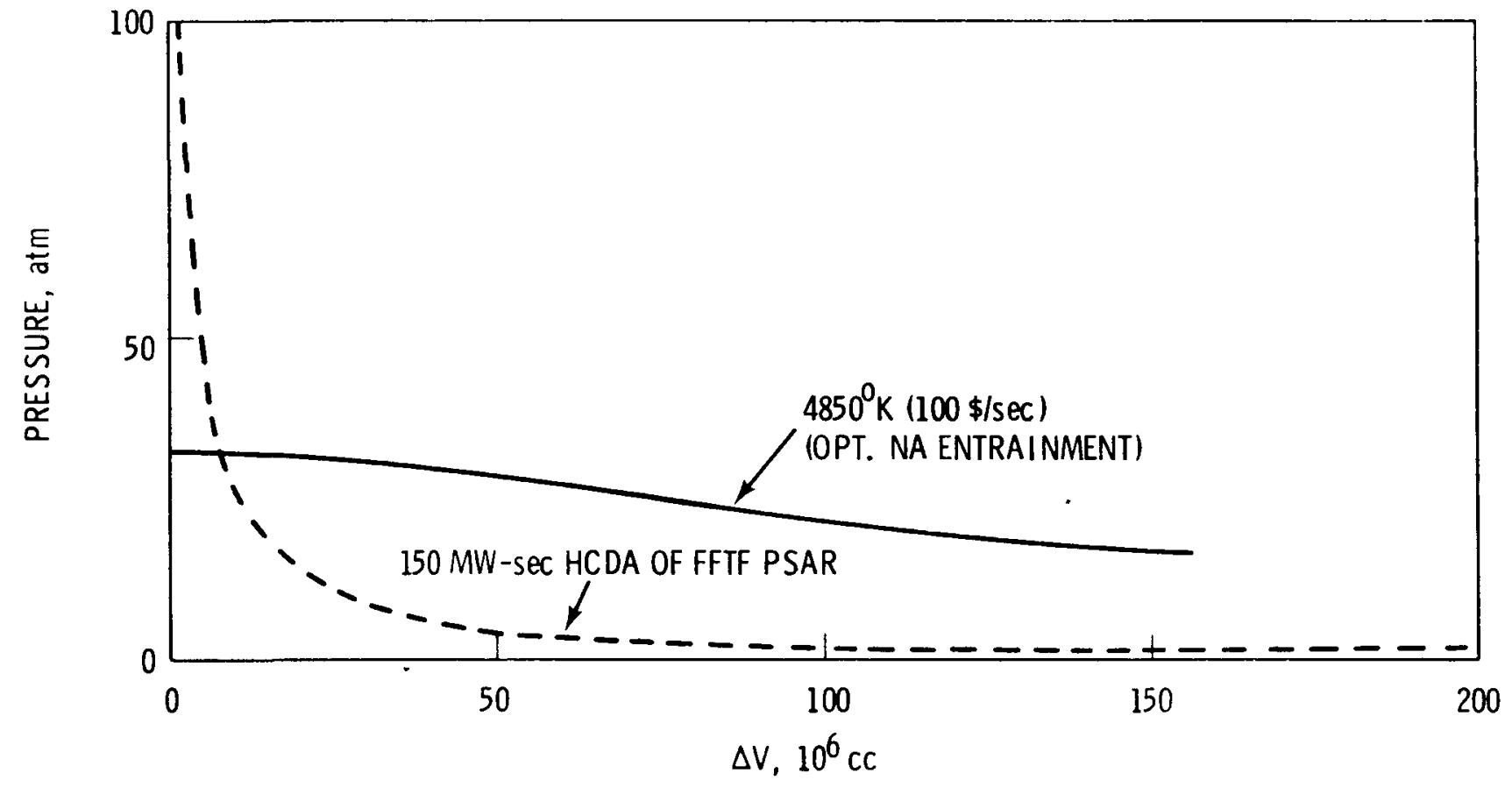


Fuel-Coolant Interaction

The original FFTF 150 MW-sec HCDA P-V curve was based on a conductivity limited model (SOCOOL-II) for fuel to sodium heat transfer and subsequent sodium vapor expansion as a means of doing work. The SOCOOL-II model allowed conversion of $5-10 \%$ of the thermal energy to work; this is only one-third or so of the $V G$ theoretical thermodynamic limit, but is more energetic than observed IV-43 experimentally for a $\mathrm{UO}_{2}$-sodium system. ${ }^{(56)}$ (See vu-graph.)

TREAT tests with their low energy conversion have been supplemented by out-of-pile tests of up to kilogram quantities of molten $\mathrm{UO}_{2}$ injected and dropped into sodium under various conditions and these also have shown very low energy conversion efficiency but extensive fuel fragmentation.

A theoretical explanation for the observed low efficiency has been made by Hans Fauske of Argonne National Laboratory. $(57,58)$

VG Fauske concludes than an energetic vapor explosion requires that IV-44 the low boiling point fluid be raised to its homogeneous nucleation temperature. If a system is physically restrained while heat transfer takes place, then an energetic vapor explosion could occur when the low boiling fluid reaches this point. However, for an energetic explosion to occur immediately on contact between two materials, it is necessary that the two fluids both be liquid, that they be in intimate contact, and that the instantaneous contact interface temperature between the two fluids be above the homogeneous nucleation temperature of the low boiling fluid.

The interface temperature is determined by the well-known relationship determined by the fluid conductivities and heat capacities.

$$
\frac{T_{j}-T_{c}}{T_{h}-T_{j}}=\left(\frac{K_{H} \rho_{H} C_{H}}{K_{c} \rho_{c} C_{C}}\right)^{1 / 2}
$$

The homogeneous nucleation temperature empirically determined for sodium is in the range of $3800^{\circ} \mathrm{F}$, whereas for water it's around 
FIGURE IV -43

COMPARISION OF SOCOOL II AND EXPERIMENTAL (S-SERIES) EFFICIENCES FOR CONVERSION OF NUCLEAR TO MECHANICALL WORK ENERGY

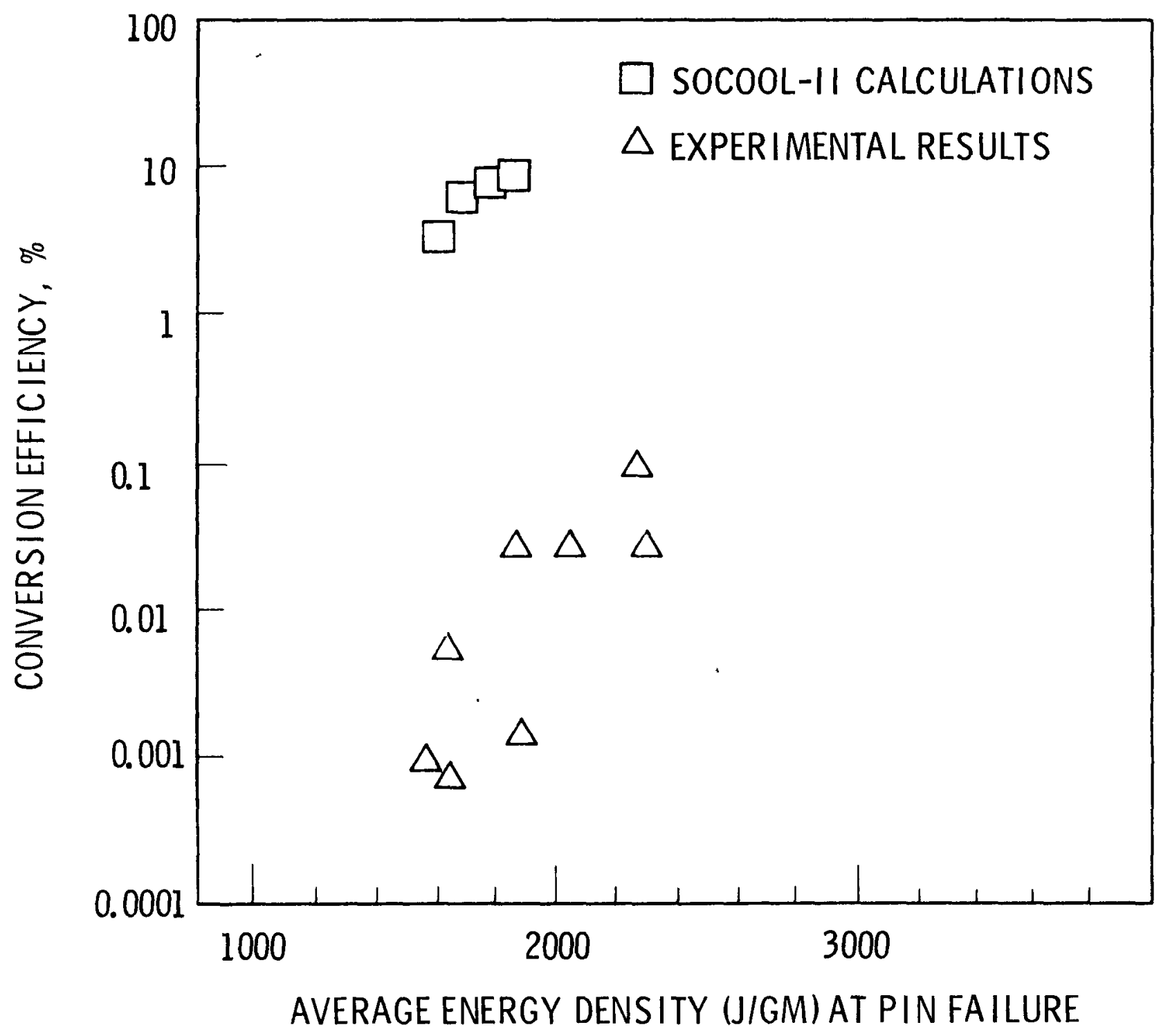


FIGURE IV-44

COMPARISON OF SPONTANEOUS NUCLEATION AND SUDDEN CONTACT TEMPERATURES

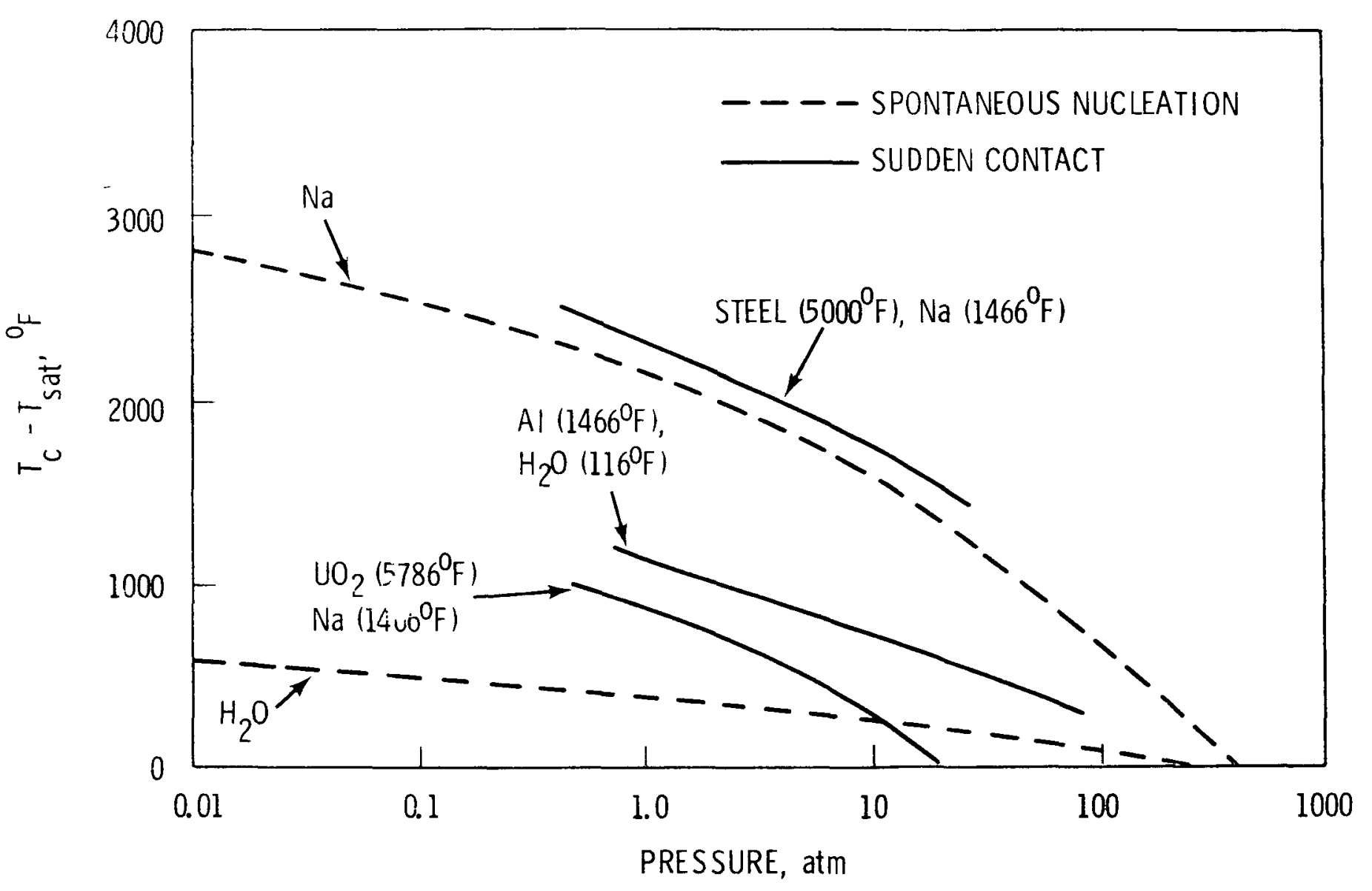


$600^{\circ} \mathrm{F}$. Fauske has shown, for example, that: the system aluminum into water results in an interface temperature above the homogeneous nucleation point of water, whereas the system uranium dioxide into sodium has an interface temperature well below the homogeneous nucleation point of sodium, even if sodium were initially at or near the boiling point. This theory provides a convincing explanation of the observed low efficiencies of $\mathrm{UO}_{2}$ sodium thermal interactions as well as the high efficiencies of observed aluminum-water interactions. It also indicates that under fast reactor accident conditions high efficiency interactions between $\mathrm{UO}_{2}$ and sodium would not occur.

\section{Current Conclusions Summary}

Let me review where we now stand with respect to the analys is of the nuclear excursion accident and assessment of the energy which might be available from such an accident.

\section{Major Phenomena}

(1) Sodium Voiding. Sodium boiling characteristics are reasonably well understood, and it is well-established that substantial superheat will not occur in reactor systems. Analytical models are satisfactory for full subassembly voiding conditions, but require improvement for analys is of sustained boiling and resumption of liquid cooling after boiling followed by reactor scram. Two-dimensional boiling models to follow void and flow profiles in multi-pin fuel assemblies need to be developed.

In an FFTF size core, boiling does not lead to a significant positive reactivity feedback, but this may not be true for larger cores. In addition to improvements in boiling analysis, better calculational capability for void reactivity effects will be needed.

(2) Fuel Motion. For transient overpower conditions, fuel failure criteria are being developed. Additional experimental data and analysis of experiments is required to pin it down but there is strong evidence for fuel failure occurring away from the centerline of the core. Expulsion of molten fuel from within the pin is a 
demonstrated phenomenon; mechanistic models have been developed for the transient expulsion of fuel, and one of these (HOTPIM) has been incorporated in the MELT-III code at HEDL. (59) The stand-alone PLUTO ${ }^{(60)}$ code is the first mechanistic fuel coolant interaction and fuel sweepout model for analysis of fuel motion outside of the pin, for fuel expelled into the coolant channel. Additional experimental evidence on the potential for plugging and/or plateout of fuel material in the coolant channel is needed, and work in these areas is in progress, including an out-of-pile experimental program which is being developed by Argonne National Laboratory.

Under loss of flow and extensive core voiding conditions, conservative models exist for calculating fuel motion. The presence of fission gases within the fuel as it melts probably is not sufficient to prevent subsequent limited slumping. Fuel slumping has been empirically observed to occur with fresh fuel in the absence of flowing vapor in the coolant channels, with an acceleration less than $1 \mathrm{~g}$. This behavior can be matched reasonably well in the SAS code models. The effects of slumping in terms of reactivity insertion rate and resulting mild dispersal are not sufficiently sensitive to the slumping characteristics to warrant a great deal of effort to further refine the fuel motion models for these conditions.

The transition to a boiled up two-phase dispersed regime involving steel and fuel has more recently been identified, and analytical models are not well developed for this condition.

(3) Clad Motion. The importance of this area of phenomenology was identified more recently. Forces exist which tend to cause upward and downward motion of the clad once melting occurs. Additional experimental data and further refinement of analytical models is required to determine whether or not the plugging of coolant channels will, in fact, occur in reactor size assemblies.

(4) Fuel-Coolant Interactions. The question of possible energetic fuel-coolant interactions as a means of producing damaging 
work seems to be nearly, if not entirely, reso ved on the side or non-energetic interactions for $\mathrm{NO}_{2}$ and sodium.

\section{Computer Codes}

Continuation of current experimental programs and correlation of the results into the SAS and MELT analytical codes should result within the next few years in adequate capability for analysis of hypothetical accident progression up to the point of an initial hydrodynamic disassembly or termination of the accident without hydrodynamic disassembly, with the core remaining in a geometry close to the original. For an initial hydrodynamic dispersal condition, the VENUS code is adequate for calculating fuel vapor pressures, initial material accelerations and the available energy in the fuel vapor.

However, if the potential remains that the core would not be fully and permanently dispersed, there currently exists no analytical technique which is adequate for assessing the transition into whole core involvement and subsequent dispersal by thermal, mechanical or hydrodynamic means. ANL and HEDL are developing preliminary models for analysis of this phase of an accident progression. Also, a substantial effort has been initiated at Los Alamos Scientific Laboratory for evaluation of hypothetical core disruptive accidents and it appears that they will concentrate on the analysis of loss of flow conditions and its progression through to the termination of the accident.

VG

For several years the development of hydrodynamic disassembly IV-45 analyses has not been emphasized; the current codes available for this type of analysis are the VENUS code and the LoS Alamos PAD code. 
FIGURE IV-45

EVOLUTION OF COUPLED NEUTRONICS-HYDRODYNAMICS MODELS

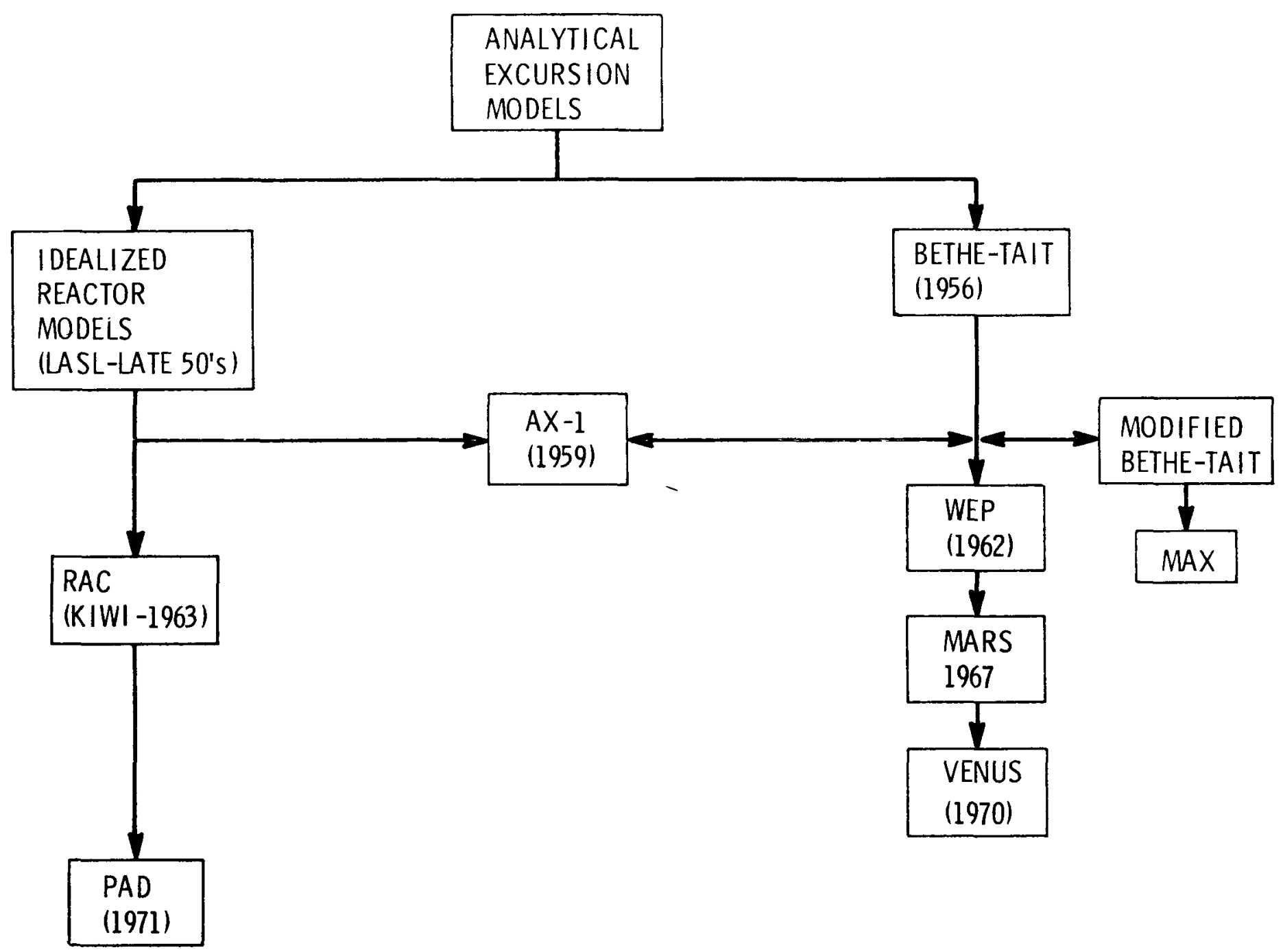




\section{Mechanical Consequences}

A. Basic Phenomena

An energetic reactor accident would be capable of doing damage

$V-1$ to the surrounding system because of the generation of pressurized vapor at or near the core location. The pressure from the vapor bubble would be felt on the reactor vessel internals and would be transmitted through the fluid to the boundaries of the system. The downward force against the core support structure might be transmitted through the fluid to the lower head of the reactor vessel and ultimately, via the vessel walls, to the reactor vessel support system. The radially propagating pressure wave would be felt at the wall of the reactor vessel and, if sufficiently high, the pressure colld cause deformation of the reactor vessel wall radially outward at approximately the same elevation as the maximum pressure. In the upward direction, if there is a free sodium surface, which is characteristic of many sodium cooled reactors, the sodium slug would be accelerated upward since there would be no resisting structural force. The acceleration of the sodium slug would impart a kinetic energy to the slug, and upon impact of this slug with the reactor vessel head the momentum of the slug would be transferred to the head, imparting some upward velocity. This impact would be inelastic, and the excess energy would be dissipated radially by deformation of the upper vessel wall. The upward motion of the vessel head would generally be resisted by its supporting structure and holddown system. Effects of an energetic accident on the remainder of the heat transport system would result from the displacement of the reactor vesse1, with corresponding nozzle displacement which could result in a deflection of piping; and from pressure waves which could be propagated throughout the primary heat transport system through the outlet and inlet sodium nozzles. 
FIGURE, V-1

REACTOR GEOMETRY AND MECHANICS OF POTENTIAL DAMAGE

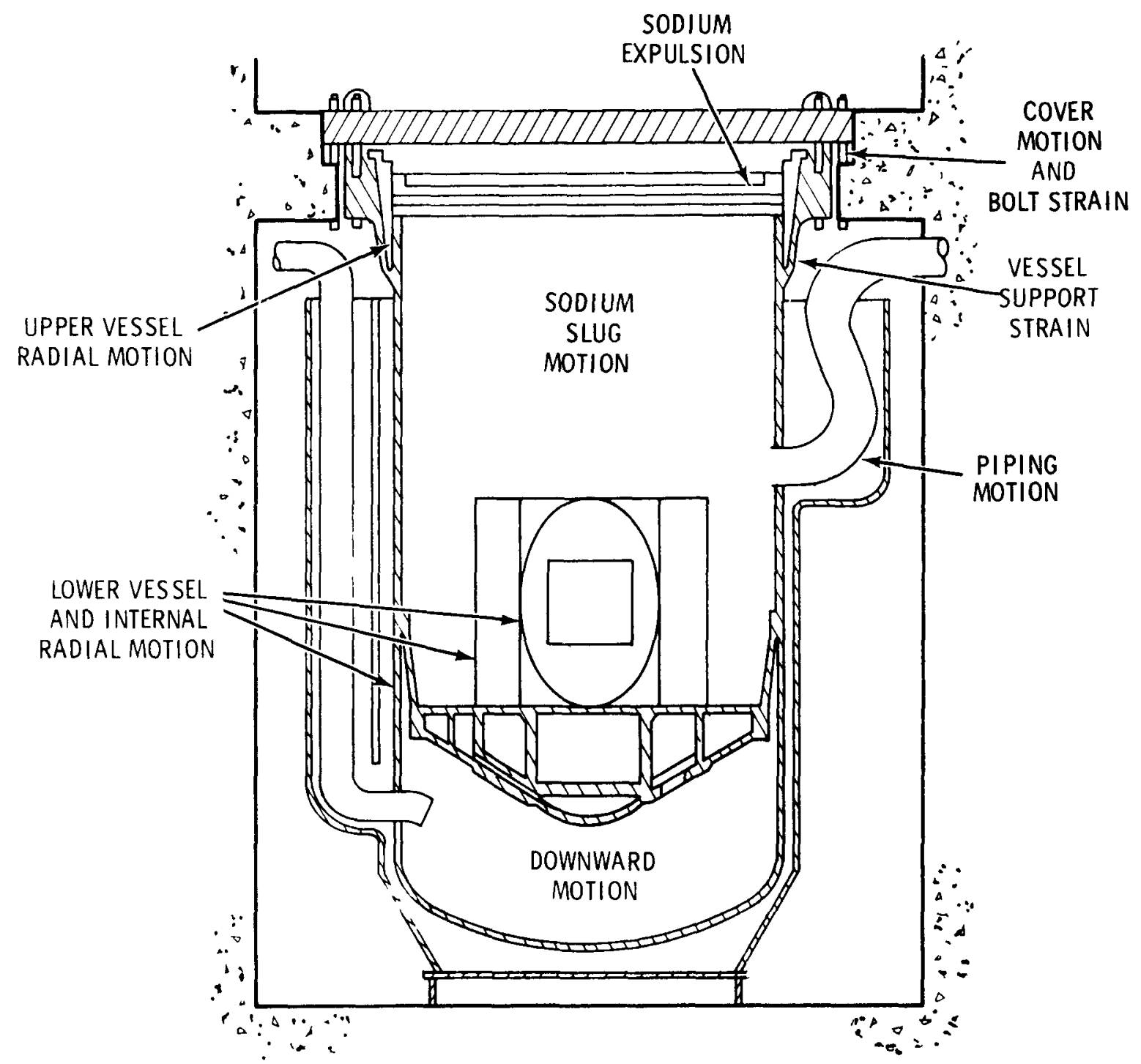




\section{B. History and Development}

A great deal of technology has been established in naval ordnance work related to the damaging effects of underwater explosions and much of this technology was documented in a hell known book by Cole, entitled Underwater Explosions. (61) Building on this technology, experiments were carried out with models of the FERMI reactor in the late 1950's and early 1960's by the Naval Ordnance Laboratory to determine the effects of explosions in that reactor vesse 1 system. It was found, for example, that an explosion equivalent to $1000 \mathrm{lb}$ of TNT in the FERMI reactor vessel could be sustained, except that the refuel-shield plug would be expelled upward high enough to penetrate the containment building. (62) Accordingly, a "machinery dome" was added to the FERMI plant design, with an energy absorbing structure within it such that it was capable of absorbing the energy imparted to the refuel$V G \quad$ ing plug. Experiments were also carried out at the Naval Ordnance V-2 Laboratory on a number of varying sizes and configurations of test vessels and a set of empirical explosion "containment laws" was developed as a result of those tests. (63) A key observation in these tests was that the radial vessel strain at the point of vessel failure was always greater than one-third the ultimate elongation to failure in an ordinary tensile test for the reactor vessel material; that is, if the ultimate strain of the vessel material was, say, $30 \%$, then the radial elongation at failure in the explosion containment test was always $10 \%$ or greater. In these explosion containment laws, the observed vessel wall strain was correlated to the high energy release for characteristic explosions similar to chemical high explosives.

Since the empirical explosion containment laws by Wise and Proctor, a number of analytical computer codes have been developed for predicting the mechanical effects of an energy release or a reactor vesse1. The most extensive and best known of these codes is the REXCO code, which is the development of the Argonne National Laboratory. (64) 
FIGURE V-2

LOCALIZATION FACTORS OF VESSELS DILATED WITH PENTOLITE IN AIR AND WATER

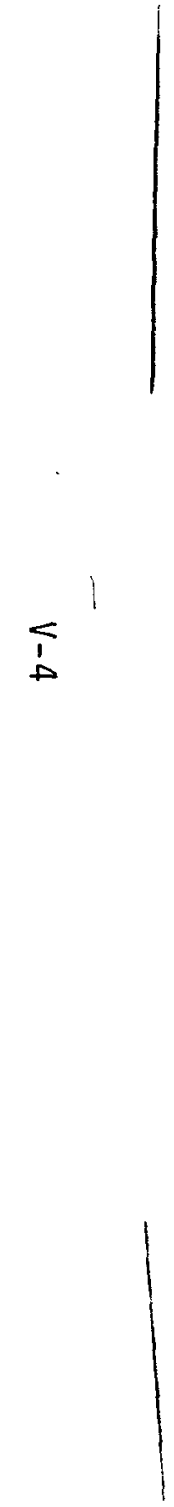

$R_{i}$ WAS INTERNAL RADIUS PRIOR TO DEFORMATION

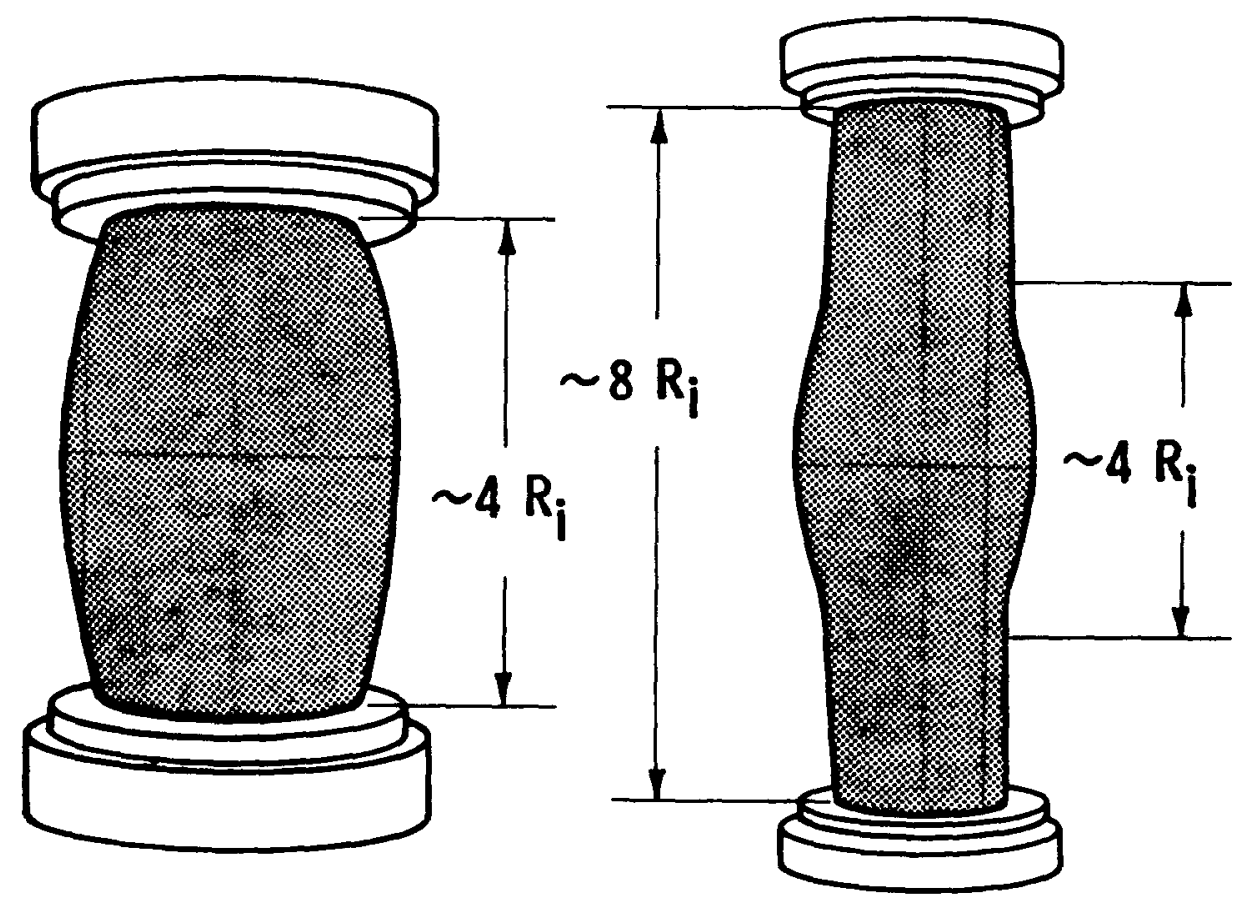

18 GRAMS IN WATER

19 GRAMS IN WATER
ALL CHARGES WERE DETONATED AT THE CENTROID

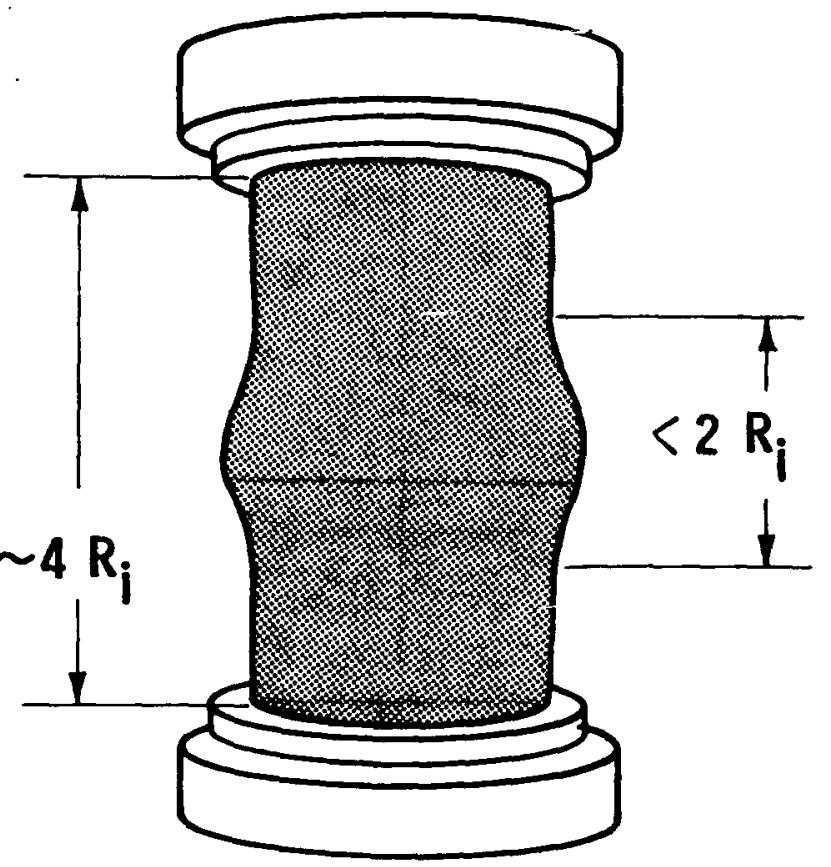

50 GRAMS IN AIR

VESSELS WERE ORIGINALLY RIGHT-CIRCLLAR CYLINDERE, 5" ID, AND 1/3" WALL, INTERNAL LENGTH OF LEFT AND RIGHT VESSELS WAS 10"; THAT OF CENTER VESSEL WAS 20". ALL WERE CENTRIFUGALLY CAST FIOM 304 STAINLESS STEEL. 
The SL-I accident has been used as experimental data for comparison with analytical methods. ${ }^{(65)}$ Proctor showed that the vessel strain correlated reasonably well with the reactor explosion containment laws. The reactor vessel wall strain was considerably less than the predicted failure strain, and no wall failure was observed. The SL-I vessel deformation pattern was not characteristic of that for experimental vessels which were fully liquid filled for tests. In the SL-I the liquid surface was, at the time of the accident, well below the reactor vessel head and the water slug phenomenon occurred. The impact of this slug on the lower face of the head resulted in the acceleration of the entire reactor vessel upward from its original position, and also resulted in a radial deformation of the upper wall of the vessel.

Explosion modeling experiments have also been conducted in Europe and in Japan. A series of tests have been made in a $1 / 16$ scale simulation of PFR, a tank-type reactor. ${ }^{(66)}$ The models included representations of heat exchangers and pumps, and the experiments used a high-explosive RDX/TNT as the energy source. Studies have been performed on 1/12 scale models of the SNR reactor by Belgo-nucleaire and Euratom at Ispra. ${ }^{(67)}$ Pyrotechnic mixtures $\left(\mathrm{KClO}_{4}, \mathrm{Ba}\left(\mathrm{NO}_{3}\right)_{2}\right.$, and $\left.\mathrm{Mg}\right)$ have been used in the SNR tests as wel1 as TNT. In addition to verifying primary vessel integrity, the Ispra tests were intended to calibrate an accident analysis computer code, SURBOUM-II. A 1/16 scale SNR test is planned as part of this program. Explosion modeling tests have been conducted in Japan on 1/10 scale models of the Fast Experimental Reactor II. Explosion tests using pentolite in the vessel were also performed to analyze wave propagation in the primary piping and IHX. As an experimental convenience, $1 / 5$ scale piping was used.

HCDA scale model tests have been conducted for FFTF in this country, and these tests will be discussed in more detail later. 
C. Procedure for Application of Hypothetical Accidents to Design

As stated earlier, hypothetical accidents are defined to provide a basis for evaluating containment safety margins. The HCDA is analyzed mechanistically to yield dynamic loads which

$V G$ become input to stress analyses for system components. Functional

V-3 requirements for systems and components exposed to the HCDA energy release are defined for the accident period and its aftermath. Components necessary to perform the defined functions are then identified. Finally, the loadings on critical components are computed to permit an assessment of their capability to withstand these loads.

Typical functional criteria would focus on reactor containment and decay heat removal systems. Release of sodium and other containment pressurization sources must be limited to levels under containment design pressure, and missile generation with the potential for penetrating the containment shell must be prevented. Pressure loads and other phenomena must not prevent removal of core decay energy by the cooling system provided.

A mechanistic analysis of a reactor system can be started by using the REXCO code to obtain force histories throughout the vessel. REXCO is a hydrodynamic structural response code based on a Lagrangian coordinate system (meshes follow the fluid motion).

VG The REXCO model of FFTF is shown in the vu-graph. State equations $\checkmark-4$ are provided for fluid representations and constitutive equations are provided for structural materials. The HCDA energy source itself is input in the form of pressure-volume data as previously shown. The principal output from REXCO is pressure history at HTS nozzles, wall strains, force histories on the vessel head and core VG support plate. The latter is shown in vu-graph V-5 as an example V-5 of REXCO output. The second peak occurring is a reflection of coolant slug impact with the vessel head. 
FIGURE V-3

TYPICAL FUNCTIONAL CRITERIA

1. NO MISSILE GENERATION

2. RETAIN CONTROL OVER RADIOACTIVE MATERIALS

3. MAINTAIN CAPABILITY FOR COOLING REACTOR CORE 
FIGURE V-4

REXCO MODEL OF FFTF

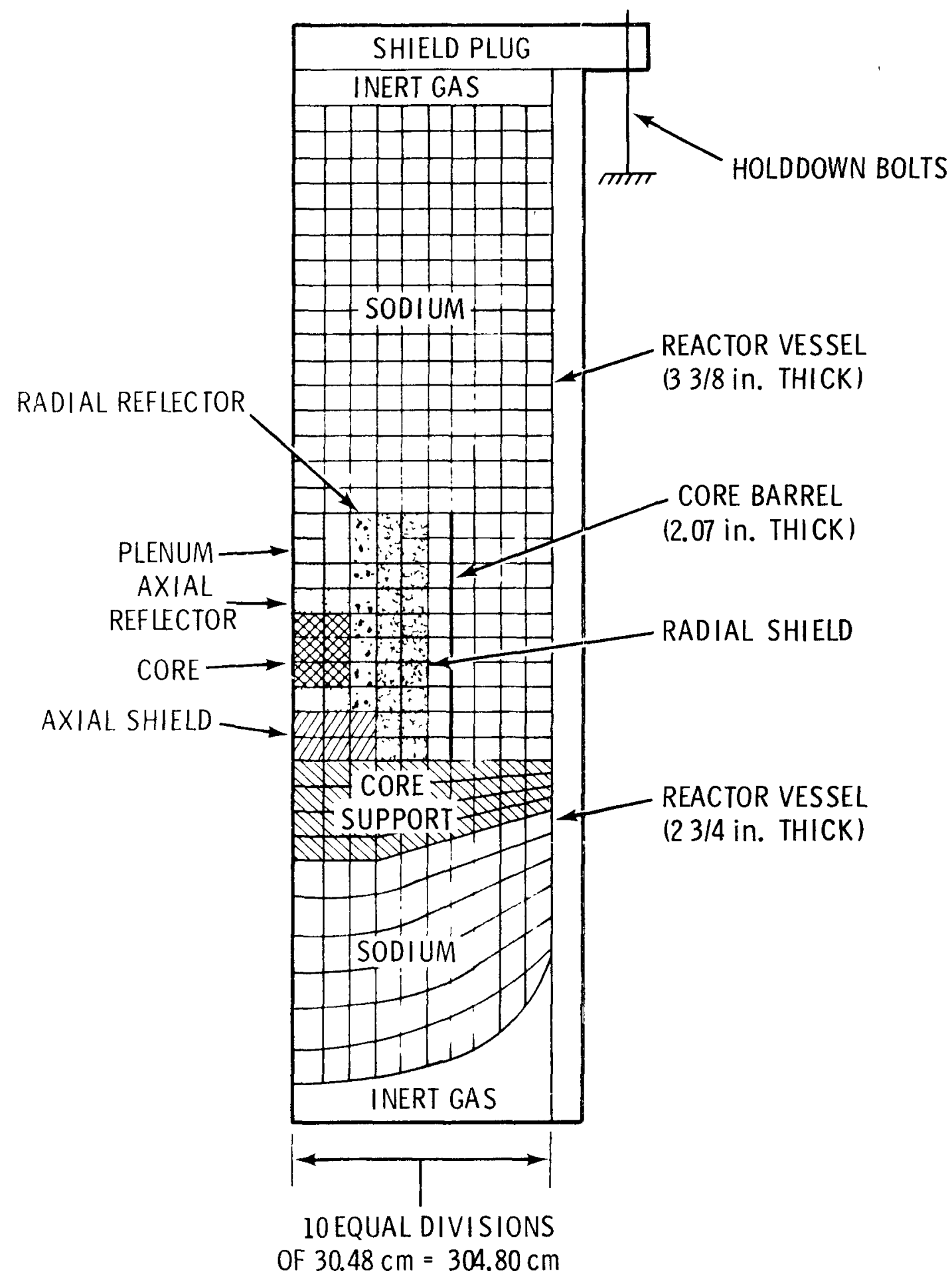


FIGURE V-5

FORCE-TIME INPUT FUNCTION FOR CORE SUPPORT STRUCTURE

$\overleftarrow{6}$

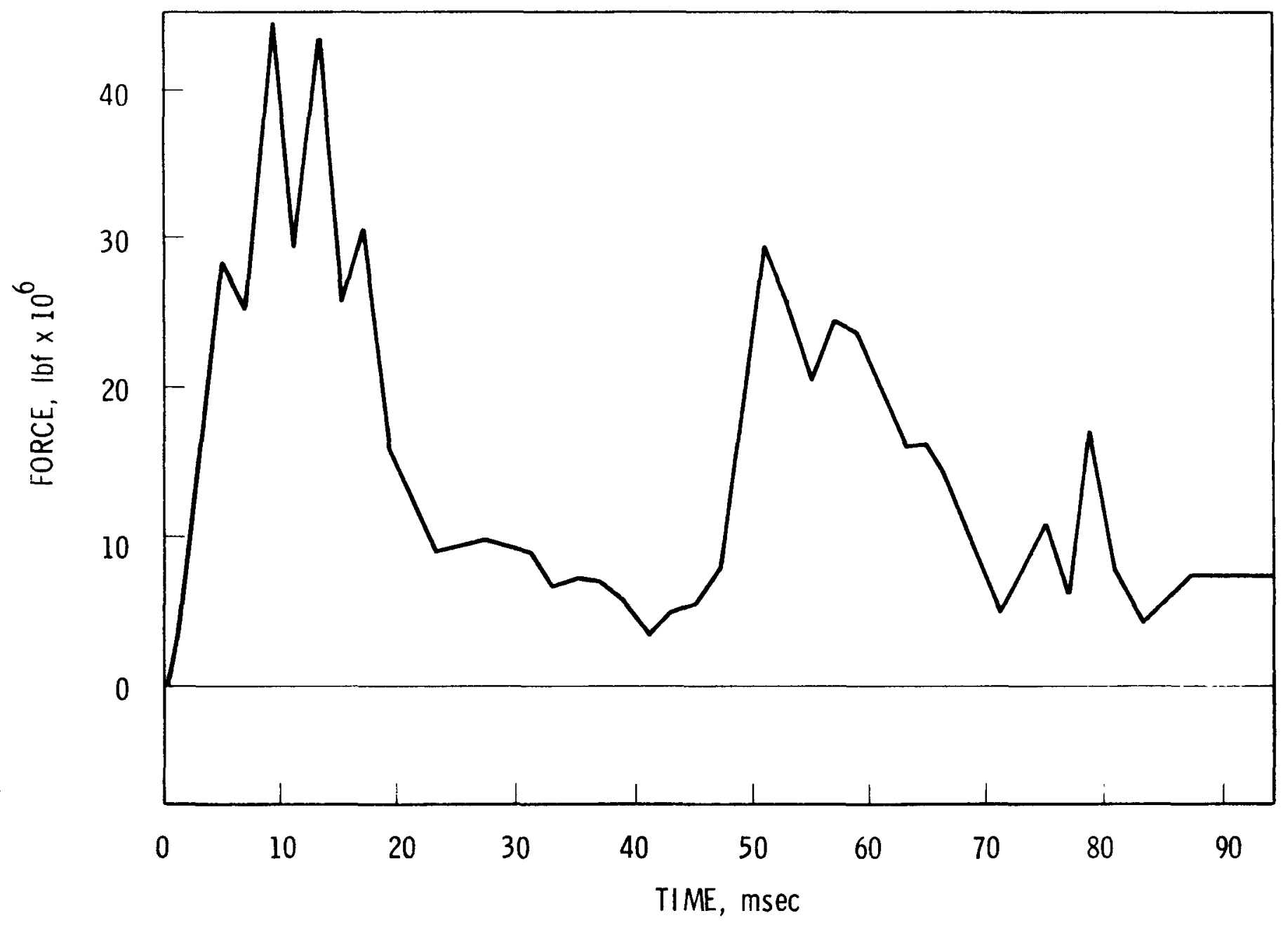


Dynamic movement of the vessel during an HCDA has been com-

V-6 puted for FFTF with a simulation code called MOTION. This code simulates the vessel, head, support structure and connecting bolt, and suspension systems as a group of discrete masses and non-linear springs. Input data consists of force histories on the vessel head VG and vessel support structure. Typical output is shown on vu-graph

V-7 V-7, which shows the downward displacement of the reactor vessel. These data are used to evaluate clearances between nozzles and the guard vessel, and also provide input to the primary piping stress analysis.

VG Primary HTS analysis starts with the pressure pulse history $V-3$ in the reactor vessel at the inlet and outlet nozzles. Pressure pulses thus enter the primary loops from both ends and meet someplace in the middle of the loop. An important property of wave transmission in pipes is that pressure peaks are attenuated by plastic deformation of the piping. In the case of FFTF, within 10 to 15 pipe diameters from the inlet, pulse pressure drops to approximately $530 \mathrm{psi}$, equivalent to the proportional limit of the stainless steel pipe at $1050^{\circ} \mathrm{F}$. Wave propagation in plastically deforming pipe may be computed with the HEDL TUBE-30 code or the ANL ICEPEL code. The pulse history from TUBE-30 at the end of the plastically deformed section is the input to an elastic wave transmission code; ICEPEL can be set up to carry out the wave analysis for the entire system. The pulse history around the loop forms the basis for stress analyses of the piping and components.

D. FFTF Stanford Research Institute (SRI) Test Program

An extensive set of scale model experiments was performed on models of the FFTF to determine empirically the mechanical effects of energy releases from the core location, and also to provide a better basis than previously existing for evaluation of analytical VG models. (68) The program was initiated with an extensive series of V-9 source development tests in simple test models. It was shown that a mixture of high explosives and diluent materials can provide a pressure volume characteristic which is similar to that calculated 


\section{MOTION FLEXIBLE HEAD SIMULATION}

$\leq$

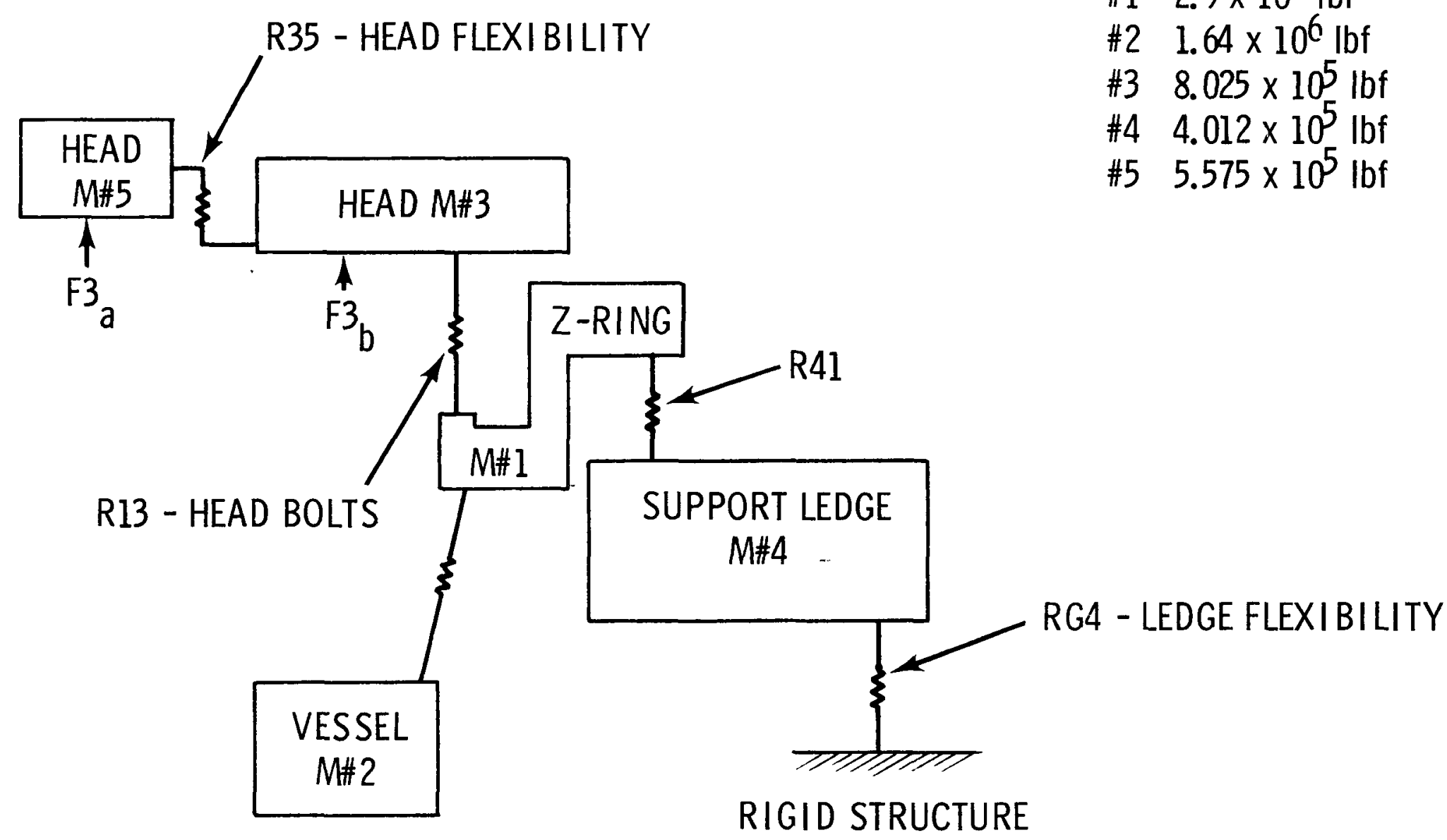

EFFECTIVE COMPONENT WEIGHTS

$\# 12.9 \times 10^{5} \mathrm{lbf}$

\#2 $1.64 \times 10^{6} \mathrm{lbf}$

\#3 $8.025 \times 10^{5} \mathrm{lbf}$

\#4 $4.012 \times 10^{5} \mathrm{lbf}$

\#5 $5.575 \times 10^{5} \mathrm{lbf}$ 


\section{FIGURE V-7}

150 MW-SEC HCDA

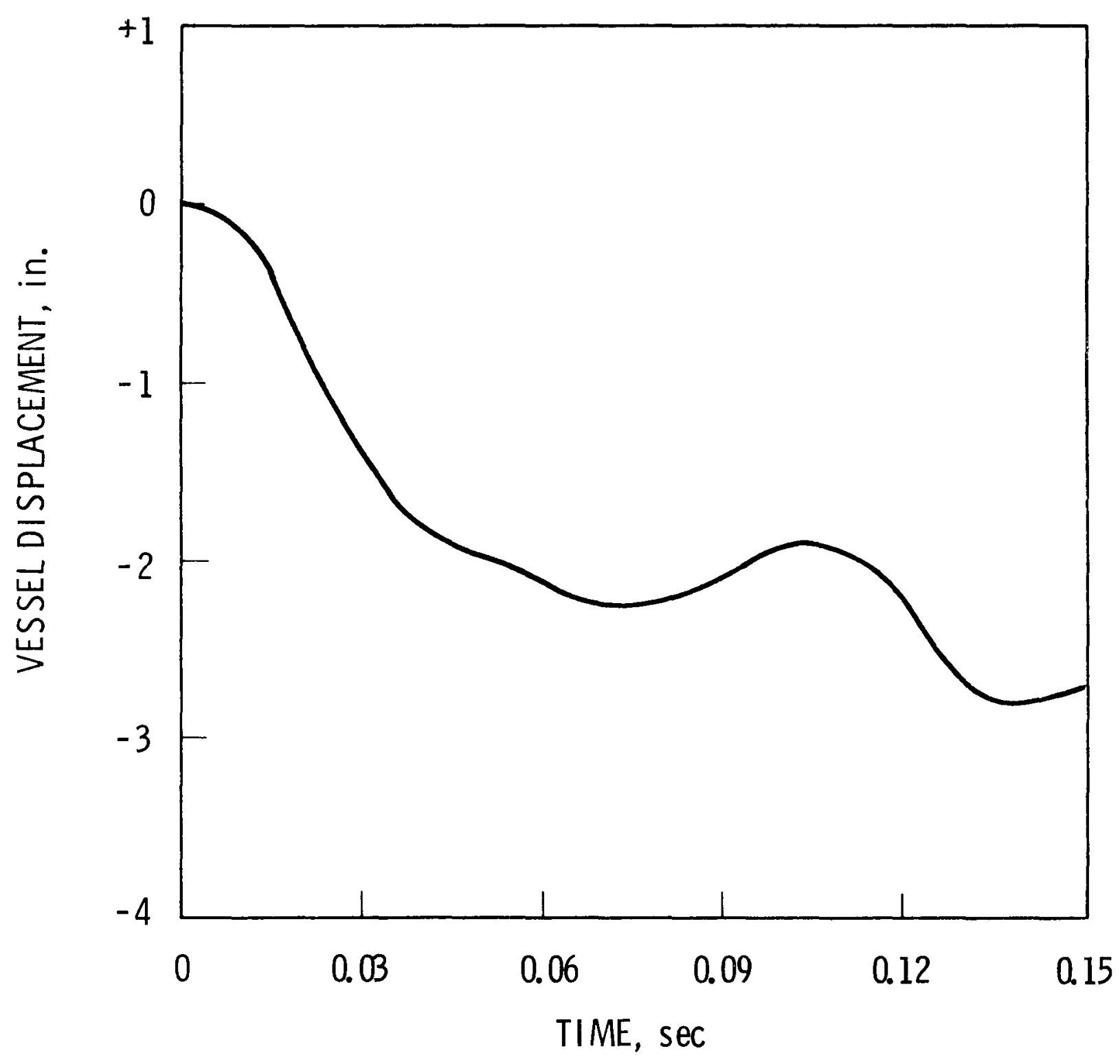


FIGURE V-8

\section{PRIMARY SYSTEM COMPONENTS}

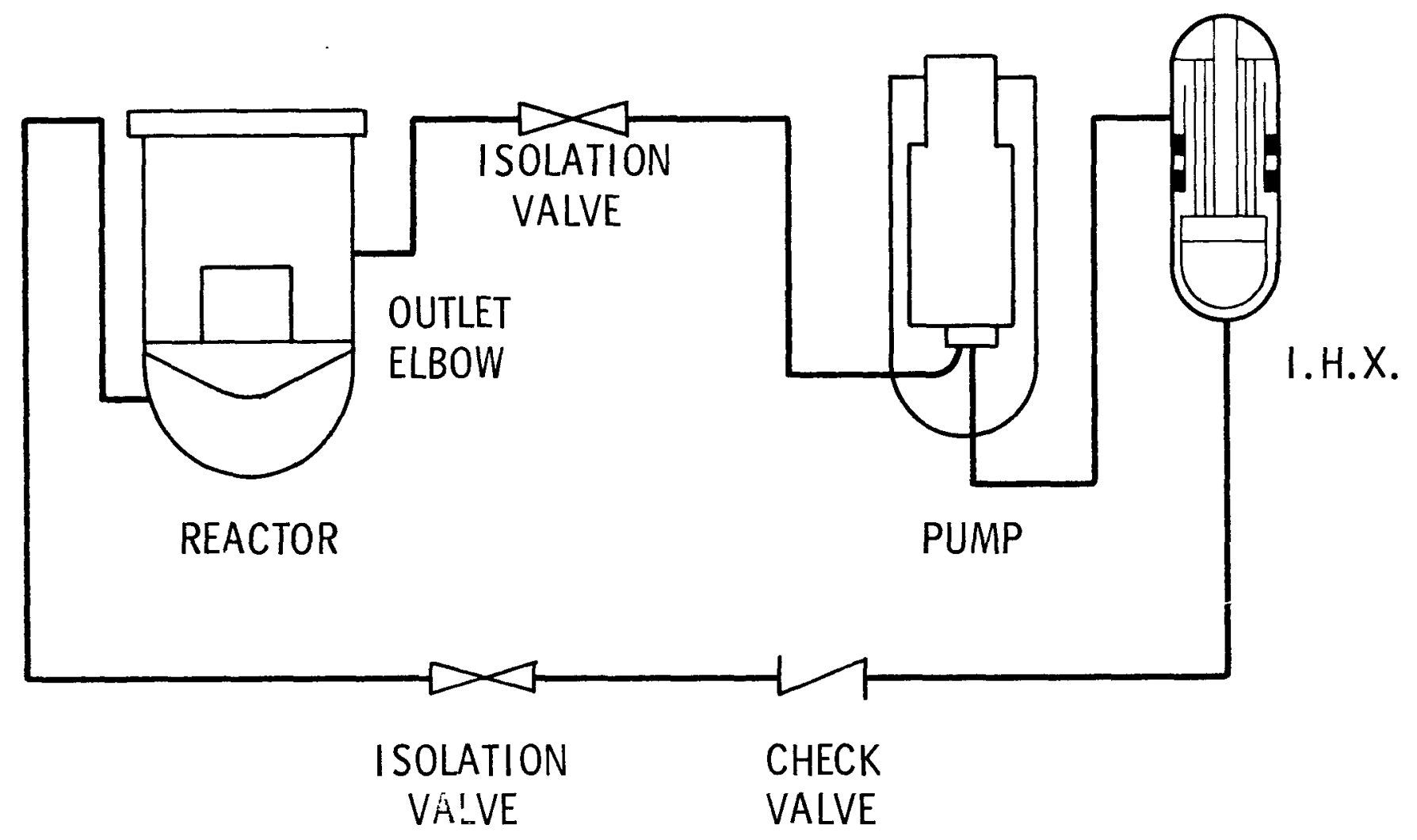




\section{FIGURE V-9}

150-MW SEC SOCOOL AND CM-10-1 PRESSURE-VOLUME CHANGE CURVES

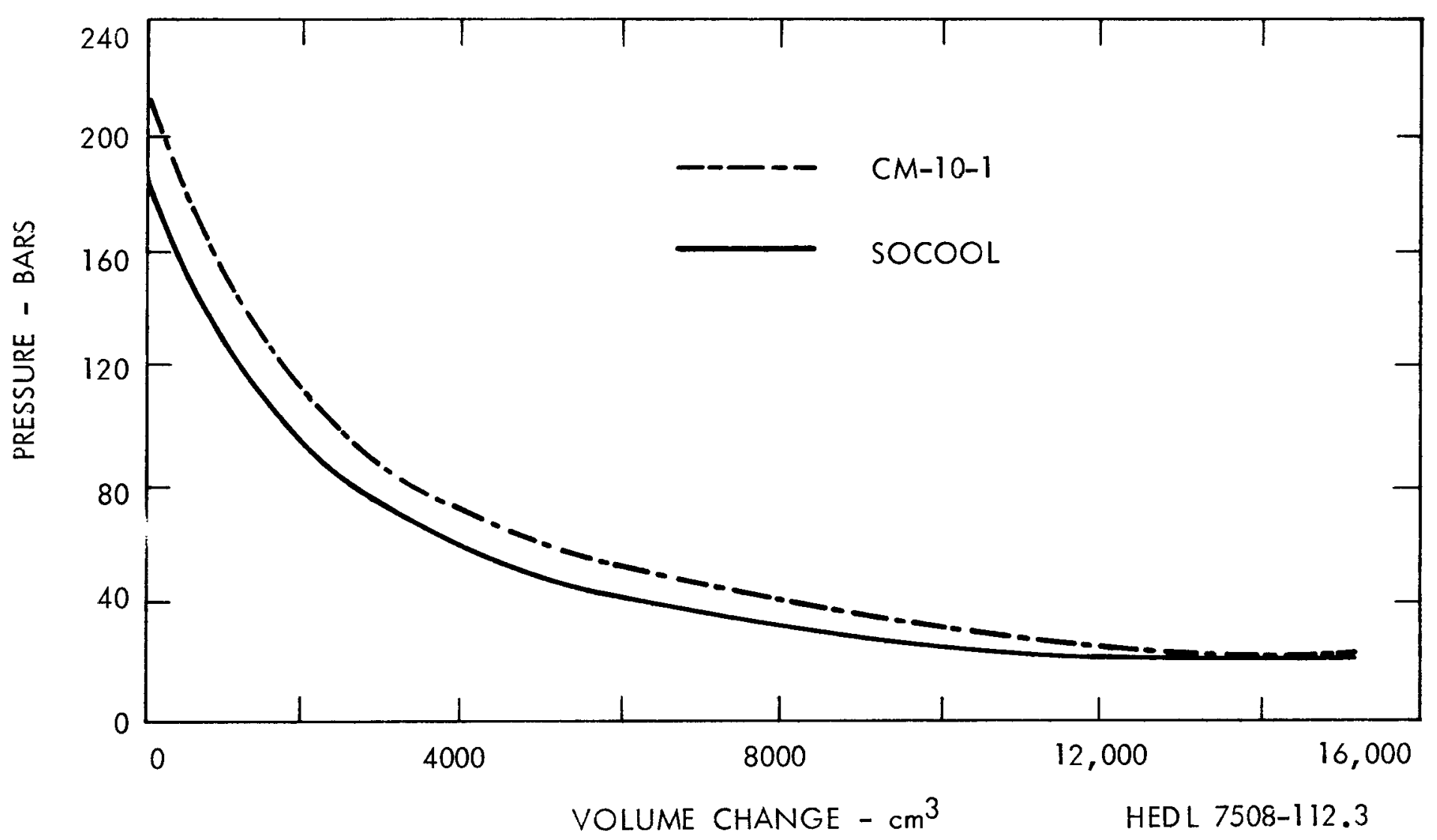


using the SOCOOL-II version of the transient thermodynamic model. That is, a source was developed which would provide an energy release similar to that which was used as the basis for the reactor and heat transport system mechanical consequences analysis at the

VG

VG

$V-11$

VG

V-12

$V G$

$V-13$ time of the FFTF Preliminary Safety Analys is Report. The source developments tests were followed by three detailed scale model tests; two scale model tests were performed at 1/30 scale, and one at $1 / 10$ scale. The $1 / 10$ scale model included hydraulic mode $1 \mathrm{~s}$ of a11 three primary heat transport sys tems of the FFTF; the $1 / 30$ scale models were limited to the reactor vessel and stubbed-off nozzles. All three sets were run with energy sources scaled to represent a $150 \mathrm{MW}-\mathrm{sec} \mathrm{HCDA}$; that is, $150 \mathrm{MW}-\mathrm{sec}$ of energy in the expansion of the vapor bubble to a pressure of 1 atmosphere. The damage to the coolant boundary was generally less than had been predicted by prior analyses with much of the reduction in damage attributed to energy absorbed by deformation of reactor vessel internals which had not been included entirely in the analytical models. The test data were scaled up to full reactor size. $(69,70)$ VG Results in terms of strain values at significant reactor locations are shown in vu-graph $\mathrm{V}-13$. Values in parentheses shown in this figure are estimates of allowable strain.

\section{E. Conclusion}

The current ability to calculate mechanical effects is satisfactory. Generally, deformations of primary boundary components and major energy absorbing structures other than reactor vessel internals can be calculated within, say, 20 to $40 \%$. This is reasonably good and probably better than our ability to predict the amount of energy which might be released or the characteristics of the energy release curve.

Argonne National Laboratory is continuing its development of REXCO with emphas is on modeling internal structure and energy absorbing members such as crushable tubing beneath the vessel head. ANL has also developed the ICE (Implicit Continuous Eulerian) code for computing fluid expelled from the vessel, and 
FIGURE V-10

\section{1/10 SIZE COMPLEX TEST}
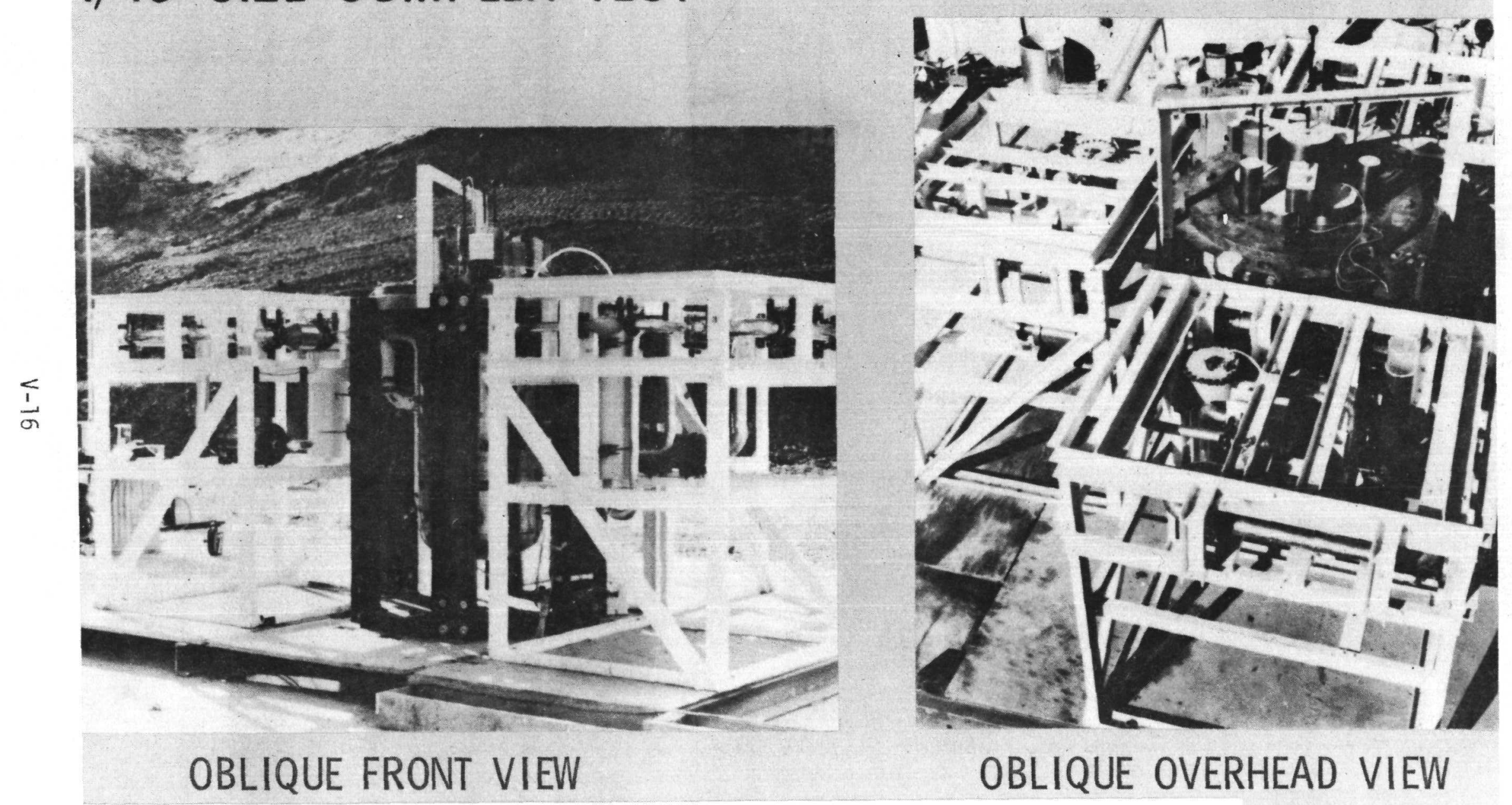

HEDL 7403-37.6 


\section{1/10 SIZE VESSEL AND SUPPORT VESSEL CONNECTIONS TO PRIMARY LOOP}
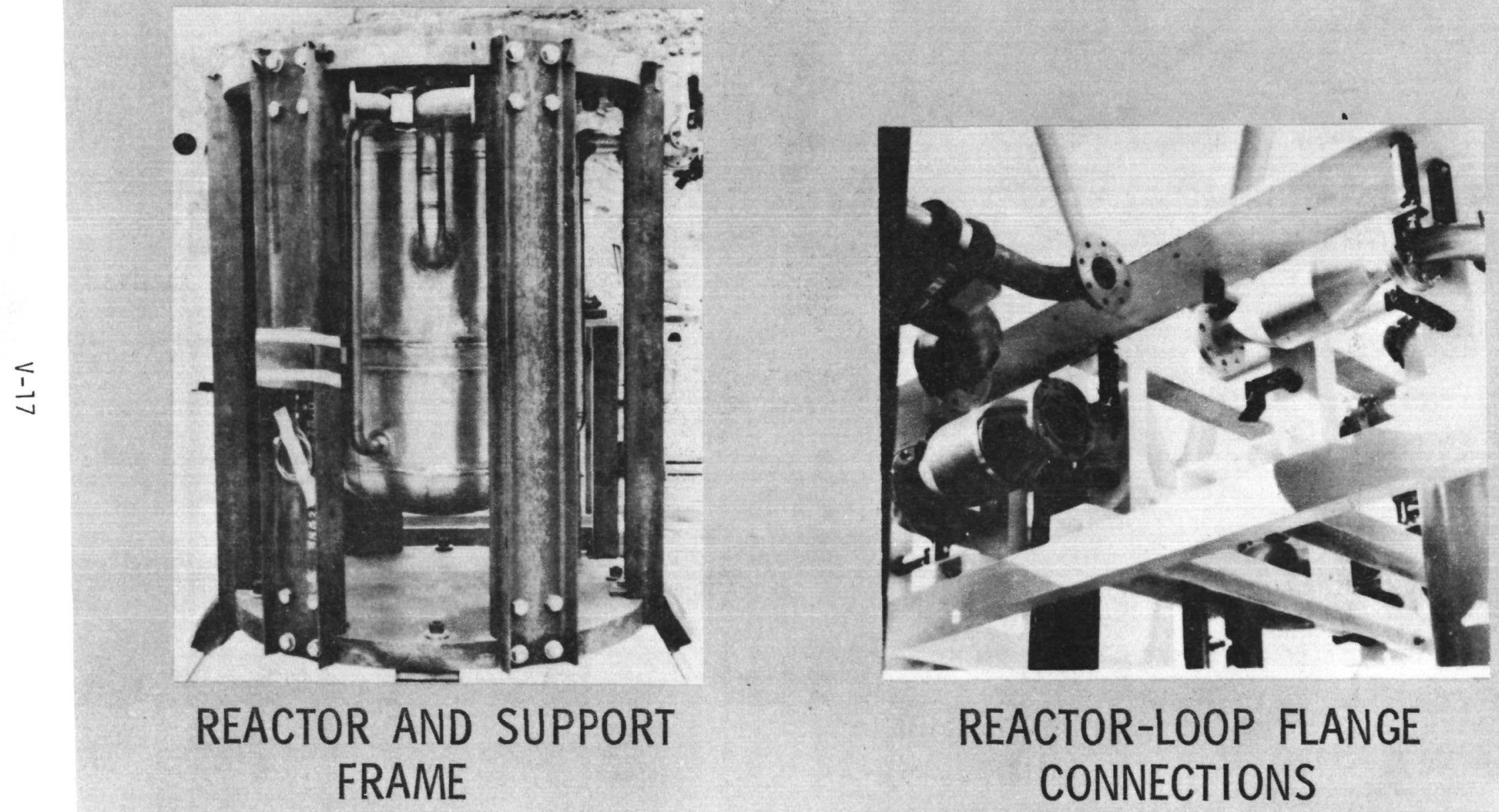

CONNECTIONS 
FIGURE V-12

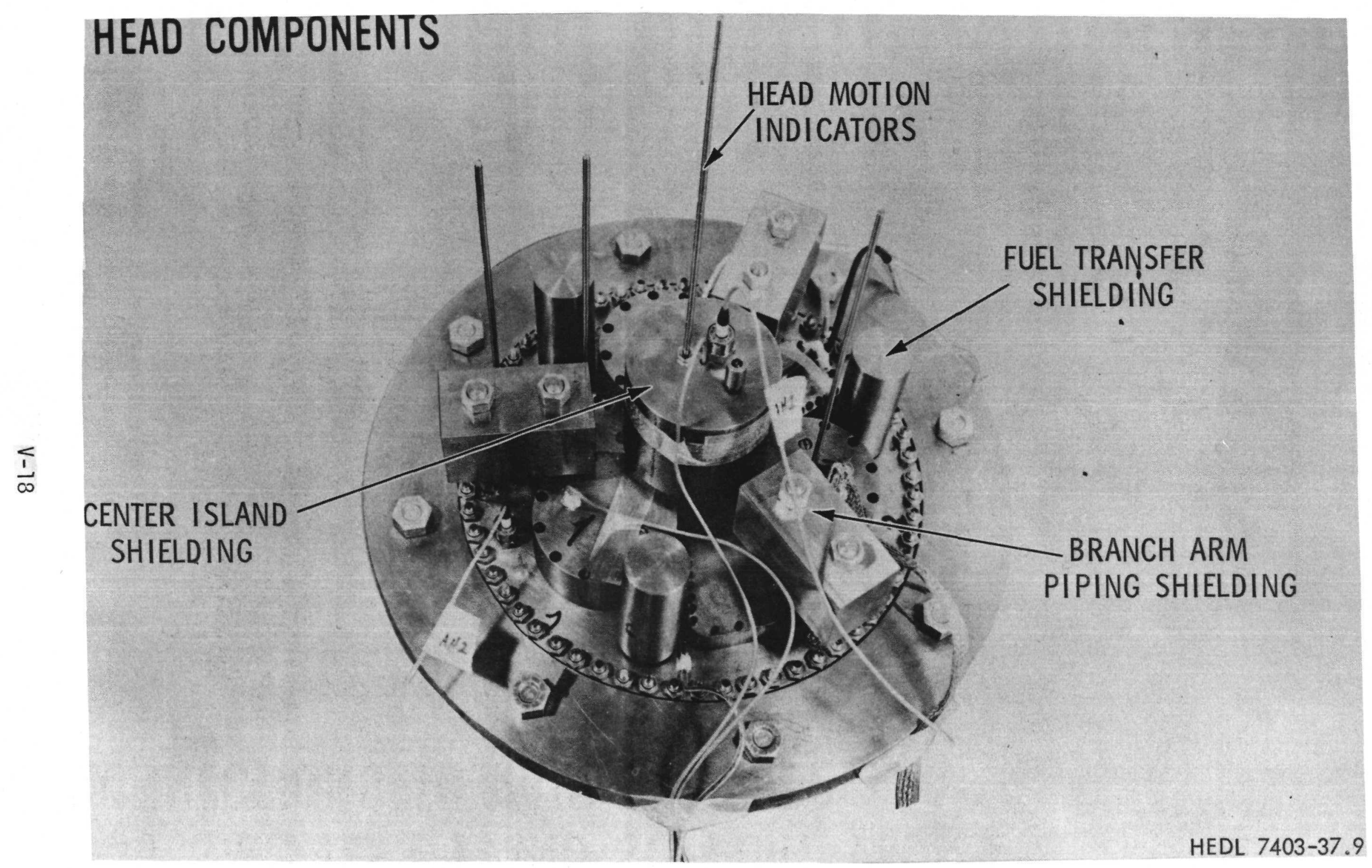


FIGURE V-13

PROTOTYPE VESSEL STRAINS

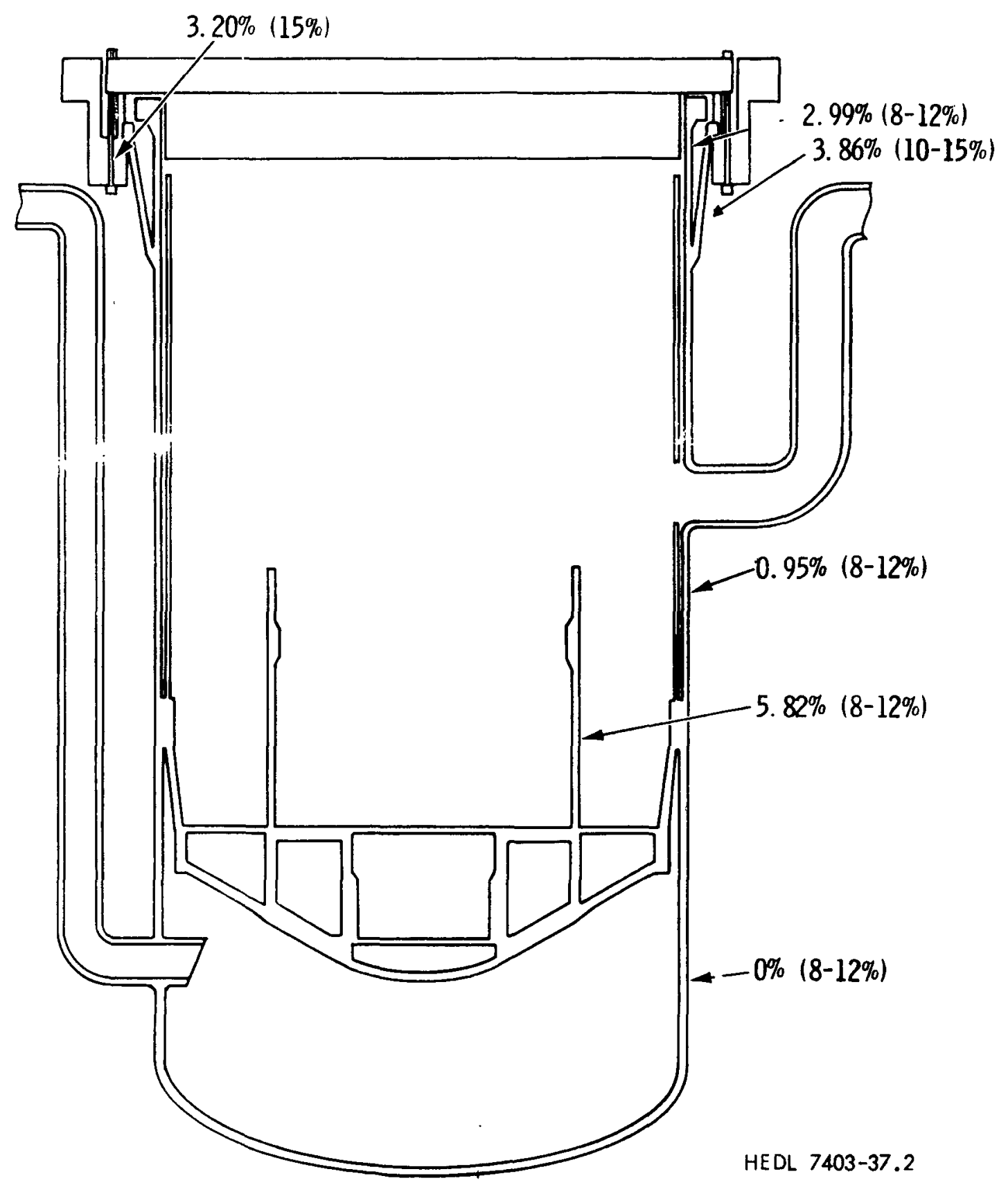


has also used this technique for primary piping analysis with ICEPEL. HEDL is developing a code called SUPWAN, a one-dimensional wave transmission piping analys is code which incorporates the elastic-plastic capabilities of the TUBE- 30 code.

The mechanical response analys is of the FFTF primary system has shown that a reactor vessel and heat transport system designed for normal LMFBR service is capable of absorbing large amounts of energy without rupture, provided clearances are available in those locations where deformations occur from the energy absorption. In FFTF, only a few features were specifically designed for accommodation of hypothetical accidents. These components are the stretch bolt system for the vessel head, crush tubes beneath the head, the dimensions of the reactor vessel support arms, the reactor vessel support ledge, and structural mounting of head-mounted components. 
VI. Post-Accident Heat Removal

The objective of a post-accident heat removal (PAHR) assessment is to substantiate the achievement of a stable, coolable core material configuration following a postulated accident. The three general potential areas for retaining fuel are: (1) In-core or In-place; (2) In-vessel; i.e., outside the core region but within the reactor vesse1; and (3) Ex-vessel; i.e., in some system or structure outside the reactor vessel.

VG Of the four fast reactors built in the United States prior to VI-1 FFTF, two made some explicit provisions for PAHR. The EBR-I and EBR-II did not; the Southeast Fast 0xide Reactor (SEFOR) (71) and the FERMI ${ }^{(72)}$ reactors did.

For SEFOR, a sodium tank capable of containing the entire quantity of primary sodium was located 45 feet below the bottom of the reactor vessel. The tank was constructed of 1/4-inch stee surrounded by 3 inches of calcium silicate insulation. Assuming a minimum of two days to melt through to the tank, the decay from the entire core would be transferred from the tank to the surrounding structure without damaging the containment barriers.

For FERMI, two devices existed for the purpose of enhancing PAHR. The first was a $7 / 8$-inch thick zirconium pan located in the inlet plenum. The pan was intended to resist penetration of molten core material while allowing the material to spread out into a non-critical geometry. The second was a 6-inch thick graphite structure located below the lower reactor vessel head. It was made of $5 \%$ borated graphite and formed a crucible capable of containing molten uranium.

In U.S. fast reactors, two incidents have occurred involving fuel meltdown in sodium cooled fast reactors. One involved a major core meltdown and the other involved two fuel subassemblies. The core meltdown occurred in the EBR-I (12) as a result of a delay in the termination of an experimental reactor transient; the subassembly meltdown occurred in the FERMI reactor ${ }^{(73)}$ as a result of 
FIGURE VI-1

\title{
PAHR PROVISIONS IN FAST REACTORS
}

\author{
$\frac{\text { REACTOR }}{\text { USA }}-$ PROVISIONS \\ EBR-1 NONE; DESIGNED FOR PREVEÑTION OF RECRITICALITY, BUT \\ NO PROVISIONS RELATED TO MELT-THROUGH \\ EBR-2 NONE; ASSUMED ADEQUATE COOLING IN LOWER AXIAL \\ BLANKET AND LOWER PLENUM REGION \\ FERMI-I IN-VESSEL: COOLING ON Zr MELTDOWN PAN \\ EX-VESSEL: GRAPHITE CRUCIBLE CATCH POT BELOW \\ VESSEL WITHIN PRIMARY SHIELD TANK \\ SEFOR EX-VESSEL: SODIUM CATCH TANK 45' BELOW VESSEL \\ FUEL DISPERSION CONES BELOW VESSEL AND IN CATCH TANK
}


plugging of the sodium inlet. In both cases the fuel relocated causing a reduction in reactivity. Following reactor shutdown by the normal scram system, the fuel froze and remained in-place until each core had been disassembled. In both, the fuel was metallic and the fuel burnup low, thus resulting in very low decay heat.

$V G$

Provisions for PAHR in western European fast reactors are shown on vu-graph VI-2. PAHR has received significant attention in the United Kingdom and Germany and in France as well.

The United Kingdom reactors include meltdown structures, a) though the approach in Dounreay $(74)$ was to protect the building by providing an easy flow path to the bedrock upon which the building rests. In the PFR, ${ }^{(75)}$ a single layer tray system is located within the tank. The trays can accommodate all the fuel from one core section which is seven subassemblies. For the CFR, three layers of trays are considered to accommodate the entire core.

The SNR ${ }^{(76)}$ will have both an in-vessel and ex-vessel system, the latter consisting of a high temperature catch pan and a NaK cooling system.

The French Phenix reactor does not have provisions specifically designed for meltdown protection, but has an externally cooled safety vesse1. Super-Phenix may incorporate in-vessel core debris catch trays, in addition to an externally cooled safety vessel.

The U.S.S.R. reactors do not contain any meltdown structures below the core, to my knowledge. A loss of primary flow is the most serious design basis accident considered. Such a loss is assumed to be accompanied by a reactor scram with attendant adequate coolant circulation for in-place cooling.

The assessment of PAHR begins when the fuel is ejected from the core region. Reference (77) contains a summary of PAHR technology and an assessment of the application of this technology to FFTF.

Following break-through of the upper structures, the molten core is envisioned as being ejected as a two-phase fluid (fuel/ steel liquid and vapor) into the sodium pool above the core region. 


\section{PAHR PROVISIONS IN FAST REACTORS (CONTINUED)}

\begin{tabular}{ll}
\multicolumn{1}{c}{ REACTOR } & \multicolumn{1}{c}{ PROVISIONS } \\
\cline { 1 - 1 } $\begin{array}{ll}\text { UNITED KINGDOM } \\
\text { - DFR }\end{array}$ & \\
- PFR & $\begin{array}{l}\text { SINGL DISPERSION CONE AND MELT TUBES TO BEDROCK } \\
\text { RETAINING SEVEN SUBASSEMBLIES }\end{array}$ \\
- CFR (PROPOSED) & $\begin{array}{l}\text { THREE LAYERS OF TRAYS WITHIN POT; RETENTION } \\
\text { CAPACITY FOR ENTIRE CORE }\end{array}$ \\
FRANCE & \\
- RAPSODIE & NONE \\
- PHENIX & EXTERNALLY COOLED OUTER VESSEL \\
- SUPER PHENIX & POSSIBLE IN-VESSEL CATCH TRAYS, EXTERNAL \\
& COOLING OF SAFETY VESSEL
\end{tabular}

FED. REPUBLIC OF GERMANY/NETHERLANDS/BELGIUM

- SNR-300

IN-VESSEL: CATCH TRAYS IN LOWER PLENUM

EX-VESSEL: HI-TEMP CATCH PAN WITH NaK COOLING 
The fraction of fuel ejected upward is likely to be large because of the two-phase nature of the blowdown $(60 \%$ to $90 \%)$. The fue 1 which is ejected upward $(>60 \%)$ is now considered separately from the fuel which remains in the core volume $(<40 \%)$.

The molten fuel and steel ejected upward from the core region would be quenched in the sodium pool. Kilogram-scale experiments have confirmed results of earlier small-scale experiments wijch showed the marked tendency of molten fuel and steel to form particulate on quenching in sodium. The molten fuel/steel mixture on entering the large sodium pool therefore would be expected to be converted into a cloud of particulates which would then settle on the large, 20-ft diameter, horizontal surface of the thermal baffle above the original core location. Assuming essentially uniform distribution, the majority of the particulate would settle $V G$ on the thermal baffle. If the bed were locally deep enough for VI-3 boiling of sodium in the bed to occur, it is expected that spontaneous bed leveling would tend to equalize the depth of particulate across the bed.

The subsequent heat generated within the bed would be transferred to the overlying sodium. The limiting heat flux-bed depth relationship derived from experimental results indicates that the entire core inventory could be accommodated on top of the thermal VG baffle without developing a dryout within the bed. Calculations VI-4 indicate that there is an adequate sodium flow rate to remove the decay heat based on the extreme assumption of a completely blocked core basket region and assuming that the only flow is due to natural convection.

Some of the particulate generated above the thermal baffle could be swept by the flow into the primary system piping. Calculations indicate that not much of the particulate would be carried into the piping, although the piping has a large capacity for settled particulate. 
FIGURE VI-3

LEVELING EXPERIMENTS WITH BED INITIALLY PEAKED IN CENTER

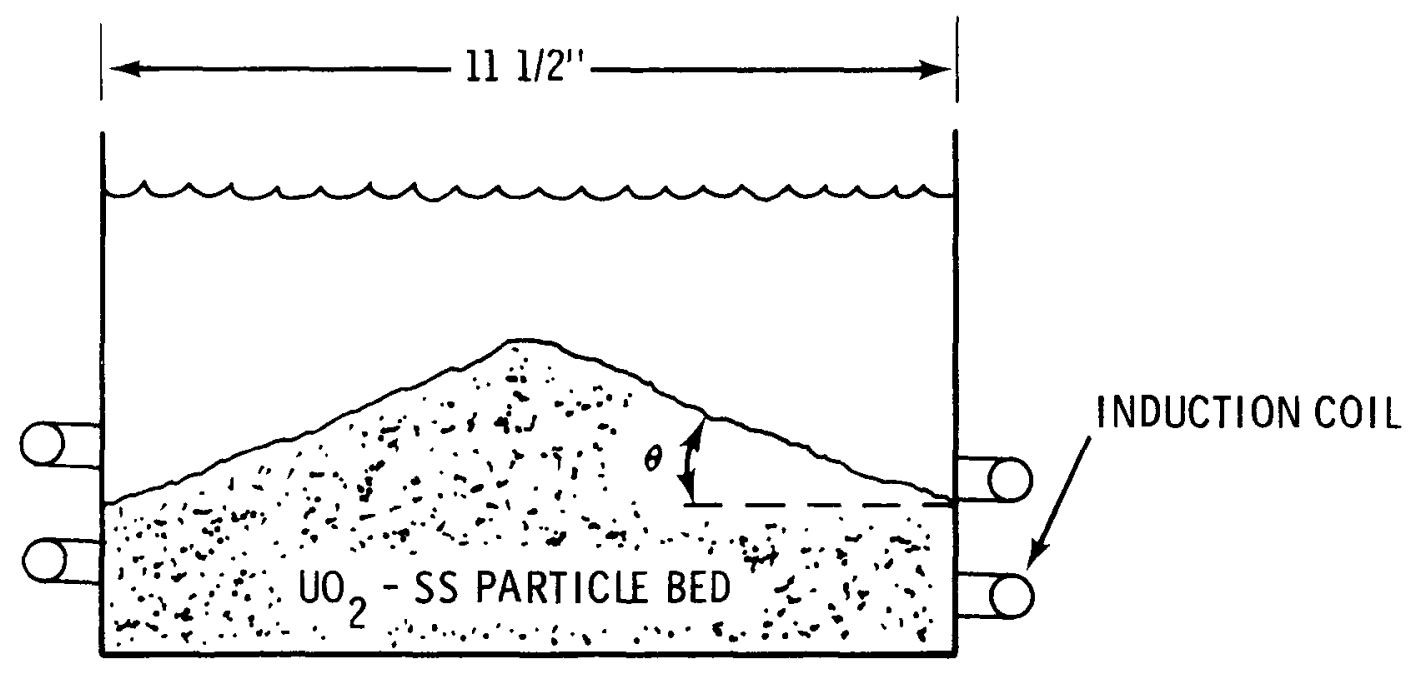

INITIAL BED GEOMETRY

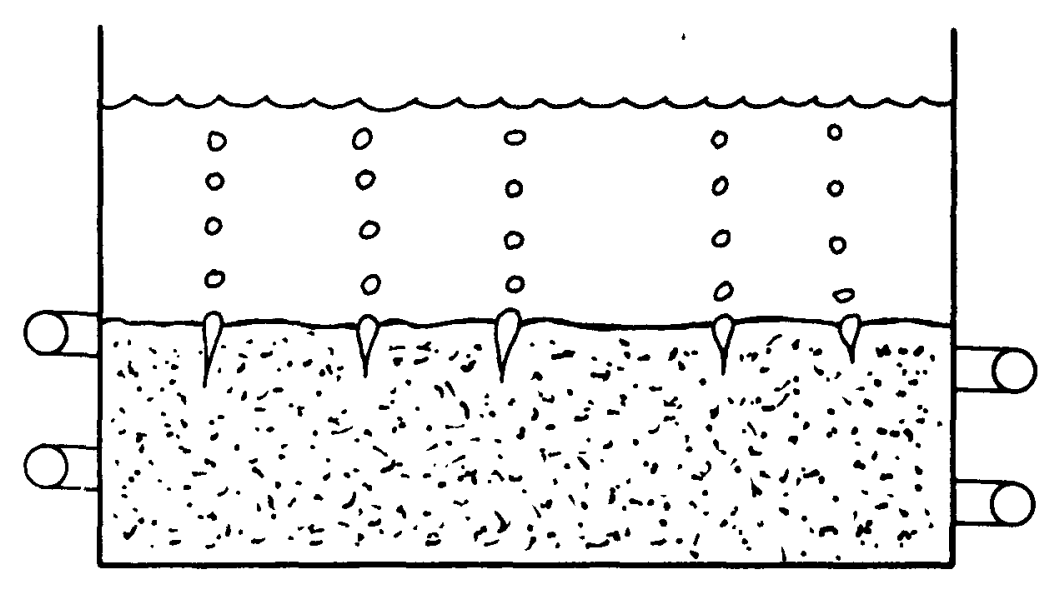

FINAL BED GEOMETRY 


\section{FIGURE VI-4}

\section{INLET AND OUTLET PIPING - GUARD - REACTOR VESSEL}

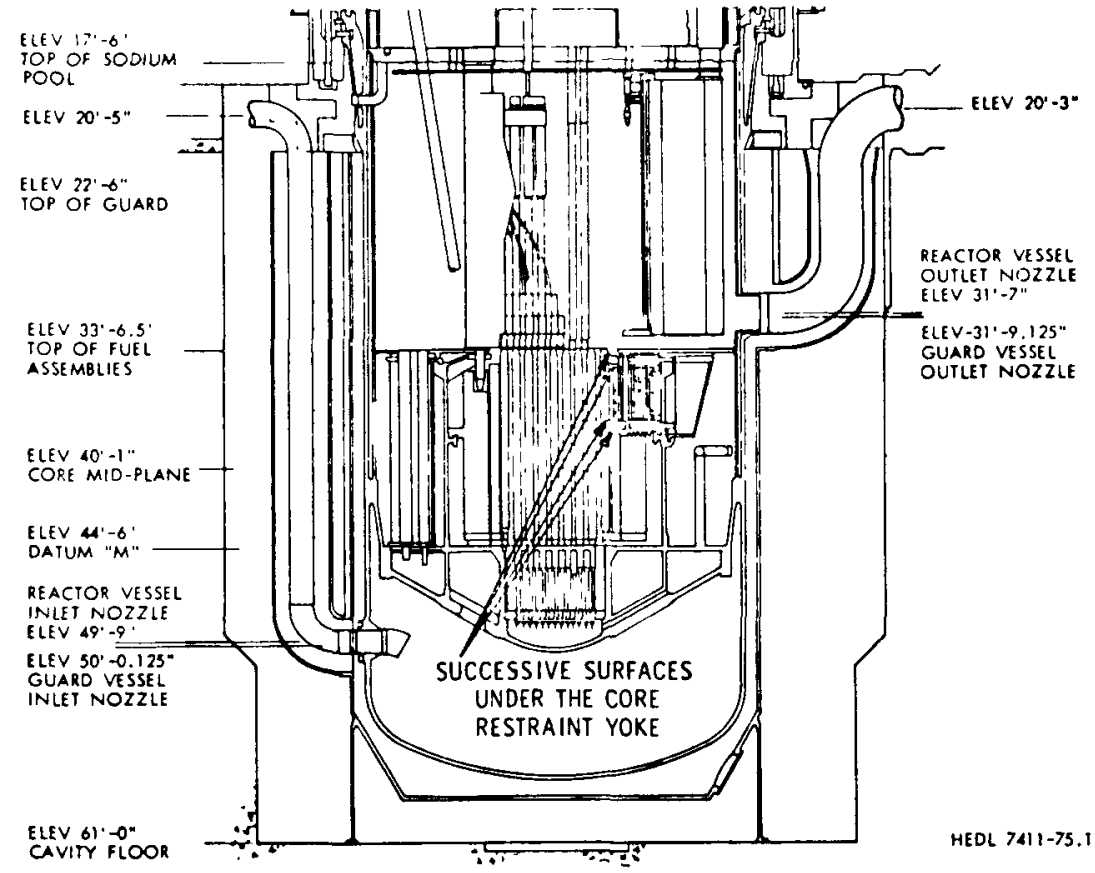


The molten fuel which is not ejected from the original core volume ( $<40 \%$ of the fuel) might gradually melt through the lower $V G$ reflector and shielding region of the core. The time for the core VI-5 material to reach the core basket region would be at least several minutes.

On reaching the core basket volume, molten fuel would be expected to flow from the subassembly inlet slots inco the basket region, which would be full of sodium. A molten fuel-sodium interaction at this location would probably result in particulate formation. This particulate would settle on top of the lower core support plate, where a substantial quantity of fuel could become stabilized as a coolable bed with transfer of the decay heat to the sodium within the basket. Excess particulate would tend to overflow the core basket region through the sodium inlet ports and settle into the lower plenum of the reactor vessel, where another substantial quantity of fuel could become stabilized as a coolable bed.

All of the fuel not ejected upward out of the core could potentially be contained within the core basket region and the lower plenum of the reactor vessel as particulate beds. However, an alternative disposition of the fuel was considered. If it is assumed that the core material melts through the lower core support plate, then it would enter the lowest portion of the core support structure which has the shape of an inverted dome. The lower surface of this steel dome is in contact with the sodium in the lower plenum of the reactor vessel. Because there is contact with flowing sodium, it is expected that the molten fuel would become stabilized and coolable within the lower dome structure. Analyses of heat transfer in fuel pools have indicated that it may be appropriate to assume as much as one-half of the heat generated is transferred downward. The total quantity of heat is 1 imited by the fact that less than $40 \%$ of the fuel is involved and also by the likelihood that volatile fission products have already boiled out of the molten fuel. 
CORE SUPPORT STRUCTURE

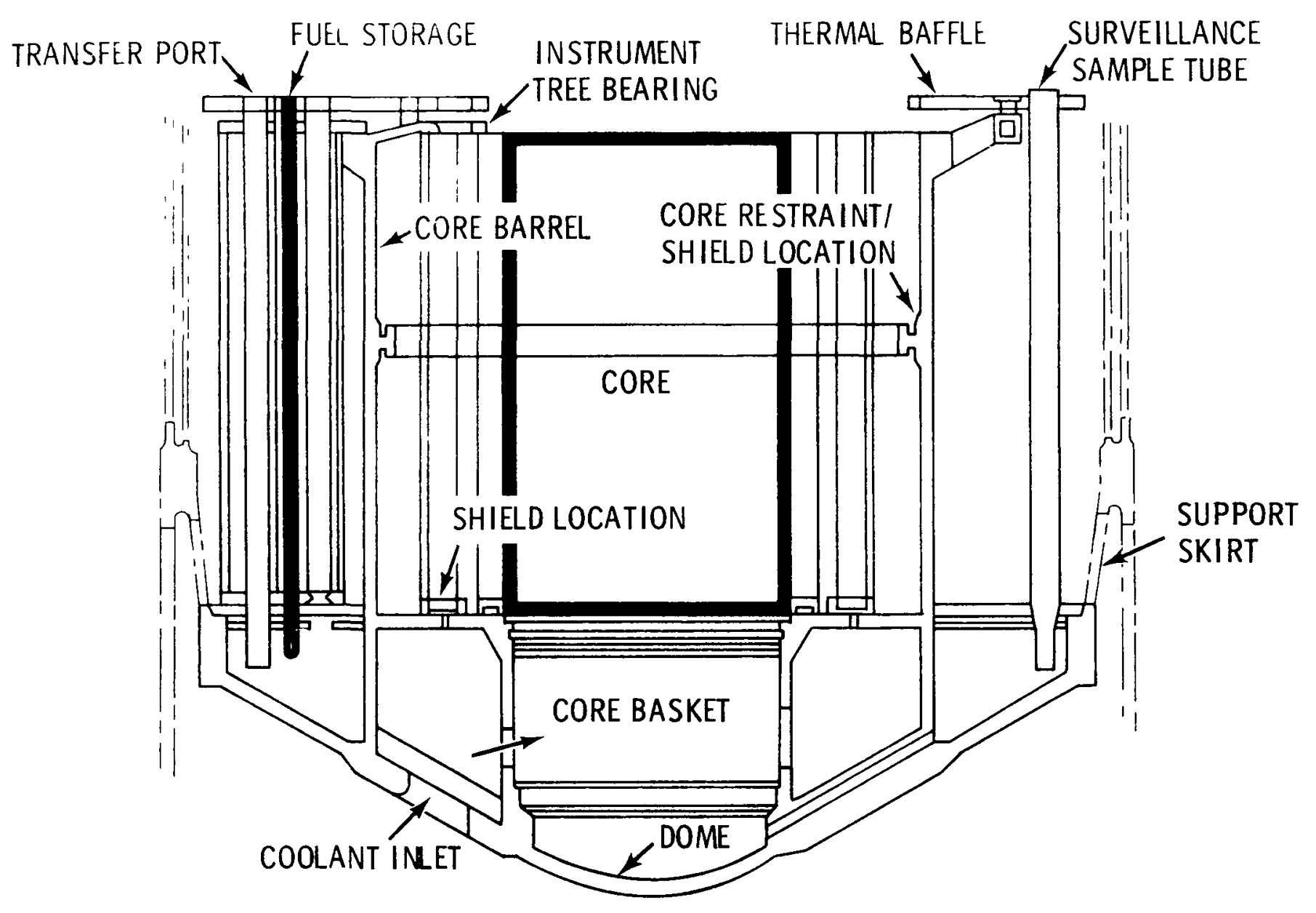


Analyses of the downfacing heat transfer from the lower dome of the core support structure to the sodium in the lower plenum of the reactor vessel were carried out. Results showed considerable margin between the heat flux likely to be available from the molten fuel and the heat flux which can be absorbed by the sodium without reaching a boiling condition in the sodium plenum.

VG In summary, there is strong evidence that adequate core-debris VI-6 retention capability and opportunity exists within the reactor vessel of FFTF to hold the core inventory in a coolable condition. (78)

An additional margin for in-vessel containment of the coredebris for FFTF results from the flat base of the guard vessel which surrounds the reactor vessel. In the unlikely event of a melt-through of the reactor vessel, the fuel/steel/sodium mixture could form a coolable particulate bed on the floor of the guard vessel.

For FFTF, it has been concluded, then, that not only is a core disruptive accident of extremely low potential, but should such an accident occur, the core material would be expected to remain cooled indefinitely within the reactor vessel and the decay heat would be dissipated through the main heat transport system.

Nevertheless, studies have been performed to assess the potential consequences of a melt-through of the core from the reactor and guard vessels, and to reach a recommendation for disposition of the lower cavity fall-back feature which was retained at the time of FFTF construction authorization.

VG The vu-graph illustrates some of the circumstances which are VI-7 conceivable if one first postulates the failure of the in-vessel PAHR.

If the core debris were located in a coolable configuration in the reactor vessel but the heat transport system for some reason failed to be effective in removing the decay heat, the debris would not be expected to melt through the reactor vessel until a major 
FIGURE VI-6

\section{IN-VESSEL PAHR SUMMARY}

HCDA EFFECTIVELY PREVENTED BY DESIGN--HYPOTHETICAL TEST

OF CONTAINMENT MARGINS

REACTOR AND HTS INTEGRITY MARGINS FOR PESSIMISTIC HCDA ENERGETICS PROVIDE POST-ACCIDENT HEAT DISSIPATION

PAHR R\&D SUPPORTS CORE DEBRIS COOLABILITY

$\therefore$ IN-VESSEL PAHR IS ADEQUATELY ASSURED FOR HCDA 
FIGURE VI.7

POST HCDA EVENT TREE

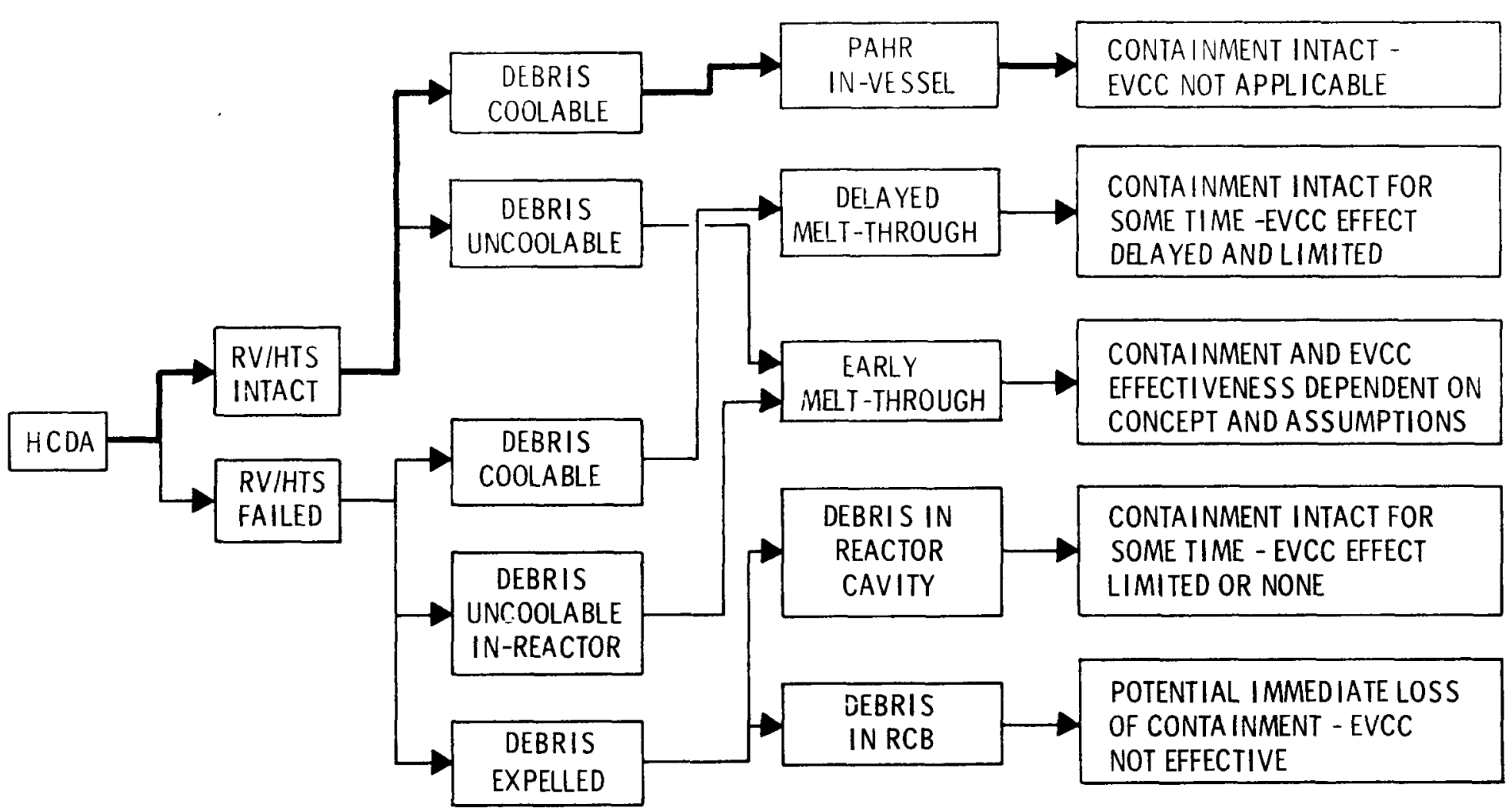


portion of the sodium had boiled away. A time of approximately one day would be requirec in order for the sodium in the reactor vesse? to reach the boiling point, and a period of several days would be required for the boiling to lower the sodium level to where a major fraction of the core debris would be uncovered. At some point in this time, or following, containment integrity might be lost, but an ex-vessel core retention system, should it be in place, would not be effective until core debris melted through to its location, which would be a substantially later time. The off-site radiological consequences would not be substantially reduced by the action of the ex-vessel core retention system.

Another potential condition, if in-vessel postaccident heat removal were ineffective, is that a substantial fraction of the core debris would be expelled from the reactor vessel. If the debris were expelled into the containment building atmosphere, for example as a result of the failure of in-vessel handling machine plugs, then containment integrity would be threatened as a result of the simultaneous expulsion of a large quantity of sodium. In such a case, an ex-vessel core retention system would be ineffective. If, or the other hand, the debris were expelled out of the reactor vessel and guard vessel and into the reactor cavity, it is probable that this material would come to rest as a dispersed fragment bed on the floor of the reactor cavity. The debris bed at that location would be coolable and an early liner penetration would not be expected. Under that condition, the containment effectiveness would be maintained for several days up to a period of weeks. Since the fuel would not get to an ex-vessel core retention system in the lower cavity in this case, such a system would be ineffective even if liner penetration occurred. An active ex-vessel core retention system would not be located where it could contain the core, al though its cooling system might have the effect of cooling sodium within the reactor cavity so as to further extend the period of containment effectiveness. 
The only case where there is a significant benefit from an ex-vessel core retention device is an early melt-through after which the debris relocated into the device. This implies an uncoolable debris configuration in the reactor vessel, whether or not failure of the HTS occurs.

VG The computer codes indicated here were used for assessing the VI-8 effects associated with various containment transients that might result from an early melt-through. The sodium fire code SOFIRE-II and the code CACECO are used to calculate the containment pressuretemperature histories and aerosol source terms versus time. Transients depend upon assumptions as to the disposition of the lower cavity, reactions of sodium with concrete, and sodium fires; the core decay heat is included. Assuming radiological source terms for initial expulsion and for subsequent boil-up where applicable, depletion as a result of aerosol characteristics is calculated with HAA-3B. The code COMRADEX is used to calculate the radiological off-site doses. Alternatively, a probabilistic assessment of the radiological consequences, using a calculational model incorporating local statistical data on meteorology and population, and allowing for population evacuation, can be used.

VG Possible designs for the FFTF lower cavity were grouped in the VI-9 following five concepts:

Category A: Leave the empty lower cavity with no modification other than filling the construction block-outs with concrete.

Category B: Modify the design to reduce the potential for sodium-concrete chemical reactions should core melt-through be postulated. The representative modification would be to fill the lower cavity with concrete.

Category C: Carry out the same modifications as identified for Category $B$ and, in addition, provide a high-temperature insulation below the reactor guard vessel with the objective of delaying any potential penetration of the lower reactor cavity liner by molten fuel from the reactor vessel. 


\section{POSTULATED MELT-THROUGH CONSEQUENCES ANALYSIS}

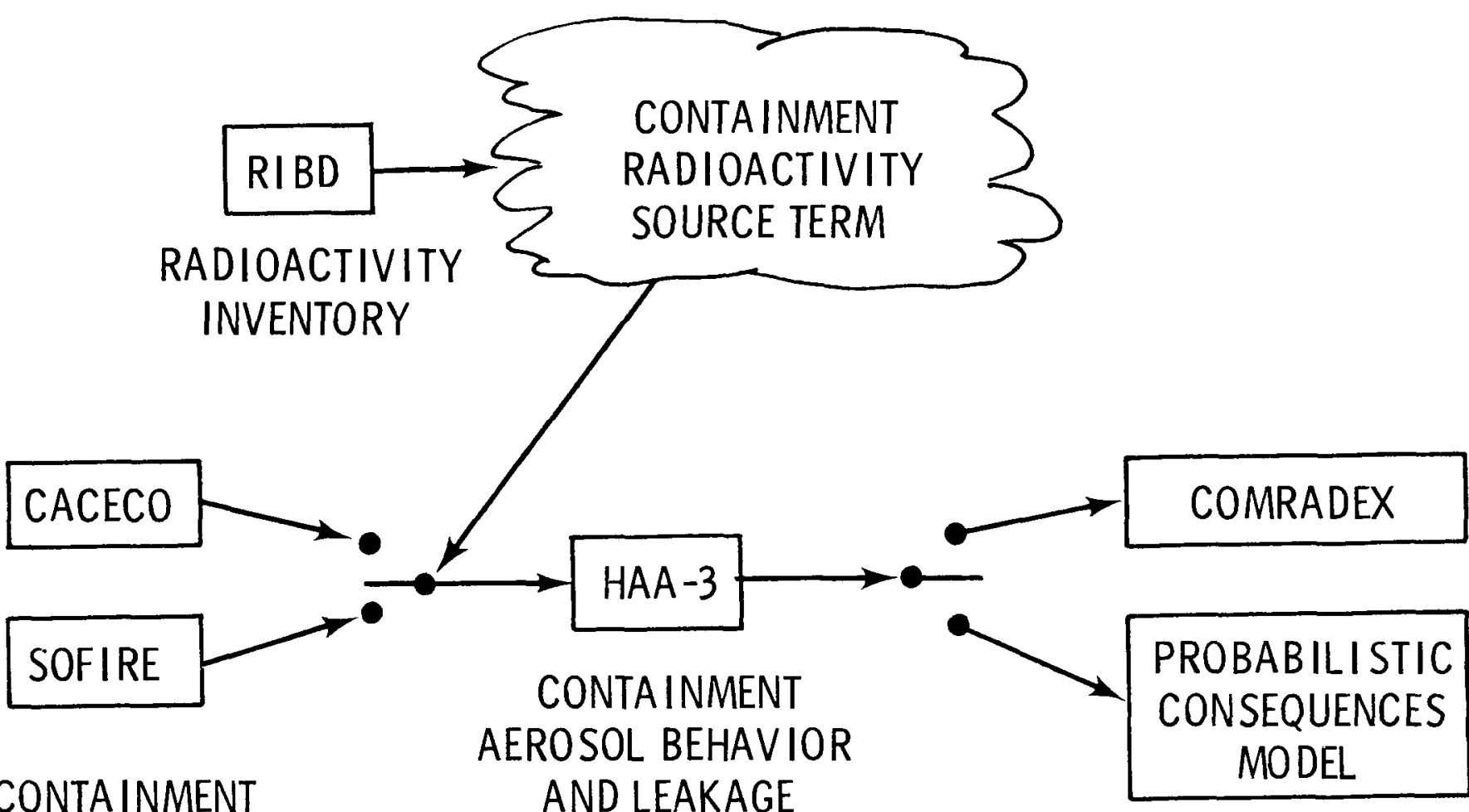

PRESSURE, TEMPERATURE, AEROSOL SOURCE CONSEQUENCES 
FIGURE VI-9

\section{LOWER CAVITY DESIGN ALTERNATIVES}

- EXISTING LOWER CAVITY

NO CHANGE IN EXISTING STRUCTURE

- CONCRETE FILLED LOWER CAVITY

REDUCTION IN SODIUM-CONCRETE REACTION POTENTIAL BY FILLING LOWER CAVITY AND VENTING COLD LINER

- MODIFIED GUARD VESSEL INSULATION

INCREASED METT-THROUGH RESISTANCE BY INSULATING MATERIAL UNDER GUARD VESSEL (WITH CONCRETE FILLED LOWER CAVITY)

- PROTECTED LINED CAVITY

"PASSIVE CORE CATCHER" DEVICE IN LOWER CAVITY

- ACTIVE CORE CATCHER 
Category D: Install a passive core retention device in the lower reactor cavity. This would be intended to maintain integrity of the reactor cavity liner for a long period of time. Representative design is a sacrificial bed similar to that incorporated in a fully cooled core retention system design, but omitting the active heat removal system.

Category E: Utilization of a fully cooled core retention system designed to maintain decay heat removal and integrity of the reactor cavity indefinitely.

HEDL's evaluation of potential melti-through consequences and of the five concepts is summarized as follows:

(1) Considering the extremely low probability of a postulated HCDA, there is an adequate level of assurance that postaccident heat removal would take place within the reactor vessel should an HCDA occur. Therefore, there is no need for an ex-vessel core retention (EVCC) sys.tem.

(2) An ex-vessel core retention system in the lower cavity could add further safety margins only under circumstances in which the containment building remained intact and the core debris melted into the lower cavity. These circumstances would not necessarily exist if conditions should arise which would prevent effective in-vessel postaccident heat removal.

(3) A significant part of the potential margin of an ex-vessel core retention system can be obtained without such a system if containment effectiveness is retained for a time of the order of a day, as opposed to indefinite containment. There is a reasonable probability that the containment would remain effective for such a period of time; and this probability can be improved by eliminating the bare concrete wall area below the reactor cavity.

(4) Even if core melt-through should occur and be followed by conditions which would lead to early loss of containment effectiveness, it is improbable that any fatalities among the general public would result. 
On the basis of the studies and conclusions, HEDL recommended that the FFTF reactor building lower cavity be filled with concrete, and that no further fallback capability for installation of an ex-vessel core retention system be maintained.

VG The NRC staff review of the HEDL recommendation was completed VI-10 in March 1975. (79) In my interpretation, the staff accepted the essence of HEDL's technical conclusions; but the staff recommendation was that the lower cavity space not be filled with concrete since that would foreclose possible other options. The staff clid agree with continuation of FFTF construction without a core catcher. 


\section{CONTAINMENT LOWER CAVITY CONCLUSION}

- FILL LOWER CAVITY WITH CONCRETE

- VENT REACTOR CAVITY COLD LINERS (OR SHOW NATURAL VENT)

BASES FOR CONCLUSION:

- HYPOTHETICAL NATURE OF POSTULATED ACCIDENTS

- ADEQUATE ASSURANCE OF IN-VESSEL PAHR

- LIMITED ASSURANCE OF EVCC EFFECTIVENESS, IF INCORPORATED

- INHERENT CONTAINMENT MARGINS WITHOUT EVCC

- COST, SCHEDULE IMPACT AND UNCERTAINTIES OF EVCC CONCEPTS

HEDL 7502-28.15 


\section{ACKNOWLEDGI:MENTS}

In preparing these lectures, I have of course drawn on the work of many investigators. I hope I have done a reasonable job of referencing their work, although I am sure it is not complete.

For assistance in assembling and preparing the lecture material, I want to express particular appreciation to J. W. Hagan, D. D. Stepnewski, A. E. Waltar, and G. R. Armstrong; and to Shirley Talbot and Connie Scherbarth for their efforts in preparation of the manuscript and visual aids.

I am also especially indebted to Hans Fauske and John Marchaterre of ANL from whose notes and presentations I have freely drawn. 
HEDL S/A-741 Rev

\section{REFERENCES}

1. "Liquid Metal Fast Breeder Reactor Program Plans - Element 10 Safety," WASH-1110, 2nd Edition, December 1972.

2. "Preparation of Environmental Reports for Nuclear Power Plants," Regulatory Guide 4.2, USAEC, Directorate of Regulatory Standards, March 1973.

3. "Report on the Integrity of Reactor Vessels for Light-Water Power Reactors," ACRS, WASH-1285, January 1974.

4. H. A. Bethe and J. H. Tait, "An Estimate of the Order of Magnitude of the Explosion When the Core of a Fast Reactor Collapses," RHM-56-113, Apri1 1956.

5. "Liquid Metal Fast Breeder Reactor Program Plans - Element 10 Safety," WASH-1110, 2nd Edition, December 1972. Appendix 1 on Safety Assurance.

6. R. M. Crawford, et al., "The Safety Consequences of Local Initiating Events in an LMFBR," ANL/RAS 73-12 (Rev. 2), September 1974.

7. J. J. Barghusen, et a1., "LMFBR Subassembly Boundary Integrity: An Interim Report," ANL/RAS 73-13 (Rev. 1), September 1974.

8. W. W. Marr, et a1., "Analytical Investigation of Certain Aspects of LMFBR Subassembly Failure Propagation," ANL/RAS 74-7, September 1974.

9. "Anticipated Transients Without Scram for Water-Cooled Power Reactor," WASH-1270, September 1973.

10. W. J. McCarthy and D. Okrent, "Fast Reactor Kinetics," The Technology of Nuclear Reactor Safety, Vol. 1, Chapter 10, M.I.T. Press, Cambridge, Mass., 1965.

11. W. E. Nyer, "Mathematical Models of Fast Transients," The Technology of Nuclear Reactor Safety, Vo1. 1, Chapter 7, M.I.T. Press, Cambridge, Mass., 1965.

12. T. J. Thompson, "Accidents and Destructive Tests," The Technology of Nuclear Reactor Safety, Vol. 1, Chapter 11, M.I.T. Press, Cambridge, Mass., 1965.

13. R. 0. Britton, "Analys is of the EBR-I Core Me1tdown," Proceedings of the Second UN International Conference on Peaceful Uses of Atomic Energy, Geneva, 1958, Vo 1. 12, p. 267.

14. L. J. Koch, et a1., "Hazard Summary Report - Experimental Breeder Reactor-II (EBR-II)," ANL-5719, Argonne National Laboratory, May 1957. Also, ANL-5719 (Addendum), Argonne National Laboratory, June 1962. 
15. "Enrico Fermi Atomic Power Plint, Technical In:Formation and Hazard Summary Report," (NP-11526).

16. R. B. Nicholson, "The Doppler Effect in Fast Neutron Reactors," APDA-139, Atomic Power Development Assoc., Inc., June 1960.

17. R. B. Nicholson, "Methods for Determining the Energy Release in Hypothetical Reactor Meltdown Accidents, "USAEC Report APDA-150, December 1962.

18. R. B. Nicholson, "Methods for Determining the Energy Release in Hypothetical Fast Reactor Meltdown Accidents," Nucl. Sci. Eng., 18(2): 204-219, February 1964.

19. W. R. Stratton, et al., "Analys is of Prompt Excursions in Simple Systems and Idealized Fast Reactors," United Nations, New York, 1958.

20. D. Okrent, et a1., "AX-1, A Computing Program for Coupled NeutroricsHydrodyanmics Calculations on the IBM-704," ANL-5977, May 1959.

21. V. Z. Jankus, "A Theoretical Study of Destructive Nuclear Bursts in Fast Power Reactors," Seminar Proceedings, Vienna, 1961, STI/PUB/49.

22. V. Z. Jankus, "A Theoretical Study of Destructive Nuclear Bursts in Fast Power Reactors," ANL-6512, February 1962.

23. B. Wolfe, et al., "Hypothetical Fast Oxide Reactor Meltdown Accident with Doppler Effect," Am. Nucl. Soc., 7(1): 138-139, June 1964.

24. P. Greebler, "Recent Improvements in Calculations of Doppler and Sodium Reactivity Effects for Large Fast Reactor," (G.E. Co.-APED), Proc. of the Conf. on Breeding, Economics and Safety in Large Fast Power Reactors, October 7-10, 1963, ANL-6792.

25. R. A. Meyer, B. Wolfe, et al., "Fast Reactor Meltdown Accident Using the Bethe-Tait Analysis," GEAP-4809, January 1967.

26. "Preliminary Safeguards Summary Report - Southwest Experimental Fast 0xide Reactor," NP-15077, General Electric Company, May 1965.

27. J. D. Geier, "Fast Reactor Test Facility (FARET), " Vol. II, Summary of Prel iminary Safety Analys is," ANL-7168 (Vol. II), Argonne National Laboratory, Apri1 1966.

28. P. J. Persiani, et al., "Some Considerations on the Meltdown Problem for FARET," Argonne National Laboratory, ANL-6935, 1964.

29. E. P. Hicks and D. C. Menzies, "Theoretical Studies on the Fast Reactor Maximum Accident," Proc. of the Conf. on Safety, Fuels and Core Design in Large Fast Power Reactors, October 11-14, 1965, ANL-7120. 
HEDL S/A 741 Rev

3C. N. Hirakawa, "MARS, A Two-Dimensional Excursion Code," APDA-198, June 1967.

31. A. E. Waltar, "MELT-I, A Simplified Meltdown Code for Fast Reactor Safety Analys is," BNWL-944, December 1968.

32. W. W. Little, Jr., "MAX, A Two-Dimensional Maximum Hypothetical Accident code in FORTRAN IV, BNWL-612, March 1968.

33. R. A. Harris, "Preliminary Analys is of Postulated Maximum Accidents for the FFTF, Supplement I - Additional Calculations for Sodium-In Conditions," BNWL-760 (Supplement I), December 1968.

34. D. E. Simpson, A. E. Waltar and A. Padilla, Jr., "Assessment of Magnitude and Uncertainties of Hypothetical Accidents for the FFTF," HEDL-TME 71-34, March 27, 1971.

35. A. E. Waltar and L. D. 0'De11, "Void Distribution Considerations for Wet Core LMFBR Disassembly Calculations," HEDL-TME 72-126, September 1972.

36. A. E. Waltar, A. Padilla, Jr., R. J. Shields, "MELT-II - A TwoDimensional Neutronics - Heat Transfer Program for Fast Reactor Safety Analysis," HEDL-TME 72-43, April 1972.

37. W. T. Sha and T. H. Hughes, "VENUS: A Twp-Dimensional Coupled Neutronics-Hydrodynamics Computer Program for Fast Reactor Power Excursions," ANL-7701, October 1970.

38. A. Padilla, Jr., "Mechanical Work Energy for Sodium-Fuel Thermal Interactions," HEDL-TME 71-94, June 1971.

39. WADCO Corporation, Fast Flux Test Facility Preliminary Safety Analys is Report, September 1970.

40. A. B. Rothman, et al., "Review of TREAT Experiments in Support of Transient Overpower (TOP) Analys is for Fast Reactor Safety," ANS Topical Meeting on Fast Reactor Safety, Los Angeles, April 1974.

41. L. W. Deitrich, et al., "Fuel Dynamics Experiments Supporting FTR Loss-of-Flow Analysis," ANS Topical Meeting on Fast Reactor Safety, Los Angeles, April 1974.

42. L. W. Deitrich, "Fuel Dynamics Transient Overpower Experiments," ANL/RAS 74-8, June 1974.

43. E. W. Bart, et al., "Fuel Dynamics Loss-of-Flow Experiments," ANL/RAS 74-9, June 1974. 
44. J. H. Scott, et al., "Microstructural Dependence of Failure Threshold in Mixed Oxide LMFBR Fuel Pins," ANS Topical Męeting on Fast Reactor Safety, Los Angeles, April 1974.

45. H. J. Willenberg and A. Padilla, Jr., "Analys is of Transient Compressible Two-Phase Flow with Heat and Mass Sources Using the Method of Characteristics, "Proceedings of the Conference on Computational Methods in Nuclear Engineering, April 15-17, 1975, Charleston, South Carolina, CONF-750413, Vol. 1.

46. J. H. Scott, et al., "Microstructural Dependence of Failure Threshold in Mixed Oxide LMFBR Fuel Pins," HEDL-TME 75-9, October 1974.

47. G. J. Fischer, et al., "Fast Reactor Accident Study Code SAS-1A," Conference on Effective Use of Computers in the Nuclear Industry, Oak Ridge National Laboratory, Apri1 20-23, 1968.

48. F. E. Dunn, et al., "The SAS2A LMFBR Accident Analys is Code," Proceedings of Conference on New Developments in Reactor Mathematics and Applications, 1971, CONF-710302, Vol. 1, pp. 120-127.

49. M. G. Stevenson, et al., "Current Status and Experimental Basis of the SAS LMFBR Accident Analys is Code System," ANS Topical Meeting on Fast Reactor Safety, Los Angeles, April 1974.

50. F. E. Dunn, et a1., The SAS3A LMFBR Accident Analysis Computer Code, ANL/RAS

51. W. Bohl, et al., "A Preliminary Study of the FFTF Hypothetical Flow Coastdown Accident," ANL-RAS 71-39, Apri1 1972.

52. M. G. Stevenson, et al., Report on the Analys is of the Initiating Phase of a Loss-of-Flow (without scram) Accident in FTR, ANL/RAS 74-24, September 1974.

53. H. K. Fauske, M. A. Grolmes, and R. E. Henry, "An Assessment of Voiding Dynamics in Sodium-Cooled Fast Reactors," ANL/RAS 74-19, August 1974.

54. J. F. Jackson, et al., "Trends in LMFBR Hypothetical Accident Analysis," ANS Topical Meeting on Fast Reactor Safety, Los Angeles, April 1974.

55. J. F. Jackson, et al., Report on the Core Disruptive Phase of an Unprotected Flow-Coastdown Accident in the FTR, ANL/RAS 74-16, August 1974. 
56. R. W. Wright, et a1., "Summary of Autocalve TREAT Tests on Molten Fuel-Coolant Interactions," Proceedings of the ANS Topical Meeting on Fast Reactor Safety, April 2-4, 1974.

57. H. K. Fauske, "Some Aspects of Liquid-Liquid Heat Transfer and Explosive Boiling," Proceedings of the ANS Topical Meeting on Fast Reactor Safety, Apri1 2-4, 1974.

58. H. K. Fauske, "An Assessment of Thermal Interactions in Sodium-Cooled Oxide Fueled Reactors," ANL/RAS 74-19, August 1974.

59. A. Padilla, Jr., "Internal Fuel Motion During Fast Reactor Overpower Transients," Transaction of the ANS Summer Meeting, June 1975.

60. H. U. Wider, et a1., "An Improved Analysis of Fuel Motion During an Overpower Excursion," CONF-740401-P3, Proceedings of the Fast Reactor Safety Meeting, April 2-4, 1974, Beverly Hills, California.

61. R. H. Cole, Underwater Explosions, Princeton University Press, 1948.

62. W. R. Wise, et al., "Response of Enrico Fermi Reactor to TNT Simulated Nuclear Accidents," NOLTR 62-207, U.S. Naval Ordnance Laboratory, November 13, 1965.

63. W. R. Wise, Jr. and J. F. Proctor, "Explosion Containment Laws for Nuclear Reactor Vesse1s," NOLTR 63-140, August 16, 1965.

64. Y. W. Chang and J. Gvildys, "Dynamic Response of Reactor Containment to High Energy Excursions," First International Conference on Structural Mechanics in Reactor Technology, Berl in, Germany, September 20-24, 1971.

65. J. F. Proctor, "Adequacy of Explosive Response Data in Estimating Reactor Vessel Damage," Nuclear Safety, Vo1. 8, No. 6, NovemberDecember 1967.

66. M. W. S. Mawbey and H. A. Taylor, "Explosion Containment in the Prototype Fast Reactor--Results of the 1/16 Scale Experiment--Test 15," Foulness Progress Report No. 3/73, January 1973.

67. M. Egleme, M. Namias, and H. Holtbecker, "Study of Nuclear Accidents by Chemical Simulation Experiments," Paper 39 of the International Conference on Engineering of Fast Reactors for Safe and Reliable Operation, Karlsruhe, Germany, October 1972.

68. A. L. Florence and G. R. Abrahamson, "Simulation of HCDA in an FFTF," HEDL-SRI- 1 and HEDL-SRI-2, May 1973.

69. D. D. Stepnewski, G. L. Fox, D. E. Simpson, and R. D. Peak, "FFTF Scale Model Structural Dynamics Tests," Fast Reactor Safety Meeting, ANS, Los Angeles, California, April 2-4, 1974. 
70. G. L. Fox, D. D. Stepnewski, L. M. Polentz, "Scale-up of Test Results from Simulation of an HCDA in the FFTF," HEDL-TME 74-54, November 1974.

71. "Southwest Experimental Fast 0xide Reactor, Facility Description and Safety Analys is Report," July 1967.

72. "Enrico Fermi Atomic Power P1ant," APDA-124, January 1959.

73. "Report on the Fuel Melting Incident in the Enrico Fermi Atomic Power Plant on October 5, 1966," APDA-233, December 15, 1968.

74. J. Graham, Fast Reactor Safety, Academic Press, New York, 1971.

75. E. V. Gilby, "Fast Reactor Safety--Problems and Solutions," paper presented at the ANS Winter Meeting, November 1972.

76. H. Huebel, "Safety-Related Criteria and Design Features for SNR," ANS Topical Meeting on Fast Reactor Safety, Los Angeles, Apri1 1974.

77. L. Baker, et al., "Postaccident Heat Removal Technology," ANL/RAS 74-12, July 1974 .

78. G. R. Armstrong, "Post accident Heat Removal Assessment for FFTF," HEDL-TME 75-60, November 1974.

79. Supplement No. 2 to the Safety Evaluation of the Fast Flux Test Facility, Project No. 448, U.S. Nuclear Regulatory Commission, Division of Reactor Licensing, March 7, 1975. 